\title{
VANessa IETo
}

\section{Efeitos da terapia miofuncional orofacial sobre o ronco e a qualidade de sono em pacientes com ronco primário e apneia obstrutiva do sono leve a moderada}

Tese apresentada à Faculdade de Medicina da Universidade de São Paulo para obtenção do título de Doutor em Ciências

Programa de Pneumologia

Orientador: Prof. Dr Geraldo Lorenzi-Filho

São Paulo

2014 
Dados Internacionais de Catalogação na Publicação (CIP)

Preparada pela Biblioteca da

Faculdade de Medicina da Universidade de São Paulo

Creprodução autorizada pelo autor

Ieto, Vanessa

Efeitos da terapia miofuncional orofacial sobre o ronco e a qualidade de sono em pacientes com ronco primário e apneia obstrutiva do sono leve a moderada / Vanessa Ieto. -- São Paulo, 2014.

Tese(doutorado)--Faculdade de Medicina da Universidade de São Paulo.

Programa de Pneumologia.

Orientador: Geraldo Lorenzi-Filho.

Descritores: 1.Terapia miofuncional 2.Ronco 3.Apneia do sono tipo obstrutiva 4.Resultado do tratamento 5.Ensaio clínico controlado

USP/FM/DBD-108/14 


\section{Dedicatória}

Ao meu marido, meu amor, Marcelo. Sem seu apoio e incentivo eu nunca teria concluído esta tese. Obrigada pela cumplicidade, pela paciência e por sempre ter me incentivado com suas palavras e com todo o seu amor.

Ao meu pai, Nelson. Espero pai, que este momento seja a colheita dos frutos plantados e incentivados por você ao longo de toda a vida.

À memória da minha mãe, Irany, exemplo de força e fé. Sua história de mãe, esposa, filha e mulher dedicada ao trabalho até seus últimos dias é inspiradora e me trouxe forças sempre que me remetia a sua lembrança.

A todos os meus pacientes que me impulsionam diariamente a buscar caminhos para Ihes oferecer o melhor tratamento. 


\section{Agradecimentos}

Ao Dr Geraldo Lorenzi Filho, por ter acreditado no trabalho e oferecido a chance de pesquisar a uma fonoaudióloga apaixonada pela clínica. Admiro sua didática, sua disposição e extrema competência na área da pesquisa e no atendimento aos pacientes. Obrigada por toda a sua orientação ao longo desta pesquisa.

Ao Prof. Dr. Adriano Mesquita Alencar por sua disponibilidade e paciência. A metodologia deste trabalho ultrapassou minhas barreiras de conhecimento e a mensuração do ronco não seria possível sem a sua orientação. Meus mais sinceros agradecimentos e meu profundo respeito e admiração por seu trabalho.

Ao meu marido, Marcelo, porto-seguro das minhas emoções e que sempre soube apaziguar minhas aflições com todo seu amor e carinho. Obrigada pela compreensão e pelo respeito nos momentos mais difíceis que atravessei.

Ao meu pai, Nelson Tadashi leto, pelo apoio incondicional e por nunca ter questionado minhas escolhas profissionais. De você, pai, ao longo da vida, só recebi incentivo. Obrigada!

À querida amiga Fabiane Kayamori, por ter me aberto as portas do Laboratório do Sono e por ter dividido comigo todo o seu trabalho, seu esforço e sua inteligência. Admiro sua incansável busca pelo conhecimento.

À querida amiga Raquel Hirata, por sua ajuda em fases decisivas deste trabalho e por quem tenho uma grande admiração por sua inteligência e dedicação à vida científica. 
À Flavia Nerbass, minha querida "preceptora", que sempre tinha a informação mais correta e mais adequada no que dizia respeito à pós-graduação. Sua ajuda e sua amizade foram inestimáveis em diversas etapas desta minha formação.

À Profa. Dra. Esther Bianchini, por quem tenho o mais profundo respeito e admiração. Você é uma fonte inestimável e inesgotável de conhecimento na Fonoaudiologia e na Motricidade Orofacial.

Ao Dr. Marcelo Gervilla Gregório pela troca de conhecimentos e pela disponibilidade nos exames de avaliação.

À Maria Isabel Montes, pela amizade e pela sempre disponibilidade na revisão dos exames de polissonografia. Meus mais sinceros agradecimentos.

A todos os amigos do Laboratório do Sono pela inestimável troca de conhecimentos, pela compreensão nas agendas de polissonografia, pela ajuda e amizade diária.

Aos queridos técnicos de polissonografia Paulo e Robson pela amizade, dedicação e pelo seu valioso trabalho.

À querida Vanderléa, pela amizade, por toda ajuda cedida, pelo incentivo e pela alegria que diariamente troca conosco no Laboratório do Sono.

Ao Prof. Dr. Rogério de Souza, ao Prof. Dr. Mario Terra Filho e ao Prof. Dr. Carlos Roberto Ribeiro de Carvalho pela oportunidade de ter participado como aluna do Programa de Pós Graduação em Pneumologia. 
Aos Professores Dra. Juliana Carvalho Ferreira, Dr. Carlos Caruso e Dr. Michel Cahali pelas importantes contribuições no Exame de Qualificação.

A todos os pacientes que participaram voluntariamente desta pesquisa. Obrigada pela confiança e por compartilharem comigo seu precioso tempo e sua vontade de melhora.

A todos os profissionais que integram a Comissão Científica e a Secretaria Pós Graduação, em especial Marcio, Klaus, Elaine e Luciana, por seu auxílio inestimável em diversas etapas deste trabalho.

A toda minha família e meus amigos, que de alguma forma se alegravam com minhas conquistas e me cediam palavras de incentivo e apoio, em especial aos meus sogros queridos Eduardo e Cida.

À Faculdade de Medicina da Universidade de São Paulo, à Disciplina de Pneumologia, ao InCor, à Fundação Zerbini, ao Instituto de Física da Universidade de São Paulo, ao Conselho Nacional de Desenvolvimento Científico e Tecnológico (CNPq) e à Fundação de Amparo à Pesquisa do Estado de São Paulo (FAPESP), sem os quais esta pesquisa não seria realizada. 


\section{Apoío Financeiro}

CNPQ - bolsa de Doutorado (Processo 142864/2011-0)

Fapesp - apoio financeiro auxílio pesquisa (Processo 2011/12120-5) 
Esta tese está de acordo com as seguintes normas:

Referências: adaptado de International Commitee of Medical Journals Editors (Vancouver)

Universidade de São Paulo. Faculdade de Medicina. Divisão de Biblioteca e Documentação. Guia de apresentação de dissertações, teses e monografias. Elaborado por Anneliese Carneiro da Cunha, Maria Julia de A. L. Freddi, Maria F. Crestana, Marinalva de Souza Aragão, Suely Campos Cardoso, Valéria Vilhena. $3^{\text {a }}$ ed. São Paulo: Divisão de Biblioteca e Documentação; 2011. 


\section{Sumário}

Listas de abreviaturas

Listas de tabelas

Listas de figuras

Resumo

Abstract

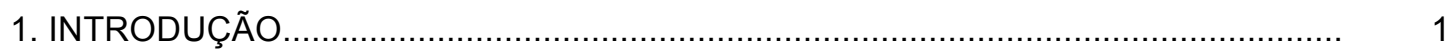

1.1 Mensuração objetiva do ronco........................................................................... 4

1.2 Tratamento da AOS e do ronco.......................................................................... 5

2. OBJETIVOS

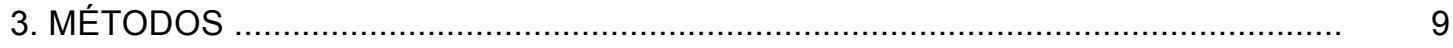

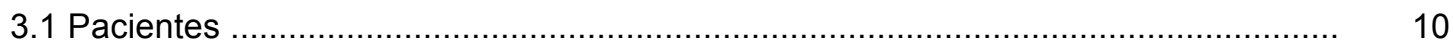

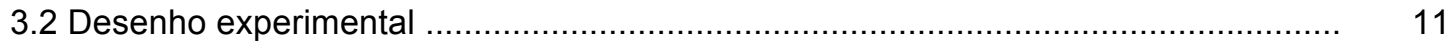

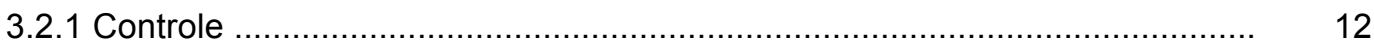

3.2.2 Terapia Miofuncional Orofacial ............................................................. 13

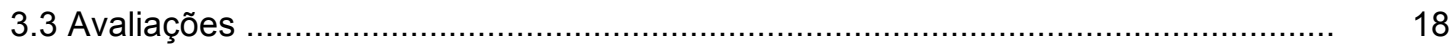

3.3.1 Anamnese ….................................................................................. 19

3.3.2 Avaliação Fonoaudiológica Miofuncional Orofacial ...................................... 19

3.3.3 Questionários ............................................................................. 31

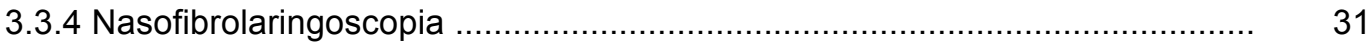

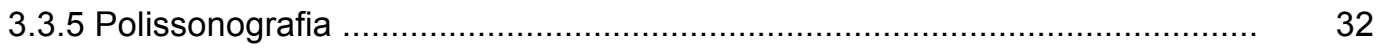

3.3.6 Análise do ronco ............................................................................. 32

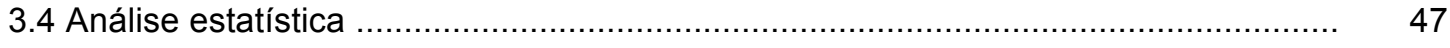

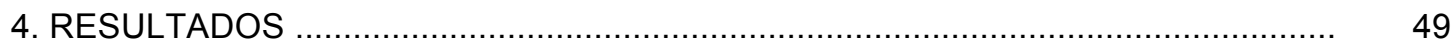

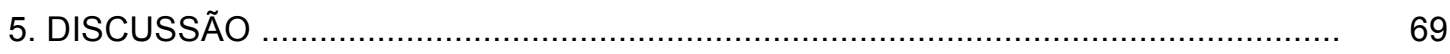

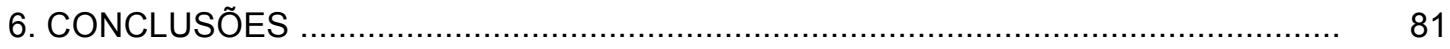

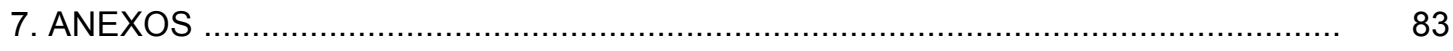

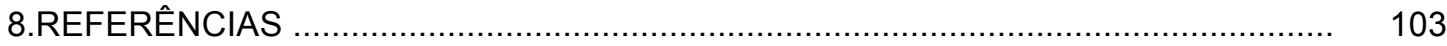




\section{Lista de abreviaturas}

\begin{tabular}{|c|c|}
\hline AOS & Apneia obstrutiva do sono \\
\hline $\mathrm{IAH}$ & Índice de apneia e hipopneia \\
\hline AASM & American Academy of Sleep Medicine \\
\hline InCor & $\begin{array}{l}\text { Instituto do Coração do Hospital das Clínicas da Faculdade de } \\
\text { Medicina da Universidade de São Paulo }\end{array}$ \\
\hline IFUSP & Instituto de Física da USP \\
\hline CPAP & Continuous positive airway pressure \\
\hline IMC & Índice de massa corpórea \\
\hline FTP & Friedman Tongue Position \\
\hline $\mathrm{dB}$ & Decibél \\
\hline $\mathrm{RR}$ & Ronco real \\
\hline IR & Índice de roncos \\
\hline IPTR & Índice potencia total do ronco \\
\hline $\mathrm{R}$ & Ronco \\
\hline TTS & Tempo total de sono \\
\hline I & Índice \\
\hline REM & Rapid eye moviment \\
\hline $\mathrm{IA}$ & Índice de apneia \\
\hline $\mathrm{IH}$ & Índice de Hipopneia \\
\hline $\mathrm{SpO}_{2}$ & Saturação periférica de oxihemoglobina \\
\hline$q$ & Questionário \\
\hline $\mathrm{CC}$ & Circunferência cervical \\
\hline CA & Circunferência abdominal \\
\hline
\end{tabular}




\section{Lista de tabelas}

Tabela 1 - Dados demográficos do total de pacientes elegíveis, excluídos, incluídos e randomizados

Tabela 2 - Número e proporção dos motivos de exclusão do estudo

Tabela 3 - Número e proporção dos motivos de exclusão durante a nasofibrolaringoscopia. O número total de pacientes excluídos $(n=18)$ não corresponde à somatória do $\mathrm{n}$ dos critérios de exclusão pois alguns pacientes apresentaram mais de um critério

Tabela 4 - Características antropométricas e clínicas dos pacientes incluídos no estudo

Tabela 5 - Características polissonográficas e de ronco dos pacientes incluídos no estudo

Tabela 6 - Resultados dos Questionários aplicados com o parceiro de quarto e com o paciente

Tabela 7 - Características antropométricas e clínicas dos pacientes incluídos no estudo no basal e após 3 meses de randomização

Tabela 8 - Características polissonográficas e de ronco dos pacientes incluídos no estudo no basal e após 3 meses de randomização

Tabela 9 - $\quad$ IAH dos pacientes com AOS moderada no basal e após 3 meses de randomização

Tabela 10 - Perfil dos pacientes que participaram de estudos que utilizaram o treinamento da via aérea superior como método de tratamento para pacientes com AOS 


\section{Lista de figuras}

Figura 1A - Dilatador nasal da marca Respire Melhor .............................................. 12

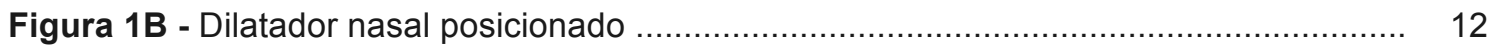

Figura 2A - Língua posicionada na papila incisiva para Início do deslizamento ânteroposterior

Figura 2B - Língua posicionada durante o deslizamento ântero-posterior

Figura 3 - Paciente mantendo língua acoplada contra o palato duro

Figura 4A - Língua empurrando o palato duro

Figura 4B - Vedamento labial mantido durante o exercício

Figura 5 - Abaixamento do dorso da língua mantido

Figura 6 - Dedo posicionado na bochecha, internamente

Figura 7A - Elevação do palato mole e úvula concomitante ao abaixamento do dorso da língua

Figura 7B - Elevação do palato mole e contração do músculo da úvula concomitante ao abaixamento do dorso da língua

Figura 8A - Primeiro sistema de gravação utilizado

Figura 8B - Segundo sistema de gravação

Figura 9 - Gravador digital ZOOM H4n. O aparelho tem dois microfones formando um ângulo de $90^{\circ}$ entre si, que permite uma gravação do som multidirecional, sem interferências eletromagnéticas.

Figura 10A - Gravador H4n sendo posicionado 
Figura 10B - Distância de 1 metro a da superfície do colchão

Figura 10C - Paciente preparado para realização do exame de polissonografia concomitante à gravação do ronco

Figura 11 - Equipamentos utilizados na calibração: (1) caixa acústica, (2) decibelímetro, (3) microcomputador, (5) equipamento de som e (6) caixa de som. A seta em azul indica o local de entrada para o microfone do gravador

Figura 12 - Comparação entre os valores em decibéis obtidos pelo decibelímetro e pelo sistema de aquisição e análise desenvolvido para o presente estudo. Os sons de calibração gravados pelo $\mathrm{H} 4 \mathrm{n}$ foram convertidos em $\mathrm{dB}$, usando a Equação 1. O parâmetro $\mathrm{I}_{\mathrm{O}}=100$ ajusta as duas curvas perfeitamente. Esse valor está em unidades arbitrárias e é interpretado como sendo a intensidade acústica mínima que um ser humano normal poderia escutar. Esse valor é válido apenas para o gravador $\mathrm{H} 4 \mathrm{n}$, quando o ganho de gravação do mesmo foi ajustado no volume 80 (em uma escala de 0 a 100)

Figura 13 - Print Screen da tela do computador visualizando ao mesmo tempo a Tabela Excel em que eram realizadas a marcação dos roncos reais e o programa Matlab em funcionamento

Figura 14 - Fluxograma resumindo as etapas de análise do ronco

Figura 15 - Fluxograma dos pacientes elegíveis, excluídos e randomizados

Figura 16 - Valores individuais da circunferência cervical no basal e após 3 meses no Grupo Controle e Terapia. Não ocorreram alterações estatisticamente significantes no Grupo Controle. Em contraste, no Grupo Terapia houve uma diminuição pequena $(0,5 \mathrm{~cm})$, porém estatisticamente significante 
Figura 17 - Valores individuais da Avaliação Miofuncional Orofacial MGBR - adaptado para AOS e Ronco no basal e após 3 meses no Grupo Controle e Terapia. Não ocorreram alterações estatisticamente significantes no Grupo Controle. Em contraste, no Grupo Terapia houve uma diminuição estatisticamente significante das pontuações

Figura 18 - Valores individuais das pontuações da Avaliação Fonoaudiológica para AOS e Ronco no basal e após 3 meses no Grupo Controle e Terapia. Não ocorreram alterações estatisticamente significantes no Grupo Controle. Em contraste, no Grupo Terapia houve uma diminuição estatisticamente significante das pontuações

Figura 19 - Achados semelhantes aos apresentados nas Figuras 17 e 18 na forma de barras. Comparação dos escores da Avaliação Miofuncional Orofacial MGBR - adaptado para AOS e Ronco e dos escores da Avaliação Fonoaudiológica para AOS e Ronco. Os resultados, no basal e após 3 meses, das duas avaliações: MGBR adaptado para AOS e Ronco e Avaliação fonoaudiológica para AOS e Ronco não se modificaram no Grupo Controle. Em contraste, a diferença entre o basal e após 3 meses foi estatisticamente significante no Grupo Terapia

Figura 20 - Valores individuais dos Índices de Roncos no basal e após 3 meses no Grupo Controle e Terapia. Não ocorreram alterações estatisticamente significantes no Grupo Controle. Em contraste, no Grupo Terapia houve uma diminuição estatisticamente significante dos Índices de Roncos

Figura 21 - Valores individuais dos Índices Potência Total do Ronco no basal e após 3 meses no Grupo Controle e Terapia. Não ocorreram alterações estatisticamente significantes no Grupo Controle. Em contraste, no Grupo Terapia houve uma diminuição estatisticamente significante dos Índices Potência Total do Ronco

Figura 22 - Índice de apneia de hipopneia (IAH) nos Grupos Controle e Terapia no basal e após 3 meses. Não ocorreram diferenças significativas no IAH médio de ambos os Grupos. O subgrupo de pacientes com apneia obstrutiva do sono moderada (15 $\leq \mathrm{IAH} \leq$ 30) tratados com Terapia Miofuncional Orofacial tiveram uma redução significativa do IAH . 
Figura 23 - Correlações entre índice de apnéia e hipopnéia com o Índice de roncos. Foram incluídos todos os pacientes no basal e após 3 meses

Figura 24 - Correlações entre índice de apnéia e hipopnéia com o Índice PotênciaTotal do Ronco. Foram incluídos todos os pacientes no basal e após 3 meses 


\section{Resumo}

leto V. Efeitos da terapia miofuncional orofacial sobre o ronco e a qualidade de sono em pacientes com ronco primário e apneia obstrutiva do sono leve a moderada. [tese]. São Paulo: Faculdade de Medicina, Universidade de São Paulo; 2014.

O ronco é gerado pela obstrução parcial e vibração da faringe durante o sono. Apesar de causar graves problemas sociais e poder indicar presença de apneia obstrutiva do sono (AOS), o ronco não é medido de forma objetiva. O tratamento do ronco primário ou associado a formas leves de AOS é controverso. A Terapia Miofuncional Orofacial consiste em exercícios isotônicos e isométricos para língua e palato mole desenvolvidos para o tratamento da AOS moderada. No entanto, os efeitos da Terapia Miofuncional Orofacial sobre o ronco não foram medidos de forma objetiva. OBJETIVOS: Primário: determinar a eficiência da Terapia Miofuncional Orofacial em reduzir o ronco de pacientes com ronco primário, AOS leve e moderada. Secundários: desenvolver uma metodologia de quantificação objetiva do ronco; avaliar a relação das características do ronco com a gravidade da AOS; avaliar o efeito da terapia miofuncional orofacial sobre a percepção do ronco e sobre a qualidade de sono do parceiro de quarto. MÉTODOS: Foram incluídos pacientes de ambos os sexos, com idade entre 20 e 65 anos com diagnóstico polissonográfico de ronco primário, AOS leve ou AOS moderada. Os pacientes foram randomizados por 3 meses para tratamento com Terapia Miofuncional Orofacial ou Controle (uso de dilatador nasal e exercícios respiratórios). Os pacientes foram avaliados no início e final do estudo por questionários de grau de sonolência (Epworth), qualidade de sono (Pittsburgh), percepção do próprio ronco e avaliação de motricidade orofacial, bem como polissonografia completa com registro contínuo do ronco. Os parceiros de quarto avaliaram o ronco do parceiro incluído no estudo e a sua própria qualidade do sono (Pittsburgh). 
RESULTADOS: Foram incluídos 39 pacientes com idade (média \pm desvio padrão) $=46 \pm 13$ anos e índice de massa corpórea $(\mathrm{IMC})=28,2 \pm 3,1 \mathrm{Kg} / \mathrm{m}^{2}$, Índice de apneia e hipopneia $(\mathrm{IAH})=15,3 \pm 9,3$ eventos/hora, sendo 6 pacientes com ronco primário, 17 com AOS leve e 16 com AOS moderada. Os pacientes não tiveram mudança de IMC, sendo que no Grupo Controle todos os parâmetros avaliados não se modificaram significativamente. Em contraste, os pacientes tratados com Terapia Miofuncional Orofacial apresentaram, em relação ao basal, melhora significativa $(p<0.05)$ na circunferência cervical ( 38,0 $[36,4-39,5]$ vs. $37,5[36,0-39,0] \mathrm{cm})$, na avaliação miofuncional orofacial $(37,0$ $[23,0-42,0]$ vs. 19 [13,0-24,0]), no Índice de Roncos $(99,5$ [49,6-221,3] vs. 48,2 [25,5-219,2]) e no Índice Potência Total dos Roncos. $(60,4$ [21,8-220,6] vs. 31,0 $[10,1-146,5])$. Os parceiros de quarto dos pacientes tratados com terapia miofuncional orofacial $(n=13)$, relataram melhora significativa na percepção da intensidade $(4,0[2,5-4,0])$ vs. $1,0[1,0-2,0])$ e frequência do ronco $(4,0[3,0-4,0]$ vs. $2,0[1,5-3,0])$. A melhora da qualidade de sono dos parceiros de quarto dos pacientes tratados com Terapia Miofuncional Orofacial tiveram uma tendência a melhorar, porém não atingiu significância estatística $(p=0,0618)$. $O$ Índice de Ronco e o Índice Potência total do Ronco no basal e após 3 meses apresentaram uma correlação moderada com a gravidade da AOS, mensurada pelo IAH ( $r$ variando entre 0,505 a 0,603). CONCLUSÕES: A Terapia Miofuncional Orofacial por 3 meses foi efetiva em reduzir a frequência e intensidade do ronco, mensurados objetivamente. A Terapia Miofuncional Orofacial portanto pode ser efetiva para uma grande parcela da população que apresenta ronco primário ou formas leves de AOS.

Descritores: 1. Terapia Miofuncional, 2. Ronco, 3. Apneia do Sono Tipo Obstrutiva, 4. Resultado de Tratamento, 5. Ensaio Clínico Controlado 


\section{Abstract}

leto V. Effects of Orofacial Myofuncional Therapy on snoring of patients with primary snoring and mild to moderate OSA. [thesis]. São Paulo: Faculdade de Medicina, Universidade de São Paulo; 2014.

Snoring is generated by pharyngeal obstruction and vibration during sleep. Snoring is extremely common and may cause severe social problems and may indicate obstructive sleep apnea (OSA). However, there are no standardized methods for measuring snoring and the treatment of primary snoring or snoring associated with mild forms of OSA is controversial. Orofacial Myofunctional Therapy consists of isometric and isotonic exercises directed to tongue and soft palate for the treatment of moderated OSA. However, the effects of Orofacial Myofunctional Therapy on snoring were not objectively measured. OBJECTIVES: Primary: to determine the efficiency of Orofacial Myofunctional Therapy in reducing snoring of patients with primary snoring, mild and moderated OSA. Secondary: to develop a methodology to objectively quantify snoring; to assess the relation of snoring characteristics with OSA severity; to assess the effect of Orofacial Myofunctional Therapy upon the perception of snoring and sleep quality of the bed partner. METHODS: We included patients of both genders aged between 20 to 65 years old with polissomnographyc diagnoses of primary snoring, mild or moderated OSA. Patients were randomized for treatment with Orofacial Myofunctional Therapy or Control (use of nasal dilator strips and respiratory exercises) for 3 months. All patients were evaluated at the beginning and end of the study by questionnaires (Epworth, Pittsburgh), orofacial motricity assessment and complete polysomnography with the register of snoring. Bed partners assessed snoring and their own sleep quality (Pittsburgh). RESULTS: Thirty nine patients aged (mean \pm standard deviation) $=46 \pm 13$ yeas old and body mass index (BMI) (mean \pm standard deviation) $=28,2 \pm 3,1 \mathrm{Kg} / \mathrm{m}^{2}$, apnea hypopnea index $(\mathrm{AHI})=15,3 \pm 9,3$ 
events/hour, being 6 patients with primary snoring, 17 with mild OSA and 16 with moderated OSA completed the study. No significant change occurred in the Control Group in all variables. In contrast, patients treated with Orofacial Myofunctional Therapy presented (as compared to baseline) a significant decrease $(p<0.05)$ in neck circumference $(38,0[36,4-39,5]$ vs. $37,5[36,0-39,0]$ $\mathrm{cm})$, Orofacial Motricity Assessment (37,0 [23,0-42,0] vs. $19[13,0-24,0])$, Snoring Index $(99,5[49,6-221,3]$ vs. $48,2[25,5-219,2])$ and Total Snoring $(60,4$ [21,8-220,6] vs. $31,0[10,1-146,5])$. Bed partners of patients treated with Orofacial Myofunctional Therapy $(n=13)$ reported a significant improvement in the perceived intensity $(4,0[2,5-4,0])$ vs. $1,0[1,0-2,0])$ and snoring frequency $(4,0[3,0-4,0]$ vs. $2,0[1,5-3,0])$. Sleep quality of bed partners also improved but did not reach statistical significance $(p=0.0618)$. Snoring Index and Total Snoring at basal and after 3 months presented a moderated correlation to OSA severity, measured by $\mathrm{AHI}$ ( $\mathrm{r}$ between 0,505 to 0,603 ).

CONCLUSIONS: Orofacial Myofunctional Therapy for 3 months is effective in reducing objectively measured snoring frequency and intensity. Orofacial Myofunctional Therapy can be effective for a great number of the population who present primary snoring or mild OSA forms.

Descriptors: 1. Myofunctional Therapy, 2. Snoring, 3. Sleep Apnea, Obstructive, 4. Treatment Outcome, 5. Controlled Clinical Trials 
1. INTRODUÇÃO 
O ronco se caracteriza por um barulho causado pela vibração dos tecidos obstruindo a nasofaringe e orofaringe durante o sono ${ }^{1,2}$. O ronco é muito comum na população em geral e está presente em praticamente todas as faixas etárias, com maior incidência com a progressão da idade. Estima-se que 15 a $54 \%$ dos adultos de meia-idade roncam ${ }^{3-6}$. Fatores como consumo de álcool, tabagismo e obesidade estão associados à presença do ronco ${ }^{7}$. Apesar da auto-percepção ser imprecisa ${ }^{8}$, o ronco é considerado um problema social potencialmente grave, pois gera incômodo no parceiro de quarto ${ }^{9}$.

O ronco pode ser um marcador da apneia obstrutiva do sono $(\mathrm{AOS})^{1,10,11}$. A AOS é caracterizada por obstrução recorrente parcial ou completa das vias aéreas superiores durante o sono levando à redução da ventilação (hipopneias) ou paradas completas da ventilação (apneias) ${ }^{12,13}$. Os eventos respiratórios (apneias ou hipopneias) geram fragmentação do sono e hipóxia intermitente. A AOS pode causar múltiplas consequências diurnas incluindo sonolência excessiva, déficit de memória, diminuição da qualidade de vida, risco de depressão e doenças cardiovasculares ${ }^{13,14}$. A AOS é considerada um problema de saúde pública dada a sua alta prevalência e suas graves consequências caso não seja tratada. O ronco dos pacientes que tem AOS é tipicamente um ronco alto e ocorre todas as noites ${ }^{15}$. A intensidade do ronco está relacionada à gravidade da $\mathrm{AOS}^{16}$. Entre os pacientes com AOS, o ronco está presente em 70 a $95 \%$ dos $\operatorname{casos}^{11}$.

Estudo recente de uma amostra representativa da população adulta da cidade de São Paulo estimou que a prevalência da Síndrome da AOS, 
definida pelo Índice de Apneia e Hipopneia (IAH) maior que 5 eventos por hora de sono associados a sintomas ou IAH maior que 15 eventos por hora de sono, é de $32,8 \%{ }^{17}$.

O ronco, mesmo em indivíduos sem AOS, denominado ronco primário, pode por si só causar muitos transtornos, como por exemplo afetar diretamente a qualidade de sono e de vida do parceiro, o relacionamento social e conjugal. O ronco pode causar problemas como insônia, dor de cabeça, fadiga e sonolência excessiva no parceiro ${ }^{18}$. Em um estudo foi constatado que quanto maior a gravidade do ronco (intensidade e frequência), menor foi a satisfação sexual, quando comparado a grupos de homens com ronco leve ou ausência de ronco ${ }^{19}$.

Estudos recentes sugerem que o ronco primário também pode contribuir potencialmente para doença cardiovascular. Em um estudo realizado com 110 participantes, com idade entre 45 e 80 anos, foi constatado que o ronco esteve associado à aterosclerose da artéria carótida, independente da presença de AOS. Os autores sugerem que a vibração na via aérea superior é transmitida diretamente para a carótida causando lesão no endotélio e aterosclerose local. Nesse estudo, a prevalência da aterosclerose da artéria carótida foi de $20 \%$ em indivíduos com ronco leve, $32 \%$ com ronco moderado e $64 \%$ nos indivíduos com ronco alto ${ }^{3}$. Outro ponto importante, ainda pouco explorado na literatura é o conceito de que o ronco primário possa contribuir para a gênese da AOS. Esse conceito é derivado da evidência de que a vibração, em nível de palato causada pelo ronco, possa contribuir para a lesão 
da placa neuro-motora ${ }^{20}$. Outros estudos sugerem que pacientes roncadores primários ou roncadores com AOS leve podem apresentar alterações localizadas na região da via aérea superior como impacto na sensibilidade térmica, aumento do limiar da detecção sensorial, aumento da vasodilatação localizada e anormalidades histopatológicas em palato mole e úvula como atrofia de fibras musculares e edema ${ }^{21}$.

\subsection{Mensuração objetiva do ronco}

Uma das grandes limitações na Medicina do Sono é que não existem medidas objetivas padronizadas de ronco ${ }^{22-27}$. O ronco é, em grande parte, uma constatação subjetiva reportada por quem ouve. A imensa maioria dos estudos utiliza questionários que são preenchidos por terceiros. Atualmente, o exame de polissonografia, que é padrão-ouro para diagnóstico da AOS, não mensura o ronco de forma objetiva. Quando o ronco é relatado numa polissonografia é simplesmente o relato subjetivo do técnico de polissonografia.

O novo manual da Academia Americana de Medicina do Sono (AASM), que reporta regras para estagiamento do sono, não especifica técnicas e regras para mensuração do ronco. O registro do ronco é reportado como opcional e não como recomendado ${ }^{28}$. Portanto o ronco permanece um relato que está "no ouvido de quem ouve".

O Laboratório do Sono da Disciplina de Pneumologia do Instituto do Coração (InCor) do Hospital das Clínicas da Universidade de São Paulo tem se 
dedicado a contribuir na mensuração do ronco de forma objetiva. Resultados preliminares do estudo realizado em parceria com o Instituto de Física da Universidade de São Paulo (IFUSP) sugerem que o padrão do ronco se correlaciona com a gravidade da $\operatorname{AOS}^{29}$. Nesta pesquisa, a frequência de roncos irregulares (com intervalo entre 10 e 100 segundos) se correlacionou com a gravidade da AOS expressa pelo IAH derivado da polissonografia. A utilização da integração de características acústicas às propriedades do ronco para estimar o IAH também foi proposta por outro grupo. Neste outro estudo, os autores propuseram um algoritmo para detecção da AOS por meio do padrão do ronco ${ }^{30}$. Estes estudos abrem a perspectiva de métodos simplificados para o diagnóstico da AOS. No entanto, nesses estudos a intensidade do ronco não foi mensurada.

\subsection{Tratamento da AOS e do ronco}

Os tratamentos da AOS incluem perda de peso, placa de avanço mandibular, cirurgias na via aérea superior e o uso de pressão positiva continua em vias aéreas (CPAP). Outras medidas consideradas complementares incluem: evitar dormir na posição supina, evitar álcool à noite e desobstrução nasa $^{23}$. Se por um lado o tratamento da AOS moderada e grave é bem estabelecido, o tratamento do ronco associado ou não a formas leves de AOS permanece controverso e inclui uma gama de possibilidades: dilatadores 
nasais, perda de peso, mudança postural durante o sono ${ }^{24}$, dispositivos intraorais, cirurgias da via aérea superior e implantes palatais ${ }^{31}$.

No entanto, não existem estudos que quantifiquem objetivamente a melhora do ronco após as intervenções, já que não existe uma recomendação ou até mesmo um consenso nesta metodologia. Na prática, a maior parte da população com ronco primário e AOS leve permanece sem qualquer tratamento estabelecido.

Em estudo recente do grupo do Laboratório do Sono do InCor realizado por Guimarães ${ }^{32}$, a Terapia Miofuncional Orofacial com a realização dos exercícios orofaríngeos, que trabalham a musculatura dilatadora da faringe; foi proposta como um método para tratar pacientes com AOS moderada. Nesse trabalho, o tratamento por quatro meses com a realização de exercícios diários e supervisão fonoaudiológica semanal, resultou em queda significativa da gravidade da AOS e redução da frequência e intensidade do ronco, medidos respectivamente por polissonografia e questionário aplicados com o parceiro de quarto. No entanto, nesse estudo foram incluídos apenas pacientes com AOS moderada. Outra limitação deste estudo é que o número de exercícios propostos era muito grande.

A hipótese principal do presente trabalho é de que a Terapia Miofuncional Orofacial reduz a frequência e intensidade do ronco, medidas de forma objetiva, em pacientes com ronco primário, AOS leve e moderada. 
2. OBJETIVOS 


\section{Primário}

- Determinar a eficiência da Terapia Miofuncional Orofacial na redução da frequência e da intensidade do ronco de pacientes com ronco primário, AOS leve e moderada.

\section{Secundários}

- Desenvolver uma metodologia de quantificação objetiva do ronco.

- Avaliar a relação das características do ronco com a gravidade da AOS.

- Avaliar o efeito da Terapia Miofuncional Orofacial sobre a percepção do ronco e sobre a qualidade de sono do parceiro de quarto. 
3. MÉTODOS 


\subsection{Pacientes}

Participaram desta pesquisa pacientes de ambos os sexos, com idade entre 20 e 65 anos com queixa de ronco e diagnóstico polissonográfico de ronco primário, AOS leve ou moderada. Foram excluídos pacientes que apresentaram qualquer uma das seguintes condições: índice de massa corpórea (IMC) superior ou igual a $40 \mathrm{~kg} / \mathrm{m}^{2}$; tabagistas; etilistas, malformações craniofaciais incluindo sinais de deformidades dento-esqueléticas, traumatismos crânio-encefálicos e síndromes genéticas; desdentados e/ou usuários de próteses dentárias totais; diagnóstico nasofibrolaringoscópico de doença obstrutiva nasal grave; hipertrofia de tonsilas palatinas (grau III e IV); antecedente de cirurgia faríngea para tratamento da apneia; uso regular de medicações hipnóticas do sistema nervoso central; uso de corticosteroides oral ou inalatório; história pregressa de acidente vascular cerebral; distrofias neuromusculares; doença pulmonar obstrutiva crônica; tratamentos prévios ou atuais da apneia e pacientes sem disponibilidade para comparecer nos retornos semanais durante o estudo.

Os pacientes foram avaliados no Laboratório do Sono da Disciplina de Pneumologia do InCor. O ronco primário foi definido como presença de ronco e $\mathrm{IAH}<5$ eventos por hora de sono. $\mathrm{O}$ ronco associado à AOS leve e moderada foi definido por presença de ronco e $\mathrm{IAH} \geq 5$ e $<15$ e $\mid \mathrm{AH} \geq 15$ e $\leq$ 30 eventos por hora de sono, respectivamente. 
Os pacientes que concordaram em participar da pesquisa assinaram o Termo de Consentimento Pós Informado (Anexo A).

\subsection{Desenho experimental}

Uma vez incluídos no estudo, os pacientes foram randomizados por 3 meses para o Grupo Controle ou Terapia Miofuncional Orofacial. A randomização foi feita por blocos de quatro e estratificada de acordo com a gravidade da AOS (ronco primário, AOS leve e AOS moderada). A polissonografia associada à gravação do ronco, a anamnese e avaliação fonoaudiológicas e os questionários com o parceiro de quarto foram realizados no início e final do estudo de cada paciente.

Durante os atendimentos, os pacientes receberam o mesmo conjunto de instruções gerais no que se refere à realização de lavagens nasais com aplicação de $10 \mathrm{ml}$ de soro fisiológico 0,9\%, em ambas as narinas, três vezes

ao dia, de acordo com estudo anterior ${ }^{32,33}$. Todos os pacientes realizaram 12 sessões de tratamento com a fonoaudióloga (Terapia Miofuncional Orofacial ou exercícios respiratórios e lavagem nasal supervisionada), totalizando três meses, uma vez por semana, por 30 minutos.

Ao final do estudo, solicitamos o retorno de todos os pacientes para informarmos os resultados dos exames e ao Grupo Controle foi oferecido tratamento com a Terapia Miofuncional Orofacial. 


\subsubsection{Controle}

Os pacientes do Grupo Controle foram instruídos a realizar lavagem nasal com aplicação de $10 \mathrm{ml}$ de soro fisiológico 0,9\% em ambas as narinas, três vezes ao dia e colocar o dilatador nasal (Figura 1A e 1B) antes de dormir. Nos retornos semanais, era feita a contagem de dilatadores a fim de controlar seu uso e a realização de exercícios respiratórios. A frequência da realização destes exercícios e da lavagem nasal foi controlada por meio de marcação em Tabela (Anexo B).
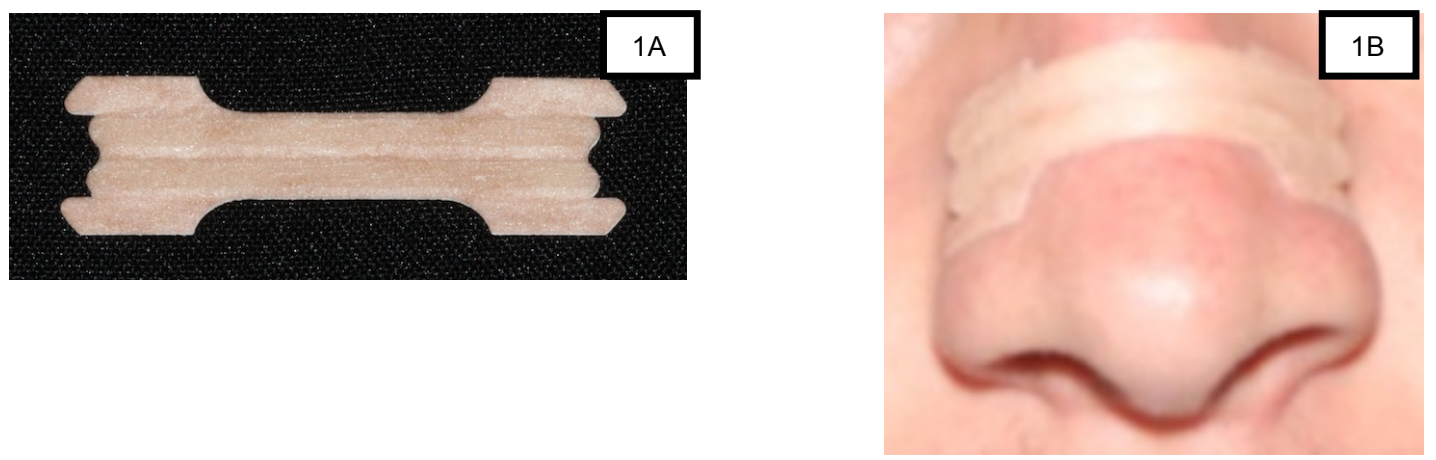

Figura 1A- Dilatador nasal da marca Respire Melhor

Figura 1B- Dilatador nasal posicionado 


\subsubsection{Terapia Miofuncional Orofacial}

Os exercícios derivados da Terapia Miofuncional Orofacial deveriam ser realizados diariamente associados às atividades de vida diárias durante aproximadamente 8 minutos, na frequência de três vezes ao dia.

O protocolo de exercícios foi baseado em pesquisa pioneira anterior que propunha a realização dos exercícios orofaríngeos no tratamento de pacientes com AOS moderada ${ }^{32,33}$. No entanto, a fim de diminuir o tempo de realização dos exercícios e simplificar a terapia, foram excluídos os seguintes exercícios: escovação da língua, exercícios faciais, pressão do orbicular da boca, elevação alternada do músculo levantador do ângulo da boca, massagens e sopro em balão.

Os exercícios foram realizados por meio de contração isotônica e/ou isométrica, de acordo com a necessidade e evolução de cada paciente. As funções de mastigação, deglutição e respiração foram reestabelecidas quando o paciente apresentou algum tipo de alteração. Buscou-se basear este protocolo em referências bibliográficas que constataram a eficácia dos exercícios para modificação da musculatura ${ }^{32-43}$.

Os exercícios realizados foram:
1) LÍNGUA 
a) Varrer: posicionar a ponta da língua na papila incisiva (Figura 2A) e realizar deslizamentos no sentido ântero-posterior contra o palato duro, em direção ao palato mole (Figura 2B). Inicialmente sem pressionamento lingual e depois com pressionamento lingual. O paciente foi orientado a realizar o exercício com lábios fechados, sem apertamento dentário 20 vezes, 3 vezes ao dia.

- Musculatura alvo: músculos genioglosso e hioglosso
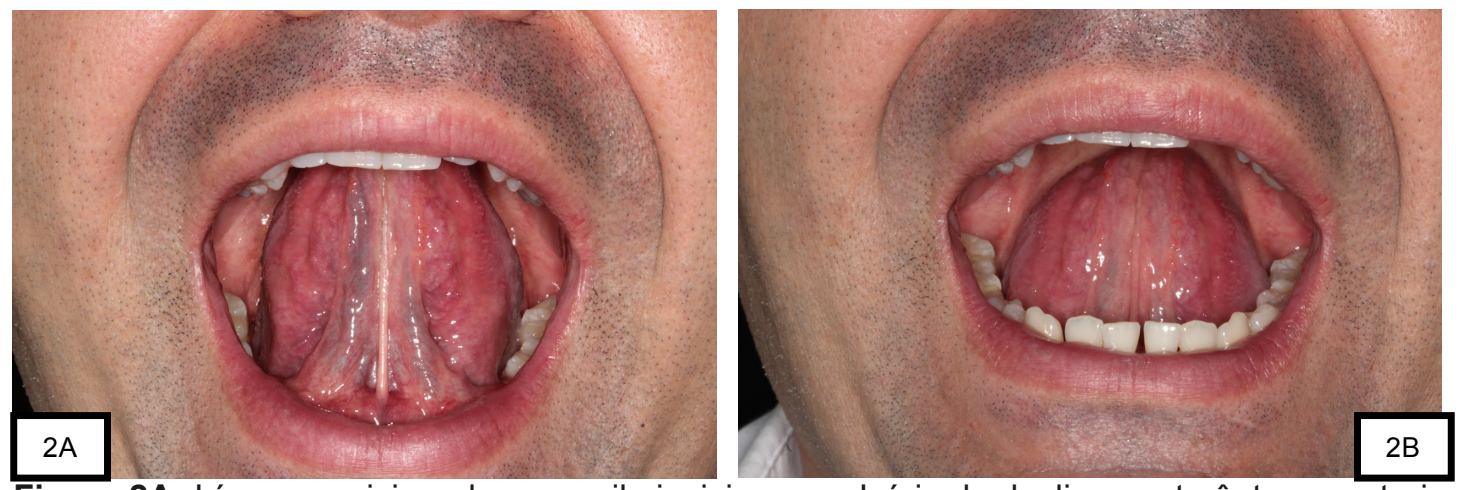

Figura 2A- Língua posicionada na papila incisiva para Início do deslizamento ântero-posterior Figura 2B- Língua posicionada durante o deslizamento ântero-posterior

b) Acoplamento: inicialmente realizar estalos de língua, com contração isotônica, depois grudar a língua contra o palato duro e manter o acoplamento lingual com contração isométrica durante 5 segundos (Figura 3). Realizar 20 vezes, 3 vezes ao dia.

- Musculatura alvo: músculos genioglosso, palatoglosso, hioglosso e suprahioideos 


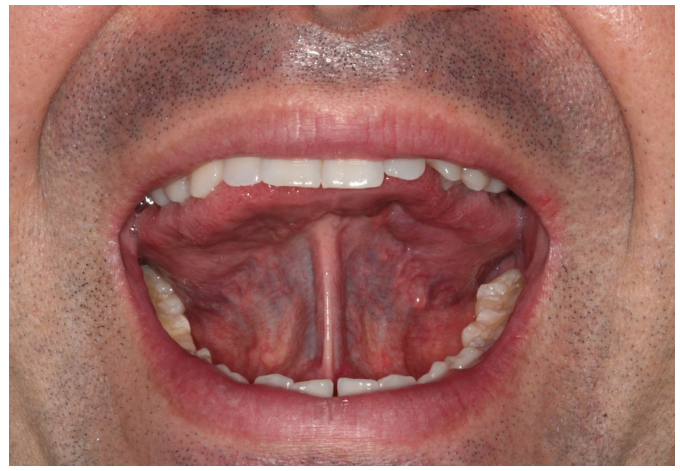

Figura 3- Paciente mantendo língua acoplada contra o palato duro

c) Empurrar o palato duro: empurrar o terço anterior da língua contra o palato duro conforme Figura 4A, mantendo o vedamento labial (Figura 4B), sem apertamento dentário. Inicialmente com contração isotônica e posteriormente com contração isométrica, mantendo a força de empurrar durante 5 segundos. Realizar 20 vezes, 3 vezes ao dia.

- Musculatura alvo: músculos suprahioideos
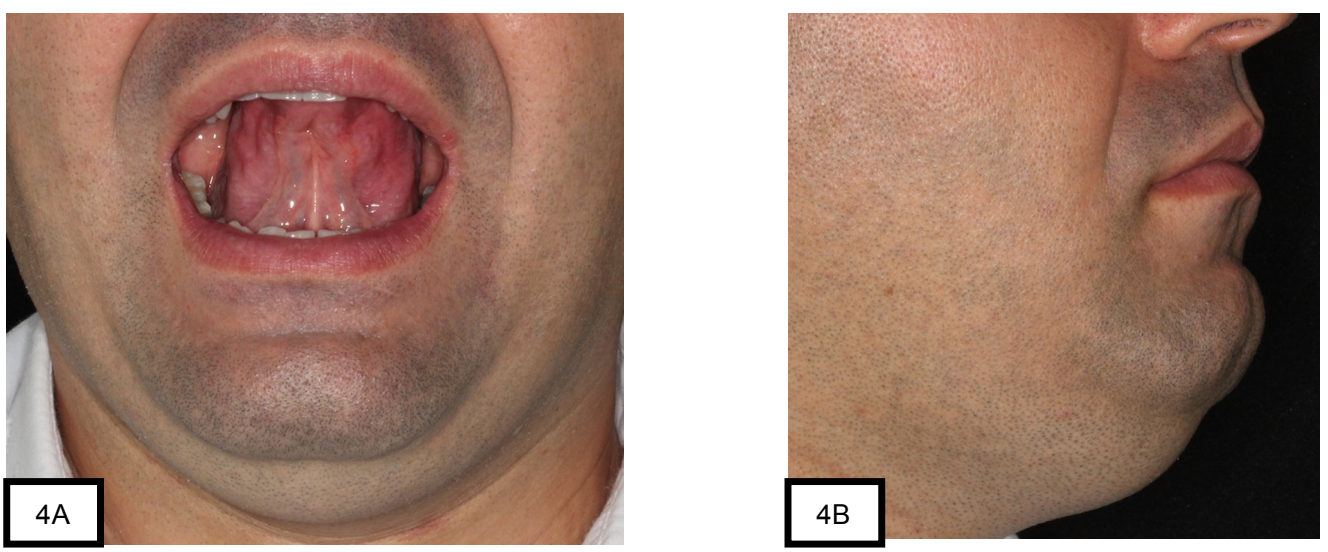

Figura 4A- Língua empurrando o palato duro

Figura 4B- Vedamento labial mantido durante o exercício 
d) Abaixar o dorso da língua: com o auxílio de uma espátula, estimular o reflexo de abaixamento do dorso da língua por meio de pequenos toques na região do dorso da língua. Após a contração voluntária, iniciar abaixamento com contração isotônica. Posteriormente, manter o dorso lingual abaixado (Figura 5), com contração isométrica durante cinco segundos. Realizar 20 vezes, 3 vezes ao dia.

- Musculatura alvo: músculos hioglosso e suprahioideos

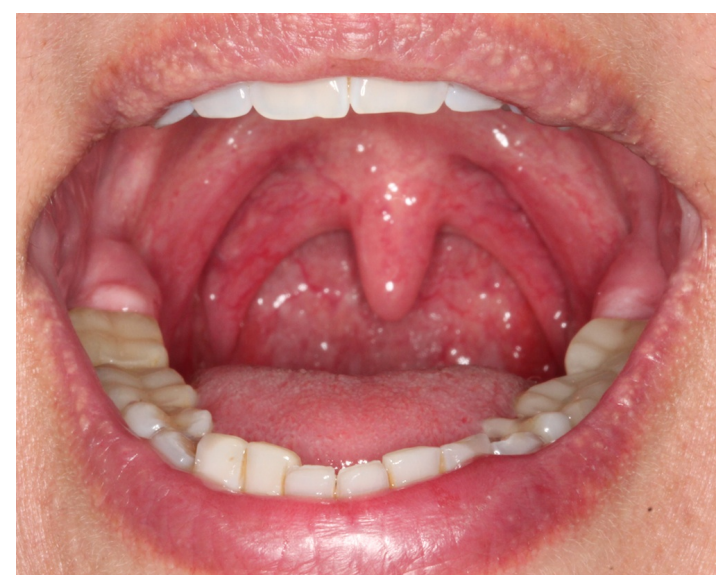

Figura 5- Abaixamento do dorso da língua mantido

\section{MÚSCULO BUCINADOR E ORBICULAR DA BOCA}

a) Dedo na bochecha: posicionar o dedo na mucosa interna da bochecha e pressionar a bochecha contra o dedo e os dentes, conforme Figura 6. Realizar contrações isotônicas, dez vezes cada lado. Posteriormente, as contrações serão isométricas durante dez segundos. Realizar 10 vezes, 3 vezes ao dia. 
- Musculatura alvo: músculo bucinador

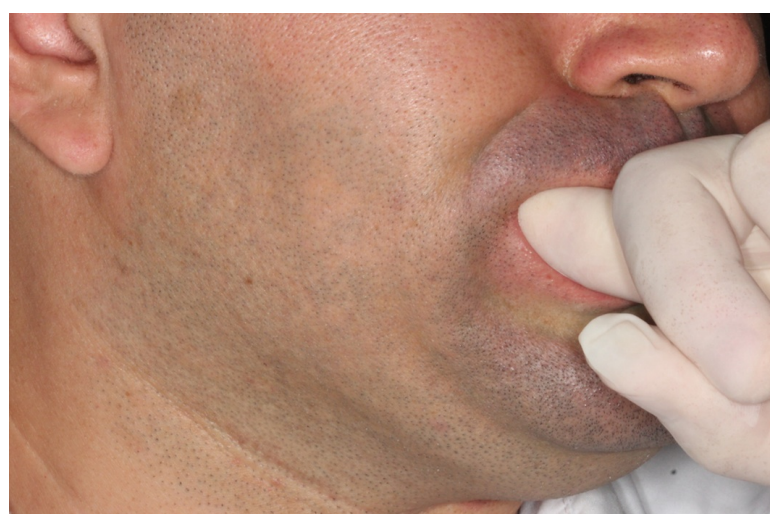

Figura 6- Dedo posicionado na bochecha, internamente

\section{PALATO}

a) Elevação do palato mole e úvula: emitir a vogal "A" de forma intermitente (contração isotônica) 10 vezes, durante uma a duas semanas. Após obtida a contração voluntária da musculatura, retira-se a vogal "A", realizando somente a elevação do palato mole, de modo intermitente, 20 vezes (Figura 7A). Após o ganho de controle e coordenação do movimento, a contração da musculatura deverá ser mantida por cinco segundos (contração isométrica), recrutando inclusive o músculo da úvula na fase final (Figura 7B). Em conjunto com este exercício foi realizado exercício de abaixar o dorso da língua. Realizar 20 vezes, 3 vezes ao dia. 
- Musculatura alvo: musculatura de arco palatoglosso, arco palatofaríngeo, tensor do palato, elevador do palato e úvula. E na última etapa, músculos hioglosso e suprahioideos
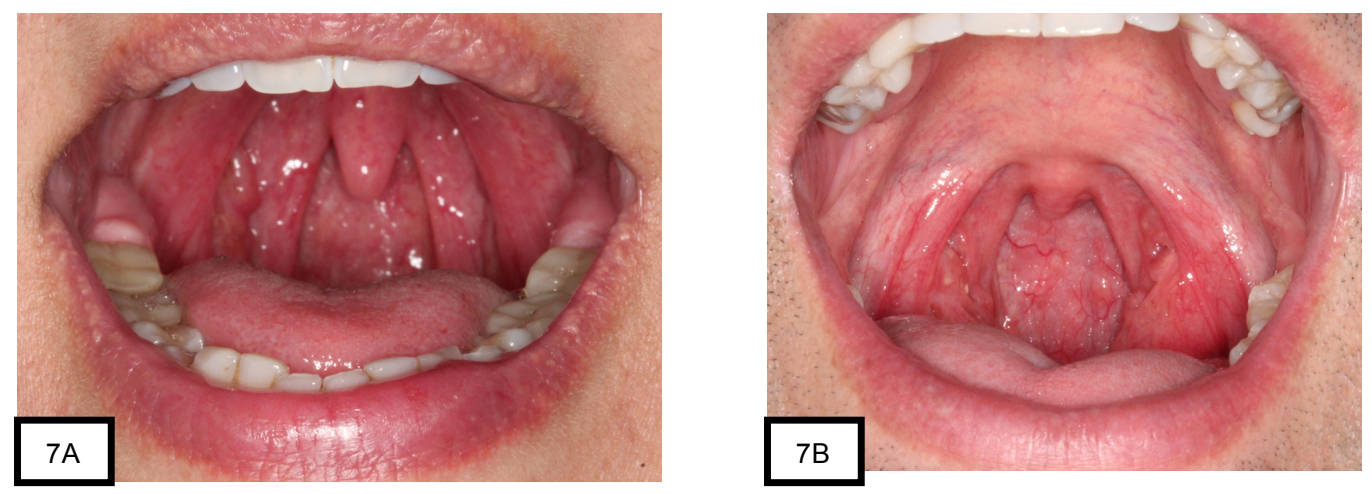

Figura 7A- Elevação do palato mole e úvula concomitante ao abaixamento do dorso da língua Figura 7B- Elevação do palato mole e contração do músculo da úvula concomitante ao abaixamento do dorso da língua

A adesão ao tratamento foi controlada por meio de uma tabela de simples visualização (Anexo C) que foi explicada e entregue ao paciente a cada sessão de atendimento. Nesta tabela, o paciente realizava as marcações do treino efetuado em casa (nenhuma, uma, duas ou três vezes ao dia) e esta frequência foi controlada pela pesquisadora.

\subsection{Avaliações}

A seguir, serão descritas as metodologias de avaliação empregadas no estudo. 


\subsubsection{Anamnese}

O paciente foi questionado sobre sua queixa principal, sintomas da apneia como sonolência excessiva diurna, ronco e fadiga; problemas de saúde geral; uso de medicamentos; problemas respiratórios; questões relacionadas ao sono e tratamentos prévios e atuais. A alimentação (qualidade e consistência habituais); problemas ou dificuldades durante a mastigação e deglutição, presença de hábitos orais, hábitos de mordida e hábitos de postura também foram investigados (Anexo D).

\subsubsection{Avaliação fonoaudiológica miofuncional orofacial}

A avaliação fonoaudiológica foi realizada por meio da adaptação do Protocolo conhecido como $\mathrm{MGBR}^{44}$, que leva como nome as iniciais do sobrenome de suas autoras. Este protocolo de avaliação foi elaborado a partir de protocolos utilizados na área de motricidade orofacial. O MGBR permite a utilização de escores por meio da atribuição de parâmetros quantitativos somada a contribuição dos aspectos qualitativos. Os achados numéricos permitem a avaliação da gravidade da disfunção apresentada pelo paciente, assim como a comprovação da eficácia da terapêutica empregada nos diferentes distúrbios miofuncionais orofaciais ${ }^{45}$.

O protocolo de exame clínico compreende observação da postura corporal, análise morfológica extra e intra-oral, avaliação da mobilidade, 
tonicidade e sensibilidade orofacial, além das funções de respiração, mastigação, deglutição, fala e voz.

A adaptação realizada para a presente pesquisa objetivou incluir alguns aspectos frequentemente avaliados por profissionais da área de Medicina do Sono, agregar parâmetros frequentemente observados em pacientes com AOS e ronco e excluir subitens pouco relacionados a estes pacientes. A este conjunto de modificações denominamos Avaliação Miofuncional Orofacial MGBR - Adaptado Para AOS e Ronco (Anexo E).

Foram incluídas medidas de peso, altura, circunferência cervical, circunferência abdominal e IMC, calculado como peso( $\mathrm{Kg}) / a$ ltura $\left(\mathrm{m}^{2}\right)$, classificação de Friedman para tonsilas palatinas e posicionamento da língua em relação ao palato ${ }^{46}$, altura do dorso lingual, forma da úvula, mobilidade de língua com abaixamento do dorso lingual espontâneo e por estimulação do reflexo, contração da úvula no bocejo e na emissão do [a] repetidamente e ativação da musculatura propulsora e retratora da língua. Foram excluídas algumas medidas de face, movimento mandibular e alguns aspectos do frênulo lingual, além da adoção da descrição simples de presença ou ausência de distúrbios da fala e da voz.

Após as adaptações realizadas a esse protocolo, a avaliação fonoaudiológica foi padronizada e realizada sempre pelo mesmo pesquisador por meio da observação, palpação da musculatura e visualização da mobilidade da musculatura e das funções orofaciais. 
Assim, os seguintes itens compuseram o Protocolo de Avaliação Miofuncional Orofacial MGBR - Adaptado Para AOS e Ronco:

1. Medidas antropométricas: peso e altura, derivando-se o índice de massa corpórea, medida da circunferência abdominal e medida da circunferência cervical (tomada logo abaixo da proeminência laríngea)

2. Medidas faciais, oclusais e movimento mandibular: tomadas de medidas com paquímetro dos terços superior, médio e inferior da face; trespasse vertical e horizontal da oclusão; abertura máxima da boca e abertura máxima da boca com a ponta da língua tocando a papila incisiva.

O resultado final da avaliação é a somatória dos escores obtidos em cada um dos itens de avaliação. Quanto maior o valor obtido, pior o resultado.

A seguir, cada item da avaliação será explicado e o valor da pontuação, atribuído ao que foi observado e classificado, está entre parênteses.

\section{Pontuação da análise da postura corporal:}

$\rightarrow$ Observação do paciente em posição frontal. Avaliação e pontuação de acordo com:

- posição da cabeça: normal (0), com rotação à direita (1), com rotação à esquerda (1), com inclinação à direita (1), com inclinação à direita (1)

- posição dos ombros: normal (0), com elevação à direita (1) e com elevação à esquerda (1).

$\rightarrow$ Observação do paciente em posição lateral. Avaliação e pontuação de acordo com: 
- posição da cabeça: normal (0), com elevação à direita (1), com elevação à esquerda (1)

- posição dos ombros: normal (0) e com rotação anteriorizada (1).

A pontuação referente à análise da postura corporal pode variar entre 0 e 7.

\section{Pontuação do exame extra-oral:}

$\rightarrow$ Palpação dos músculos temporal e masseter enquanto o paciente realizava apertamento dentário. A contração dos músculos de cada paciente foi observada e pontuada segundo os seguintes critérios: normal (0), contração primeiro à direita (1), contração primeiro à esquerda (1).

$\rightarrow$ Observação da postura de mandíbula e pontuação segundo os seguintes critérios: normal (0), semi-abaixada (1), abaixada (2) ou em apertamento dentário (2).

$\rightarrow$ Visualização dos lábios e pontuação segundo os seguintes critérios:

- posição habitual: fechados (0), fechados com tensão (1), entreabertos (2), ora abertos ora fechados (2), fechados em contato dentário (3) ou abertos (4);

- presença de saliva: deglutida (0), acumulada na comissura direita (1), acumulada na comissura esquerda (1), acumulada no lábio inferior (1) e presença de baba (2);

- mucosa: normal (0), com marcas dentárias (1), ressecada (1) e ferida (1);

- forma e comprimento: lábio superior normal (0), lábio superior em asa de gaivota (1), lábio inferior normal (0), lábio inferior com eversão discreta (1) e 
comprimento do lábio superior (cobre $2 / 3$ dos incisivos, cobre mais que $2 / 3$ dos incisivos (1) e cobre menos que $2 / 3$ dos incisivos (1).

A pontuação referente ao exame extra-oral pode variar entre 0 e 21 .

\section{Pontuação do exame intra-oral}

$\rightarrow$ Inspeção da mucosa e frênulos labiais e pontuação segundo os seguintes critérios:

- mucosa: normal (0), ferida (1);

- fixação do frênulo superior: normal (0) ou baixa (1);

- espessura do frênulo superior: normal (0) ou alterada (1).

$\rightarrow$ Visualização da mucosa das bochechas e pontuação segundo os seguintes critérios: normal (0), marcas dentárias à direita (1), marcas dentárias à esquerda (1), linha alba à direita (1), linha alba à esquerda (1), ressecamento à direita (1), ressecamento à esquerda (1), ferida à direita (1), ferida à esquerda (1).

$\rightarrow$ Visualização da língua e pontuação de acordo com:

- presença de sulco longitudinal adequado (0) ou profundo (1);

- posição habitual: acoplada (0), no assoalho (1) ou interdental (1);

- simetria: presente (0) ou ausente (1);

- largura: adequada (0) ou aumentada (1);

- altura do dorso: adequada (0), aumentada (1) ou muito aumentada (2);

- tremor: ausente (0), na posição habitual (1), ao protrair (1), nos movimentos (1); 
- mucosa: normal (0), geográfica (1), fissurada (1), marcada por dentes (1), marcada por aparelho (1), ferida (1);

- frênulo: extensão normal (0), curto (1), fixação na parte média (0), fixação anterior à parte média (1), fixação no ápice (2)

$\rightarrow$ Classificação de Friedman para língua (Friedman Tongue Position - FTP) solicitando ao paciente que deglutisse e abrisse a boca, mantendo a língua relaxada dentro da boca e pontuação segundo os seguintes critérios: FTP 1 (0), FTP 2 (1), FTP 3 (2), FTP 4 (3).

$\rightarrow$ Visualização do palato duro e pontuação de acordo com:

- profundidade: normal (0), reduzida (1) ou aumentada (2)

- largura: normal (0), aumentada (1) ou reduzida (2)

$\rightarrow$ Visualização do palato mole e pontuação de acordo com:

- simetria: presente (0) ou ausente (1)

- extensão: adequada (0), longa (1) ou muito longa (2)

$\rightarrow$ Visualização da úvula e pontuação segundo os seguintes critérios: normal (0), longa (1), muito longa (2), desviada para direita (1), desviada para esquerda (1).

$\rightarrow$ Classificação de Friedman para tonsilas palatinas e pontuação segundo os seguintes critérios: tonsilas ausentes (0), tonsila grau 1 (1), tonsila grau 2 (2), tonsila grau 3 (3) e tonsila grau 4 (4).

$\rightarrow$ Visualização e pontuação dos aspectos dos dentes e da oclusão de acordo com:

- conservação dentária: boa (0), regular (1) ou ruim (2) 
- conservação gengival: boa (0), regular (1) ou ruim (2)

- linha média: adequada (0), desviada para a direita (1) ou desviada para a esquerda(1)

- oclusão: normal (0) ou alterada (1)

- classificação de Angle para os lados direito de esquerdo seguindo a mesma pontuação: Classe 1 (0), Classe II (1) ou Classe III (1)

- alteração vertical: ausente (0), mordida em topo (1), sobremordida (1), mordida aberta anterior (1), mordida aberta posterior (1)

- alteração transversal: ausente (0) ou mordida cruzada posterior (1)

A pontuação referente ao exame intra-oral pode variar entre 0 e 60.

\section{Mobilidade}

$\rightarrow$ Para avaliação da mobilidade de lábios, solicitou-se ao paciente a execução dos seguintes movimentos: protrusão labial ("bico") com lábios fechados, protrusão labial ("bico") com lábios abertos, retração labial ("sorriso") com lábios fechados, retração labial ("sorriso") com lábios abertos, lábios estirados para dentro, abaixar o lábio inferior como se fosse "mostrar dentes inferiores" e elevar lábio superior e asa do nariz como se fizesse "cara de cheiro ruim". A pontuação de cada movimento obedeceu aos seguintes critérios: normal (0), aproximado (1), tenta realizar (2) ou não realiza (3).

$\rightarrow$ Para avaliação da mobilidade da língua, solicitou-se ao paciente a execução dos seguintes movimentos: protrair, elevar na papila incisiva, elevar no lábio superior, tocar a comissura labial direita, tocar a comissura labial esquerda, tocar internamente a bochecha direita, tocar internamente a 
bochecha esquerda, estalar o ápice, estalar o corpo, sugar a língua no palato, e vibrar. A pontuação de cada movimento obedeceu aos seguintes critérios: normal (0), aproximado (1), tenta realizar (2) ou não realiza (3). Além disso, também foi verificado o abaixamento do dorso espontaneamente e o abaixamento do dorso através da estimulação do reflexo, utilizando toques de espátula na região do dorso da língua. A pontuação de cada movimento obedeceu aos seguintes critérios: normal (0), lentificado (1), muito lentificado (2) ou ausente (3).

$\rightarrow$ Para avaliação da mobilidade de bochechas, solicitou-se ao paciente inflar as bochechas simultaneamente e alternadamente. A pontuação de cada movimento obedeceu aos seguintes critérios: normal (0), aproximado (1), tenta realizar (2) ou não realiza (3).

$\rightarrow$ Para avaliação da mobilidade de véu palatino, solicitou-se ao paciente a emissão da vogal [a]. A classificação e a pontuação obedeceram aos seguintes critérios: movimento normal (0), movimento reduzido (1) ou movimento ausente (2).

$\rightarrow$ Para avaliação da mobilidade da úvula, solicitou-se ao paciente duas provas: emissão da vogal [a] e bocejo. A classificação e a pontuação obedeceram aos seguintes critérios: movimento normal (0), movimento reduzido (1) ou movimento ausente (2).

$\rightarrow$ Para avaliação da mobilidade mandibular, solicitou-se ao paciente os movimentos de abertura, lateralidade à direita e à esquerda. A classificação e a pontuação obedeceram aos seguintes critérios: normal (0), reduzido (1), 
aumentado (1) ou não realiza (2). Nos movimentos mandibulares também foi observado e pontuado: presença de desvio (1) e dor (1).

A pontuação referente à avaliação da mobilidade pode variar entre 0 e 87.

7. Tônus: observação visual e palpação do lábio superior e inferior, mento, sulco mento labial, assoalho da boca e bochechas direita e esquerda. Para pontuação da musculatura da bochecha, foi realizada observação da contração do músculo bucinador, introduzindo o dedo indicador internamente à bochecha solicitando-se que o paciente realizasse a contração A classificação e a pontuação de cada estrutura obedeceram aos seguintes critérios: normal (0), reduzido (1) ou aumentado (1).

A pontuação referente à avaliação do tônus pode variar entre 0 e 7 .

8. Ativação da musculatura da língua: ativação da musculatura extrínseca propulsora e retratora da língua, solicitando ao paciente que mantivesse a língua no assoalho bucal e abaixasse o dorso da língua. Observou-se (ou não) a ativação da musculatura retratora da língua. A classificação e a pontuação obedeceram aos seguintes critérios: normal (0), tônus da musculatura retratora reduzido (1), tônus da musculatura propulsora aumentado (1).

A pontuação referente à avaliação da ativação da musculatura da língua pode variar entre 0 e 2 .

9. Dor à palpação: pressionamento bilateral dos músculos temporal anterior, masseter superficial, trapézio, esternocleidomastóideo e articulação 
temporomandibular. A classificação e a pontuação obedeceram aos seguintes critérios: dor ausente (0), dor presente à direita (1), dor presente à esquerda (1).

A pontuação referente à avaliação da dor à palpação pode variar entre 0 e 10.

\section{Funções orais}

$\rightarrow$ Para avaliação da respiração foi observado:

- tipo respiratório: médio/inferior (0) ou médio/superior (1)

- modo: nasal (0), oronasal (1) ou oral (2)

- fluxo nasal utilizando o espelho de Glatzel: simétrico ao chegar (0), reduzido à direita (1), reduzido à esquerda (1), simétrico após a limpeza (0), reduzido à direita após a limpeza (1), reduzido à esquerda após a limpeza (1)

- possibilidade de uso nasal (2 minutos ou mais (0), entre 1 e 2 minutos (1) ou menos que 1 minuto (2)

$\rightarrow$ Para avaliação da mastigação, foi oferecido pão de queijo ao paciente. A incisão do alimento foi classificada e pontuada de acordo com o local da incisão: anterior (0) e lateral (1). A trituração do alimento foi classificada e pontuada de acordo com os seguintes critérios: eficiente (0), ineficiente (1), com dentes posteriores (0), com dentes anteriores (1) e com a língua (1). O padrão mastigatório foi classificado e pontuado de acordo com os seguintes critérios: bilateral alternado (0), unilateral preferencial (0), bilateral simultânea (1) ou unilateral crônico (2). O fechamento labial foi observado e pontuado se sistemático (0), assistemático (1) ou ausente (2). Quanto à velocidade da mastigação, foi observada e pontuada se adequada (0), aumentada (1) ou 
diminuída (1). Foi observada a ausência (0) ou presença (0) de ruídos e ausência (0) ou presença (1) de contrações musculares atípicas. O paciente foi questionado se havia um lado preferencial para a mastigação e a pontuação obedeceu aos seguintes critérios: direito e esquerdo (0), direito (1), esquerdo (1) ou não soube responder (0). O paciente foi questionado por ausência (0) ou presença (1) de dor ao mastigar e ausência (0) ou presença (1) de ruído na articulação temporomandibular.

$\rightarrow$ Para avaliação da deglutição, foram realizadas duas provas. Na primeira prova, foi oferecido pão de queijo ao paciente e observado no momento da deglutição: fechamento labial adequado (0), parcial (1) ou ausente (2). Foi observada e pontuada a postura da língua durante a deglutição: atrás dos dentes (0), contra os dentes (1) ou entre os dentes (2). Foi observada a postura do lábio inferior e pontuada: em contato com o superior (0) ou atrás dos dentes incisivos superiores (1). A contenção do alimento foi classificada e pontuada se adequada (0), parcial (1) ou inadequada (2). Foi observada contração do músculo orbicular da boca, se adequada (0), pouca (1) ou acentuada (2). Foi observada contração do músculo mentual, se ausente (0), pouca (1) ou acentuada (2). Foi observada contração da musculatura cervical, se ausente (0), pouca (1) ou acentuada (2). Foi observado ainda: ausência (0) ou presença (1) de movimento de cabeça, ausência (0) ou presença (1) de ruídos durante a deglutição, coordenação adequada (0), presença de engasgo (1) ou tosse (1). Após deglutir, foi observada ausência (0) ou presença (1) de resíduos. 
Na segunda prova, foi oferecido água para o paciente. Foram observados e pontuados os mesmos critérios da primeira prova. Além disso, o paciente ainda foi questionado sobre ausência (0) ou presença (1) de dificuldades para deglutir e posição da língua durante a deglutição: atrás dos dentes superiores (0), atrás dos dentes inferiores (1), entre os dentes (2) ou não sabe (0).

A pontuação referente à avaliação das funções orais pode variar entre 0 e 61.

Ainda foram observadas e descritas, mas não pontuadas, alterações de voz e fala.

Os resultados da avaliação utilizando esta versão adaptada geraram uma pontuação (entre 0 e 255) que foi utilizada nesta pesquisa com a adoção da sigla "MGBR adaptado". No entanto, também foi utilizada uma subpontuação deste protocolo englobando somente os itens específicos que mais representavam os grupos musculares especificamente trabalhados com os pacientes do grupo tratamento. Os itens específicos utilizados foram: classificação de Friedman para língua, mobilidade de véu palatino, contração de úvula, tônus da musculatura orofacial e ativação da musculatura da língua. A esta sub-pontuação, que variou entre 0 e 20, denominou-se Avaliação Fonoaudiológica para AOS e Ronco. 


\subsubsection{Questionários}

\section{Avaliação subjetiva do ronco com o paciente e com o parceiro de quarto}

A avaliação foi feita por meio de entrevista padronizada em que foram feitas perguntas derivadas do questionário de Berlim ${ }^{47}$. Foram extraídas apenas as questões relativas à intensidade (questão 3) e frequência do ronco (questão 4). De maneira a quantificar esse sintoma, estabeleceram-se valores às respostas ${ }^{32,33}$ (ANEXO $\left.\mathrm{F}\right)$.

\section{Qualidade de Sono}

Todos os pacientes e seus respectivos parceiros de quarto responderam ao questionário de Qualidade de Sono de Pittsburgh ${ }^{48}$ (ANEXO G).

\section{Sonolência excessiva diurna}

Todos os pacientes responderam ao questionário de Epworth ${ }^{49}$ (ANEXO H).

\subsubsection{Nasofibrolaringoscopia}

A fim de diagnosticar problemas nasais obstrutivos (hipertrofia de conchas nasais, desvio de septo e hipertrofia de adenoide) que compõe um dos critérios de exclusão da pesquisa, todos os pacientes que apresentaram 
critérios para inclusão no estudo realizaram exame de nasofibrolaringoscopia antes de dar sequência às avaliações descritas a seguir.

\subsubsection{Polissonografia}

Todos os participantes foram submetidos a uma polissonografia basal durante a noite (Alice 5, Philips Respironics, Murrysville, PA). A monitorização incluiu eletroencefalografia, eletrocardiografia, eletromiografia submentoniana e tibial, oximetria de pulso, medições de fluxo de ar (termístor oronasal e cânula de pressão), e movimentação da caixa torácica e abdominal através de cintas. A apneia foi definida como redução de $90 \%$ ou cessação completa do fluxo aéreo por no mínimo 10 segundos. A hipopneia foi definida como uma redução (>50\%) nos sinais respiratórios por no mínimo 10 segundos associado à dessaturação da oxihemoglobina em no mínimo $3 \%$ ou despertar ${ }^{28}$. O IAH foi calculado como o número total de eventos respiratórios (apneias e hipopneias) por hora de sono.

A montagem da polissonografia foi realizada e monitorada durante toda a noite no Laboratório do Sono, por um técnico especializado. Os exames de polissonografia foram laudados sempre pelo mesmo pesquisador, cego para a identificação do grupo e momento.

\subsubsection{Análise do ronco}

A captação do som do ronco foi feita por meio da gravação dos sons de uma noite inteira utilizando um gravador digital de alto desempenho, 24bit e 
$96 \mathrm{~Hz}$, da marca Zoom, modelo $\mathrm{H} 4 \mathrm{n}$. Esta gravação foi concomitantemente ao exame de polissonografia, realizado pelos pacientes participantes do estudo no Laboratório do Sono do InCor. Já a análise dos sons do ronco, captados pelo gravador $\mathrm{H} 4 \mathrm{n}$, foi realizada em rotinas de processamento em um ambiente de programação matemática (Matlab R2011, The Mathworks, EUA). Neste trabalho, denominamos Roncômetro ao conjunto de captação e análise do ronco.

Devido ao pioneirismo e à complexidade das etapas que envolveram a captação e análise do som do ronco, os seguintes tópicos descreverão detalhadamente tal metodologia: Desenvolvimento do Roncômetro; Captação do som do ronco; Calibração do Roncômetro e Análise das gravações.

\section{Desenvolvimento do Roncômetro}

O desenvolvimento do Roncômetro contou com a parceria do Prof. Dr. Adriano Mesquita Alencar do IFUSP. Os primeiros testes para a gravação do ronco utilizaram uma versão diferente para captação do som cuja metodologia de gravação e análise foi fruto de duas iniciações científicas de bolsistas financiados pela FAPESP (Carolina Beatriz Gonzalez de Oliveira 2009/52855-4 e Diego Greatti Vaz da Silva 2009/52854-8), além de publicações posteriores $^{29,50,51}$.

Esta metodologia de gravação envolvia dois microfones conectados a um dispositivo de gravação e a um notebook (Figura 8A). Para viabilizar um produto mais simples, foi feita uma nova versão para captação e 
armazenamento dos sons do ronco (Figura 8B) em que não existia a necessidade de um notebook. Os dados ficavam gravados em um cartão de memória microSD, similar aos utilizados por telefones celulares.
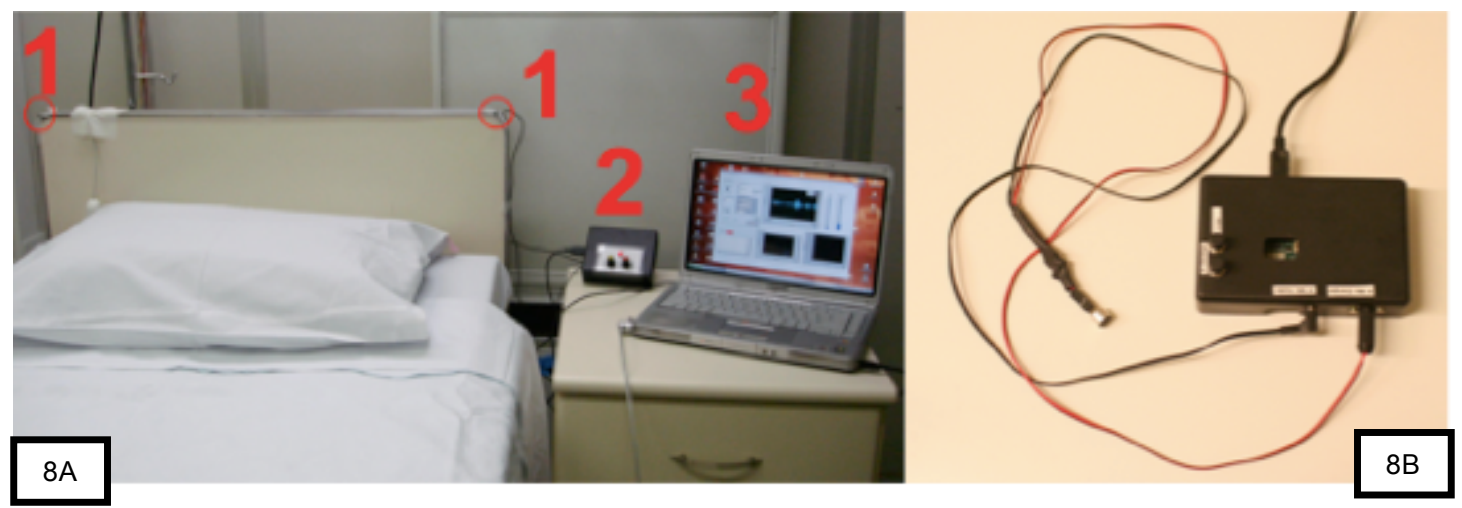

Figura 8A- Primeiro sistema de gravação utilizado

Figura 8B- Segundo sistema de gravação

Apesar do aparente avanço, as gravações realizadas com este dispositivo apresentaram ruídos, possivelmente provenientes de interferências eletromagnéticas. Este equipamento se mostrou pouco acurado para determinação da intensidade do ronco e portanto não foi possível sua utilização para cumprir os objetivos centrais do presente estudo.

Após inúmeros testes, foi decidido pela mudança da tecnologia de aquisição do sinal sonoro com a compra de um equipamento de gravação profissional, o Zoom H4n. 


\section{Captação do som do ronco}

O Zoom H4n (Figura 9) possui excelente sistema de captação de som com isolamento total das interferências eletromagnéticas (que se mostraram muito presentes em nosso laboratório e até então desconhecidas).

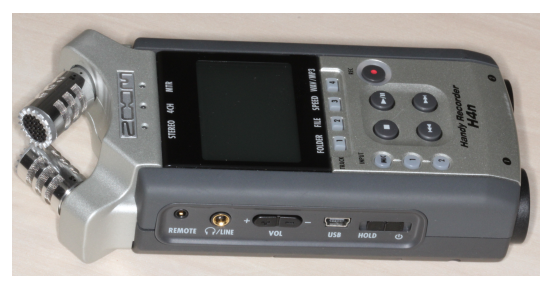

Figura 9- Gravador digital ZOOM H4n. O aparelho tem dois microfones formando um ângulo de $90^{\circ}$ entre si, que permite uma gravação do som multidirecional, sem interferências eletromagnéticas.

Dessa forma, toda a metodologia de gravação do ronco foi modificada para atender a um dos objetivos primários do estudo, que é o de medir a intensidade do ronco antes e após a Terapia Miofuncional Orofacial.

A nova metodologia utilizada concomitante ao exame de polissonografia está demonstrada na Figura 10A, 10B e 10C. O microfone foi colocado a um metro da superfície do colchão, com boa captação do ronco independente da posição da cabeça do paciente. 


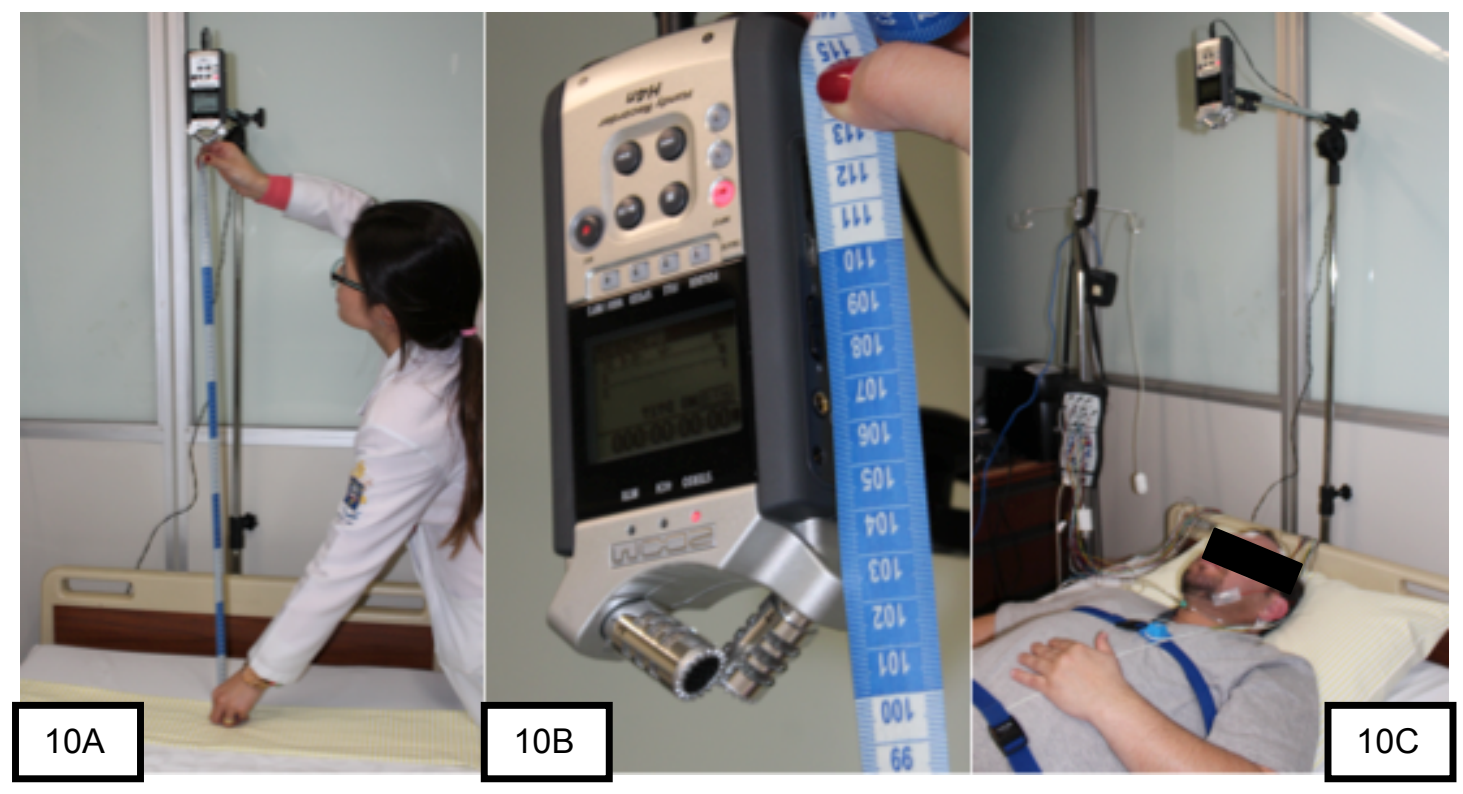

Figura 10A- Gravador H4n sendo posicionado Figura 10B- Distância de 1 metro a da superfície do colchão Figura 10C- Paciente preparado para realização do exame de polissonografia concomitante à gravação do ronco.

\section{Calibração do Roncômetro}

Após a aquisição do sinal acústico, iniciou-se o processamento inicial ou condicionamento do sinal. Nessa etapa o sinal acústico original foi filtrado eliminando ruídos de baixa e alta frequência. Para tanto, foi desenvolvido um filtro digital de banda entre 80 e $300 \mathrm{~Hz}$, frequência característica do ronco ${ }^{29}$. Em seguida, o sinal foi elevado à segunda potência e integrado em pequenas janelas temporais, dando origem a um sinal de intensidade $\left(I_{m}\right)$, ou energia acústica, expresso em unidades arbitrárias. Assim, foi necessário criar um procedimento de calibração que, além de garantir a confiabilidade dos dados gerados a partir da aquisição sonora, pudesse convertê-los para intensidade acústica em decibéis $\left(\mathrm{I}_{\mathrm{DB}}\right)$, uma escala logarítmica padrão bastante utilizada. 


$$
I_{D B}=10 \log \left(I_{m} / I_{o}\right)
$$

onde $\mathrm{I}_{\mathrm{o}}$ é a menor intensidade acústica percebida pelo ouvido humano normal.

Foi elaborado um som padrão com frequência exatamente no meio do espectro acústico filtrado, ou seja, de $190 \mathrm{~Hz}$, garantindo que o som de calibração não fosse atenuado no processo de filtragem. Esse som padrão iniciava com uma intensidade bem baixa, imperceptível, e mantinha essa intensidade sonora durante 15 segundos, uma pausa de mais 15 segundos e um aumento da intensidade geometricamente por um fator de 2, isto é, dobrava a intensidade a cada 30 segundos. Este aumento ocorreu 8 vezes, atingindo máximo permitido pelo formato de áudio do arquivo de som. Nesse caso, o tempo total de gravação foi de 4 minutos.

Este som padrão foi reproduzido por um aparelho de áudio e registrado pelo gravador $\mathrm{H} 4 \mathrm{n}$. Para minimizar possíveis ruídos do ambiente que pudessem interferir na gravação, foi confeccionada uma caixa acústica feita de espuma com perfurações que permitiram a entrada do microfone do gravador e do decibelímetro Minipa MSL-1352C em uma extremidade, e da caixa de som do aparelho de áudio na extremidade oposta (Figura 11). 

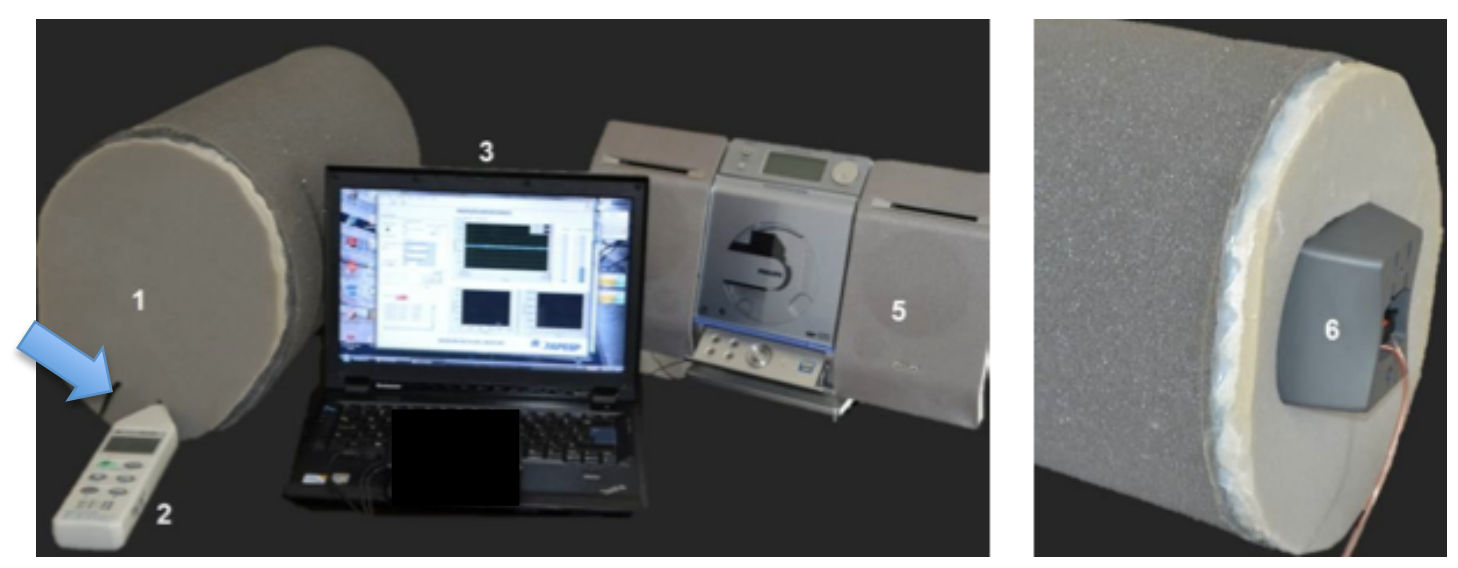

Figura 11- Equipamentos utilizados na calibração: (1) caixa acústica, (2) decibelímetro, (3) microcomputador, (5) equipamento de som e (6) caixa de som. A seta em azul indica o local de entrada para o microfone do gravador

Durante a gravação, o decibelímetro registrava as intensidades em Decibel, que eram anotadas para análise posterior. Para os valores de interesse, houve um ótimo ajuste entre os dados obtidos pelo decibelímetro e os dados obtidos pelo roncômetro $\left(I_{m}\right)$ após a conversão pela equação

$$
I_{d B}=10 \log \left(I_{m} / I_{o}\right)
$$

onde $\mathrm{I}_{\mathrm{dB}}$ é o som de base gravado pelo $\mathrm{H} 4 \mathrm{~N}$ no ambiente em que as medidas foram feitas. A Figura 12 ilustra o ajuste obtido pelos dois equipamentos. 


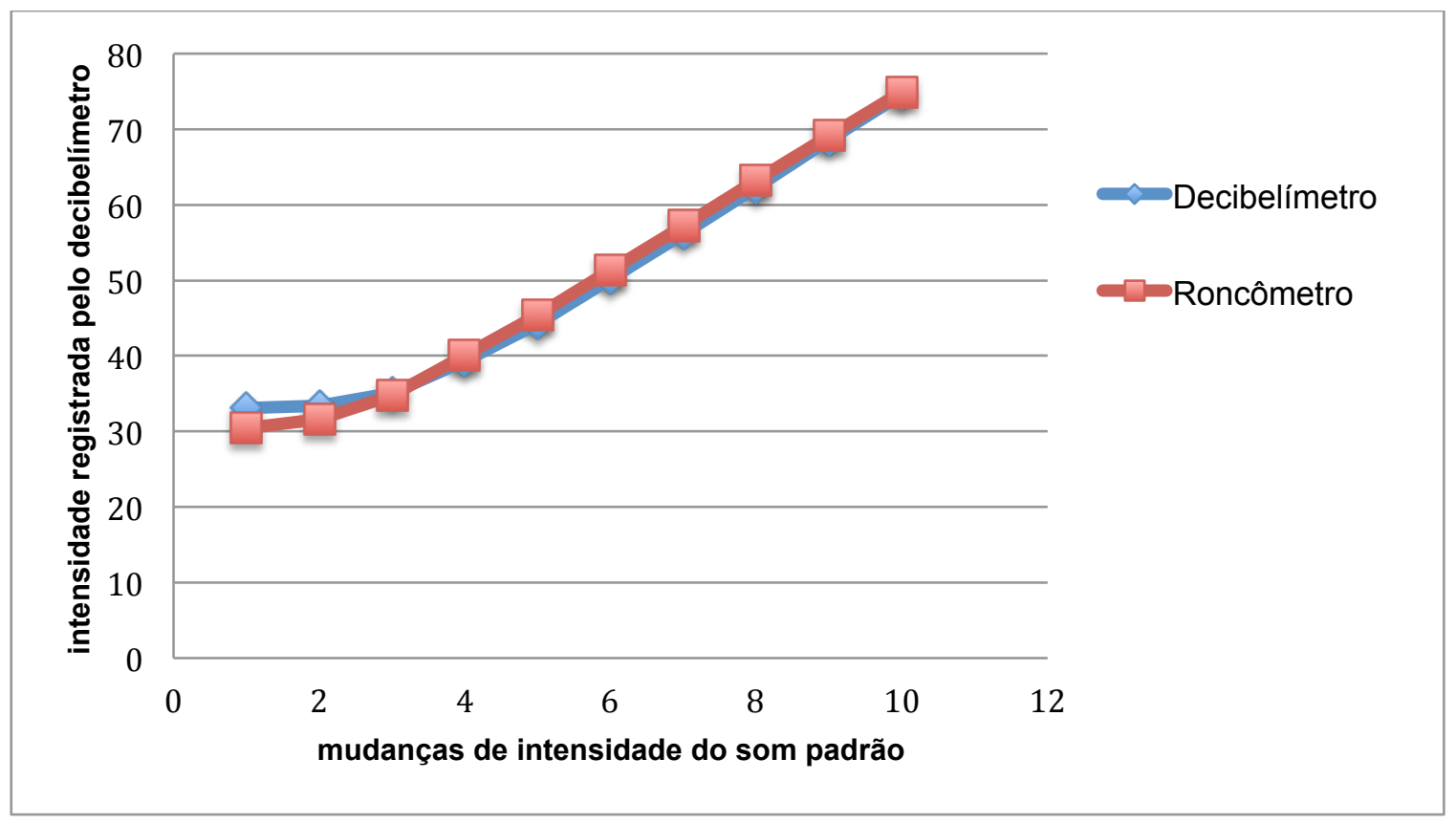

Figura 12 - Comparação entre os valores em decibéis obtidos pelo decibelímetro e pelo sistema de aquisição e análise desenvolvido para o presente estudo. Os sons de calibração gravados pelo $\mathrm{H} 4 \mathrm{n}$ foram convertidos em dB, usando a Equação 1 . O parâmetro $\mathrm{I}_{\mathrm{o}}=100$ ajusta as duas curvas perfeitamente. Esse valor está em unidades arbitrárias e é interpretado como sendo a intensidade acústica mínima que um ser humano normal poderia escutar. Esse valor é válido apenas para o gravador $\mathrm{H} 4 \mathrm{n}$, quando o ganho de gravação do mesmo foi ajustado no volume 80 (em uma escala de 0 a 100)

Uma vez definida, esta equação foi incorporada às rotinas de análise possibilitando a aproximação do som do ronco captado durante a gravação com a intensidade em decibéis.

\section{Análise das gravações}

Além da mudança da metodologia da captação, toda a metodologia de análise, realizada em parceria com o Prof. Dr. Adriano Mesquita Alencar, foi modificada.

Nesse contexto, foram realizadas reuniões quinzenais no IFUSP para criação de novas rotinas de processamento em um ambiente de programação 
matemática (Matlab R2011, The Mathworks, EUA). Como resultados destas reuniões, cerca de 6 versões foram desenvolvidas durante 3 anos a fim de minimizar as dificuldades encontradas ao se analisar o ronco.

Uma das dificuldades se refere ao tamanho dos arquivos gerados pelo gravador H4n. Cada gravação de aproximadamente 7 horas resultava, em média, arquivos com tamanho aproximado de 5 GigaBytes. Estes arquivos precisaram ser compactados para serem submetidos à análise posterior. Portanto, foi criado um programa na linguagem computacional $\mathrm{C}++$ que compactava estes arquivos em arquivos menores com aproximadamente 500 megabytes. Após este processo, este arquivo era enviado para um servidor localizado no IFUSP que realizava um filtro de banda $(80$ a $300 \mathrm{~Hz})$ para eliminar as frequências abaixo e acima do ronco. Como resultado, o arquivo disponibilizado, agora no formato de texto, em ASCII, poderia ser analisado de acordo com as rotinas de processamento desenvolvidas no Matlab.

Contudo, mesmo após este procedimento de filtragem de banda, a principal dificuldade encontrada durante o processo de análise do ronco foi a identificação de falsos positivos, que foi possível devido a horas de trabalho dedicadas à escuta atenta da gravação e sincronização manual com os eventos que a rotina de processamento do Matlab identificava como ronco. Nesta etapa do estudo, muitos ruídos do ambiente como bater de portas e som de vozes ou até mesmo ruídos produzidos pelo próprio paciente como a fricção na cama para mudança de posição ou tosse haviam sido detectados e classificados como ronco. 
Dentre as alternativas para solucionar este problema, cogitou-se a possibilidade de realizar o tratamento acústico do local onde estavam sendo realizadas as gravações. No entanto, esta solução mostrou-se inviável devido aos prazos do presente estudo e ao número de pacientes que já haviam realizado o exame de polissonografia concomitante à gravação do ronco e que já estavam seguindo o tratamento para o qual haviam sido randomizados.

Portanto, a rotina de análise utilizada no presente trabalho contou com dois procedimentos para minimizar a interferência dos ruídos do ambiente. São eles:

1. Adaptação do software a possíveis mudanças nos limiares de ruído no ambiente em decorrência da identificação das oscilações de intensidade que eram geradas durante o ronco (picos) e das baixas intensidades nos intervalos entre roncos (vales).

2. Conferência manual dos eventos classificados como ronco por meio da escuta e discriminação do evento apresentado em ruído ou ronco real (RR). A rotina de análise criada na plataforma Matlab solicitava a definição de um limiar de corte que, para o presente trabalho, foi definido em $4.10^{5}$ em unidades arbitrárias (equivalente a $36 \mathrm{~dB}$, se convertidos) para a análise de todos os pacientes. Após esta definição, a rotina apresentava um evento a cada 5 segundos, ao qual a pesquisadora classificava em RR ou ruído

A Figura 13 exemplifica o processo de conferência manual dos eventos classificados como RR pela rotina de análise na plataforma computacional Matlab. Neste processo, a pesquisadora utilizou um fone de 
ouvido para realizar a marcação no programa Excel do que classificou como $\mathrm{RR}(1)$ ou ruído(0).

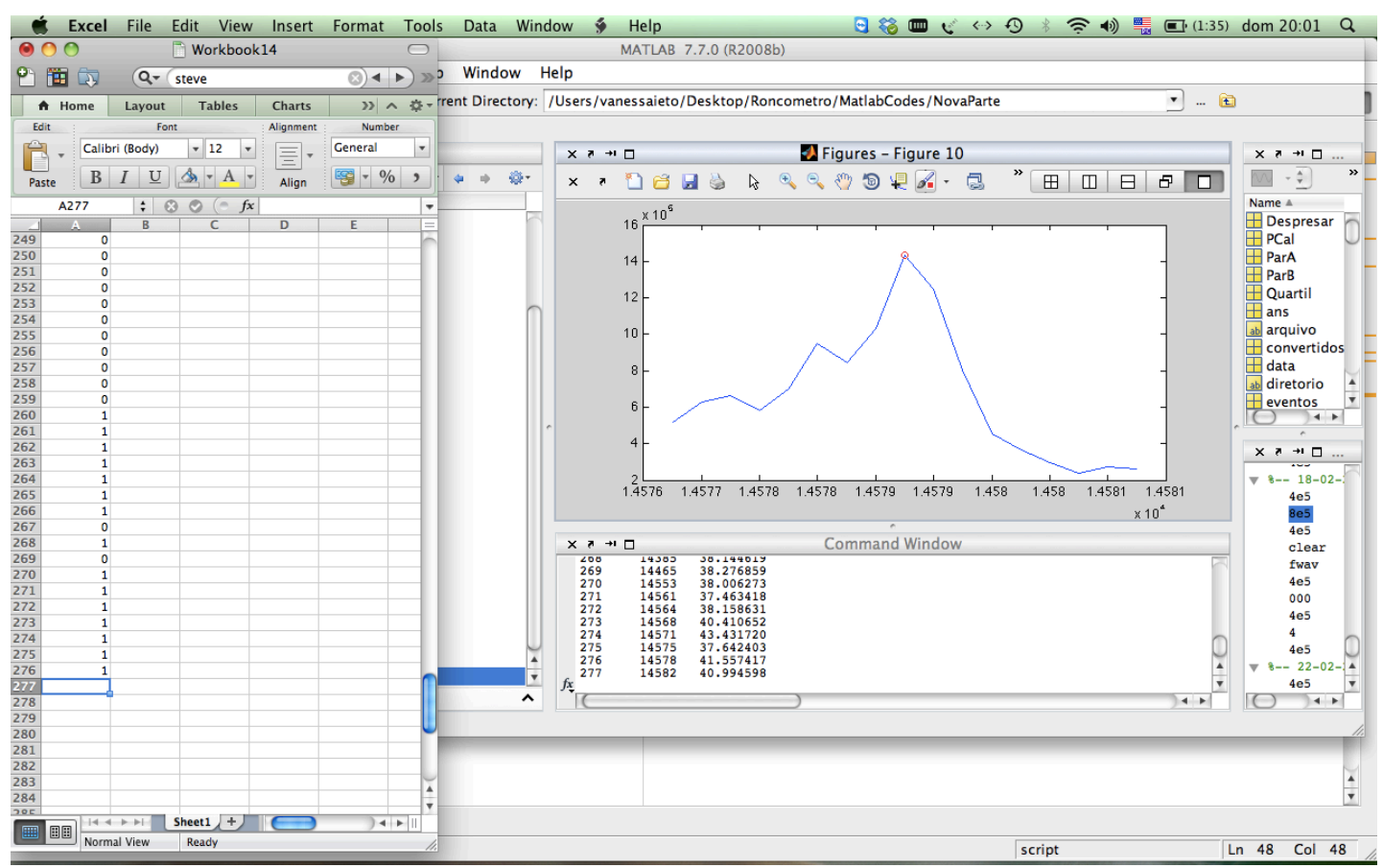

Figura 13: Print Screen da tela do computador visualizando ao mesmo tempo a Tabela Excel em que eram realizadas a marcação dos roncos reais e o programa Matlab em funcionamento.

Solucionados os problemas em decorrência do tamanho dos arquivos de som gerados pelo gravador e da detecção de falsos positivos, a seguir serão descritos os procedimentos de análise do ronco.

Após a classificação dos eventos em ruído ou $\mathrm{RR}$, a rotina de processamento Matlab gerou os seguintes dados: tempo em que o evento ocorreu e intensidade em decibéis. Estas características foram então transferidas para uma planilha Excel em que os eventos classificados como ruído foram descartados e não seguiram nas próximas etapas de análise. 
Outro desafio superado ao longo deste processo foi $o$ de sincronização dos RR com a posição do paciente. Estudos apontam ${ }^{52,53}$ que a posição do paciente pode influenciar a ocorrência de apneias e ronco. Portanto, a fim de controlar este possível viés em nosso estudo, uma nova rotina de processamento foi criada no Matlab.

Nesta rotina, foi necessário se remeter aos dados da polissonografia. A pesquisadora utilizou os exames de polissonografia para obter os horários em que o paciente mudava de posição (supino, direita, esquerda, prono). Com esta informação, foi possível realizar uma sincronização entre as informações de posição do polígrafo e as informações de ronco do gravador. Vale ressaltar que a cada gravação, o horário do gravador era ajustado ao horário do computador em que o polígrafo era instalado.

Como resultado, o tempo de permanência, número de roncos e pico de intensidade em cada posição (supino, direita, esquerda, prono) foram determinados.

No entanto, durante o processo de análise de cada paciente, pôde-se perceber que, em alguns exames, o tempo de permanência na posição não coincidia com o tempo de sono na mesma posição. Portanto, para o cálculo dos Índices de Roncos Supino e não Supino, foi utilizado o tempo de sono na posição, derivado da polissonografia.

Além disso, o fato de alguns pacientes não terem permanecido, por exemplo na posição prono ou até mesmo decúbito lateral direito ou esquerdo, fez com que alguns índices fossem igual a zero. Desta forma, a fim de viabilizar 
a análise estatística, as posições prono, decúbito lateral direito e esquerdo foram somadas e consideradas como posição não supina.

Portanto, as variáveis de ronco derivadas da análise das rotinas de processamento no Matlab e dos dados de sincronização com a polissonografia serão descritas a seguir:

1. Índice de roncos: razão entre o número total de roncos e o tempo total de sono derivado da polissonografia

2. Índice de roncos supino: razão entre o número total de roncos na posição supina e o tempo total de sono na posição supina, derivado da polissonografia 3. Índice de roncos não supino: razão entre a somatória do número total de roncos nas posições decúbito lateral direito, esquerdo e prono e a somatória do tempo total de sono nas mesmas posições.

4. Pico de intensidade máxima: intensidade máxima atingida pelo ronco, convertida em decibéis

5. Índice Potência Total: razão entre a soma de todas as potências geradas durante os eventos de ronco e o tempo total de sono. A unidade desta variável é uma unidade arbitrária e gerou números bastante extensos. Por esta razão, todos os valores de potência foram divididos por $10^{7}$.

6. Índice Potência Total do Ronco supino: razão entre a soma de todas as potências geradas durante os eventos de ronco na posição supina e o tempo total de sono na posição supina. A unidade desta variável é uma unidade arbitrária e gerou números bastante extensos. Por esta razão, todos os valores de potência foram divididos por $10^{7}$. 
7. Índice Potência Total do Ronco não supino: razão entre a somatória de todas as potências geradas nas posições decúbito lateral direito, esquerdo e prono e a somatória do tempo total de sono nas mesmas posições. A unidade desta variável é uma unidade arbitrária e gerou números bastante extensos. Por esta razão, todos os valores de potência foram divididos por $10^{7}$.

Os valores advindos da análise no Matlab expressam quantitativamente a frequência e intensidade do ronco, mensuradas respectivamente pelo Índice de roncos e pelo Índice Potência Total do Ronco.

O fluxograma da Figura 14 resume o processo de gravação e análise do ronco. 


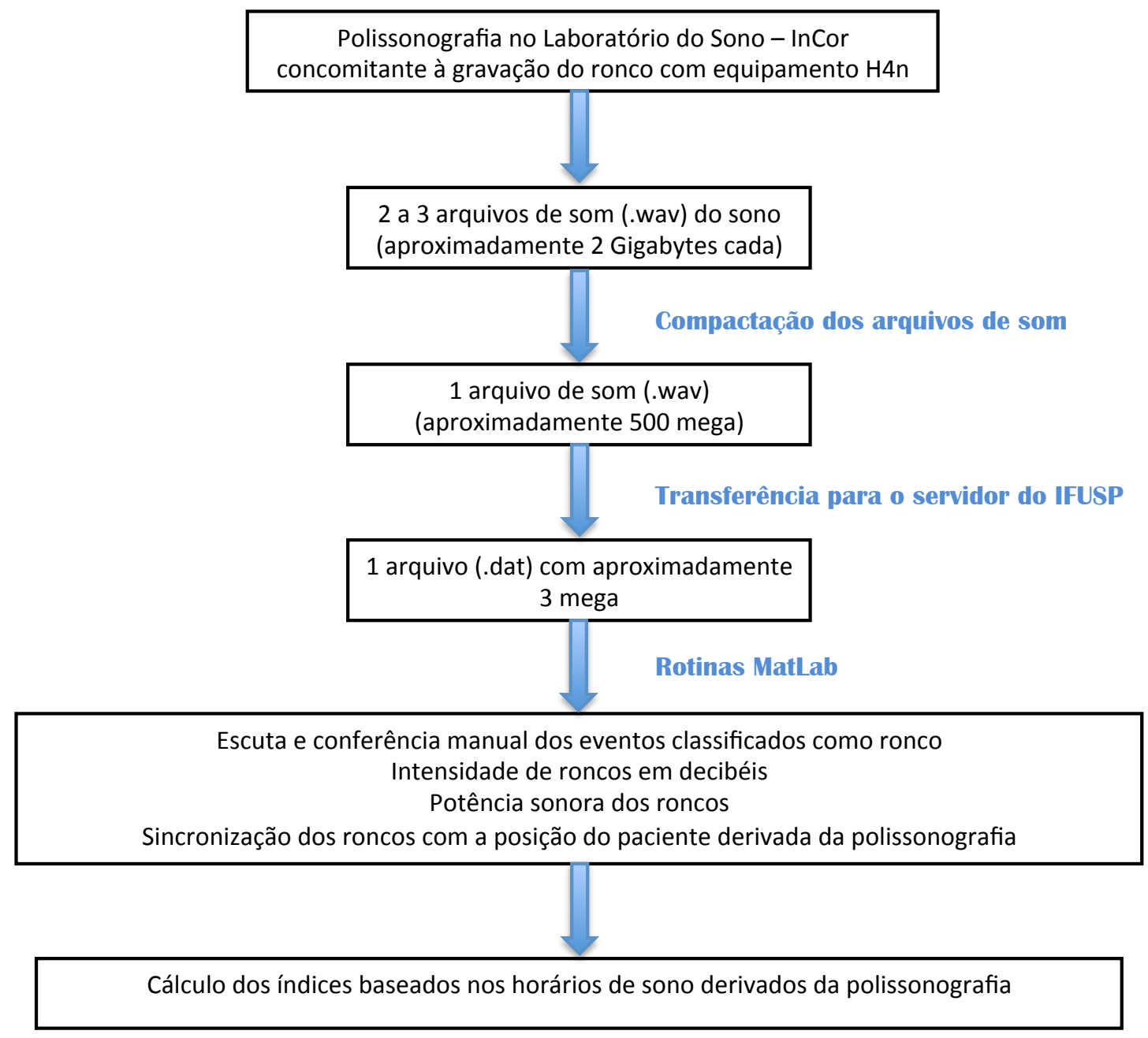

Figura 14- Fluxograma resumindo as etapas de análise do ronco 


\subsection{Análise estatística}

Consideramos que seriam necessários incluir 38 pacientes no estudo a partir da pressuposição de que os pacientes tratados com Terapia Miofuncional Orofacial teriam uma redução mínima de 50\% dos índices de ronco, enquanto o Grupo Controle não teria variação significativa do ronco. Portanto, o cálculo da amostra foi baseado numa magnitude de efeito de $50 \%$, assumindo $\alpha=0,05$ e poder amostral de $80 \%$. Imaginando perdas após a randomização, a estratégia do estudo foi incluir 40 pacientes.

As variáveis numéricas foram testadas por meio do teste de normalidade de Kolmogorov-Smirnov para verificar a normalidade da distribuição dos dados. Foi realizada uma análise descritiva onde os dados foram apresentados como médias \pm desvio padrão ou mediana [intervalo interquartil] quando necessário (distribuição não normal).

Para a comparação das características demográficas, antropométricas, resultados de polissonografia e análise do ronco intergrupo no basal, foram aplicados os testes: teste t não pareado, teste Mann-Whitney e Qui-Quadrado quando apropriado.

Para investigar os efeitos do grupo, tempo e interação grupo-tempo foram utilizadas técnicas de análise de variância não paramétrica para medidas repetidas - ANOVA não paramétrica ${ }^{54}$. 
Para distinguir os efeitos no basal e após 3 meses de randomização no Grupo Tratamento e Grupo Controle, fizemos adicionalmente o teste $t$ pareado ou Wilcoxon, quando apropriado.

As comparações foram feitas por meio da análise "intention to treat". Os dados dos pacientes que abandonaram o estudo após terem sido randomizados e iniciado o tratamento foram incluídos na análise estatística ${ }^{55}$ segundo o método de tratamento para dados incompletos "Última observação realizada" (Last Observation Carried Forward) ${ }^{56}$. A análise estatística foi realizada utilizando-se o software estatístico SPSS versão 20.0 e software estatístico $R\left(R\right.$ Core Team, 2013) ${ }^{57}$. Um valor de $p<0,05$ foi considerado significante. 
4. RESULTADOS 
Entre novembro de 2011 e novembro de 2013 foram recrutados 156 pacientes. Os pacientes foram encaminhados primariamente do Laboratório do Sono através do Ambulatório de Sono do InCor. O recrutamento ocorreu em horário previamente agendado e foi realizado pela pesquisadora. No momento do recrutamento os sujeitos forneceram seus dados pessoais e foram submetidos a avaliação padrão para certificação dos critérios de inclusão e exclusão da pesquisa e também foram informados sobre o propósito e etapas do estudo.

As características demográficas dos pacientes elegíveis estão resumidas na Tabela 1.

Tabela 1 - Dados demográficos do total de pacientes elegíveis, excluídos, incluídos e randomizados

\begin{tabular}{lccc}
\hline & $\begin{array}{c}\text { Total } \\
\mathrm{n}=156\end{array}$ & $\begin{array}{c}\text { Excluídos } \\
\mathrm{n}=117\end{array}$ & $\begin{array}{c}\text { Incluídos } \\
\mathrm{n}=39\end{array}$ \\
\hline Gênero masculino, $\mathrm{n}$ & 98 & 76 & 22 \\
Idade, anos & $45 \pm 13$ & $43 \pm 13$ & $48 \pm 13$ \\
$\mathrm{IMC}, \mathrm{kg} / \mathrm{m}^{2}$ & $28,1 \pm 4,0$ & $28,1 \pm 4,2$ & $27,9 \pm 2,8$ \\
\hline IMC: índice de massa corpórea; AOS: apneia obstrutiva do sono & & \\
Dados expressos em valor absoluto ou média \pm desvio padrão. &
\end{tabular}

Dos 156 sujeitos recrutados para a pesquisa, 117 foram excluídos devido aos seguintes critérios: indisponibilidade de comparecimento semanal $(n=24)$; AOS grave $(n=21)$; desdentados ou usuários de prótese total $(n=19)$; presença de doença nasal obstrutiva grave $(n=18)$; tonsila palatina hipertrófica grau 3 ou $4 \quad(n=12)$; uso de medicação hipnótica $(n=9)$ fumantes $(n=8)$; 
deformidades craniofaciais $(n=5)$ e cirurgia de uvulopalatofaringoplastia $(n=1)$, conforme Tabela 2.

Tabela 2 - Número e proporção dos motivos de exclusão do estudo

\begin{tabular}{lcc}
\hline Critério de exclusão & $\mathbf{N}$ & \% \\
\hline Indisponibilidade de comparecimento semanal, n (\%) & 24 & 20,5 \\
AOS grave & 21 & 17,9 \\
Desdentados/prótese total & 19 & 16,2 \\
Doença nasal obstrutiva grave & 18 & 15,4 \\
Tonsila palatina hipertrófica & 12 & 10,3 \\
Uso de medicação hipnótica & 9 & 7,7 \\
Fumante & 8 & 6.8 \\
Deformidade craniofacial & 5 & 4,3 \\
Cirurgia de uvulopalatofaringoplastia & 1 & 0.9 \\
\hline Total & 117 & 100 \\
\hline
\end{tabular}

AOS: apneia obstrutiva do sono

Dados expressos em valor absoluto e porcentagem

\section{Nasofibrolaringoscopia}

Foram realizados 80 exames de nasofibrolaringoscopia e 18 pacientes foram excluídos por apresentar uma ou mais alterações definidas como doença nasal obstrutiva grave. A Tabela 3 descreve a frequência destas alterações. 
Tabela 3 - Número e proporção dos motivos de exclusão durante a nasofibrolaringoscopia. 0 número total de pacientes excluídos $(n=18)$ não corresponde à somatória do $n$ dos critérios de exclusão pois alguns pacientes apresentaram mais de um critério

\begin{tabular}{lc}
\hline Critério de exclusão & $\mathbf{n}$ \\
\hline Desvio de septo grau 3 & 15 \\
Desvio de septo grau 4 & 1 \\
Hipertrofia de conchas nasais & 8 \\
Pólipo nasal & 2 \\
Hipertrofia de adenoide superior a 50\% & 1 \\
Hipertrofia de tonsila palatina grau 3 & 1 \\
\hline Dados expressos em valor absoluto &
\end{tabular}

Após o recrutamento dos pacientes e a randomização, 2 pacientes (um de cada grupo) abandonaram o estudo.

O fluxograma (de acordo com o Consort ${ }^{55}$ ) dos pacientes elegíveis, excluídos, incluídos e randomizados estão representados na Figura 15. 


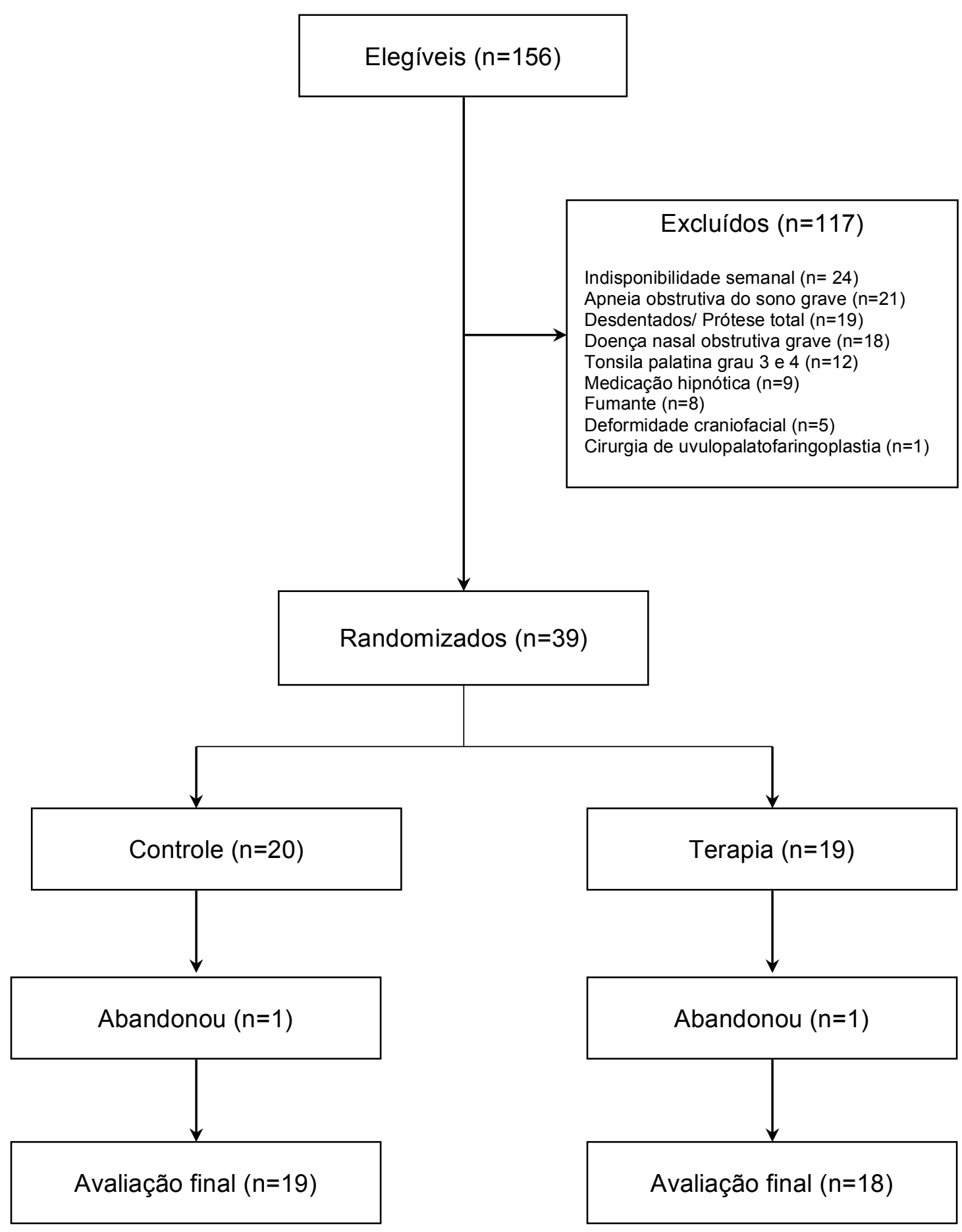

Figura 15 - Fluxograma dos pacientes elegíveis, excluídos e randomizados 
A Tabela 4 representa as características antropométricas e clínicas dos pacientes incluídos na pesquisa. A distribuição de gênero e pacientes com ronco primário, AOS leve, moderada e ronco primário foi semelhante nos dois grupos. Além disso, os pacientes randomizados entre controle e terapia foram similares em relação às características antropométricas (idade, IMC, circunferência cervical e abdominal). Em relação às características clínicas, somente a intensidade do ronco referida por meio de questionário com o próprio paciente foi levemente mais significante em pacientes randomizados para 0 Grupo Controle. 
Tabela 4 - Características antropométricas e clínicas dos pacientes incluídos no estudo

\begin{tabular}{lccc}
\hline & $\begin{array}{c}\text { Controle } \\
(\mathrm{n}=20)\end{array}$ & $\begin{array}{c}\text { Terapia } \\
(\mathrm{n}=19)\end{array}$ & $\begin{array}{c}\mathrm{p} \\
\text { valor }\end{array}$ \\
\hline Gênero masculino & $11(55 \%)$ & $11(57,9 \%)$ & 1,000 \\
Idade & $44,9 \pm 12,7$ & $48,1 \pm 13,6$ & 0,458 \\
IMC, kg/m ${ }^{2}$ & $28,3 \pm 2,5$ & $28,1 \pm 2,7$ & 0,818 \\
Ronco primário & $3(15 \%)$ & $3(15,8 \%)$ & \\
AOS leve & $9(45 \%)$ & $8(42,1 \%)$ & 0,984 \\
AOS moderada & $8(40 \%)$ & $8(42,1 \%)$ & \\
Circunferência cervical & $38,0 \pm 3,5$ & $38,0 \pm 2,6$ & 0,994 \\
Circunferência abdominal & $94,3 \pm 10,2$ & $93,9 \pm 5,7$ & 0,872 \\
Qualidade de sono, Pittsburgh & $6,9 \pm 3,4$ & $6,0 \pm 3,2$ & 0,427 \\
Sonolência excessiva, Epworth & $9,0[7,0-13,5]$ & $7,0[3,0-11,0]$ & 0,154 \\
Intensidade do ronco, questionário & $3,0 \pm 1,0$ & $2,3 \pm 1,1$ & 0,037 \\
Frequência do ronco, questionário & $4,0[3,0-4,0]$ & $3,0[2,0-4,0]$ & 0,070 \\
MGBR adaptado & $37,9 \pm 8,6$ & $35,0 \pm 10,8$ & 0,357 \\
Av. Fono AOS e Ronco & $10,3 \pm 3,2$ & $9,5 \pm 2,4$ & 0,397 \\
\hline
\end{tabular}

IMC: índice de massa corpórea; AOS: apneia obstrutiva do sono; MGBR adaptado: Exame miofuncional Orofacial MGBR - adaptado para AOS e ronco; Av. FONO AOS e Ronco: avaliação fonoaudiológica para pacientes com ronco e AOS

Dados expressos em valor absoluto ou média \pm desvio padrão para as variáveis com distribuição normal e medianas [intervalo interquartil] para variáveis sem distribuição normal

A Tabela 5 representa os resultados obtidos através do exame de polissonografia e da mensuração objetiva do ronco dos pacientes incluídos na pesquisa. Não houve diferença estatisticamente significante entre os grupos Controle e Terapia. 
Tabela 5 - Características polissonográficas e de ronco dos pacientes incluídos no estudo

\begin{tabular}{|c|c|c|c|}
\hline & $\begin{array}{c}\text { Controle } \\
(n=20)\end{array}$ & $\begin{array}{c}\text { Terapia } \\
(n=19)\end{array}$ & $\begin{array}{c}\mathrm{p} \\
\text { valor }\end{array}$ \\
\hline \multicolumn{4}{|l|}{ Polissonografia } \\
\hline TTS (hs) & $6,2 \pm 0,6$ & $6,1 \pm 0,8$ & 0,755 \\
\hline TTS supino (hs) & $3,2 \pm 1,8$ & $3,3 \pm 1,8$ & 0,874 \\
\hline Eficiência do sono (\%) & $84,4 \pm 7,5$ & $86,0 \pm 9,7$ & 0,565 \\
\hline I despertares & $15,3 \pm 5,4$ & $20,0 \pm 10,2$ & 0,080 \\
\hline $\mathrm{IAH}$ & $15,1 \pm 9,5$ & $15,6 \pm 9,3$ & 0,875 \\
\hline IAH NREM & $11,3 \pm 8,3$ & $14,2 \pm 9,2$ & 0,321 \\
\hline IAH REM & $30,1 \pm 23,1$ & $20,6 \pm 17,5$ & 0,156 \\
\hline IAH supino & $24,5 \pm 15,2$ & $22,1 \pm 16,2$ & 0,632 \\
\hline IA obstrutiva & $0,5[0,0-4,8]$ & $0,5[0,2-3,2]$ & 0,864 \\
\hline $\mathrm{IH}$ & $11,6 \pm 7,3$ & $12,3 \pm 6,7$ & 0,761 \\
\hline $\mathrm{SpO}_{2}$ mínima & $85,1 \pm 5,8$ & $85,5 \pm 7,5$ & 0,844 \\
\hline Índice de dessaturação & $12,3 \pm 8,7$ & $10,8 \pm 8,8$ & 0,600 \\
\hline \multicolumn{4}{|l|}{ Mensuração do ronco } \\
\hline 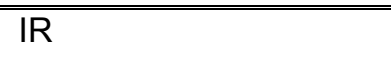 & $180,6 \pm 203,1$ & $156,1 \pm 164,4$ & 0,682 \\
\hline IR sup & $233,0 \pm 235,4$ & $181,1 \pm 168,1$ & 0,436 \\
\hline IR nsup & $109,8 \pm 159,8$ & $71,9 \pm 119,9$ & 0,431 \\
\hline IPTR & $54,4[3,5-386,6]$ & $60,4[21,8-220,6]$ & 0,613 \\
\hline IPTR sup & $86,2[3,4-472,0]$ & $120,9[4,7-374,6]$ & 0,955 \\
\hline IPTR nsup & $5,7[0,6-73,3]$ & $7,7[1,1-47,2]$ & 0,937 \\
\hline $\mathrm{R} \max (\mathrm{dB})$ & $51,2 \pm 4,5$ & $52,4 \pm 4,6$ & 0.447 \\
\hline
\end{tabular}


Em relação aos efeitos da Terapia Miofuncional Orofacial sobre a qualidade de sono do parceiro de quarto, a Tabela 6 apresenta os resultados de teste ANOVA não paramétrica do questionário de Pittsburgh no basal e após 3 meses de randomização. Além disso, também foram apresentadas as variáveis Intensidade do Ronco e Frequência do Ronco, ambas determinadas por meio de questionário com o parceiro de quarto e Escala de sonolência excessiva diurna de Epworth.

O número de parceiros de quarto foi 25 , pois nem todos os pacientes randomizados foram acompanhados por companheiros de quarto no período do tratamento para o qual foram randomizados.

A escala de sonolência de Epworth e os questionários de Intensidade e Frequência do ronco apresentaram significância estatística quanto à interação grupo e período. 
Tabela 6 - Resultados dos Questionários aplicados com o parceiro de quarto e com o paciente

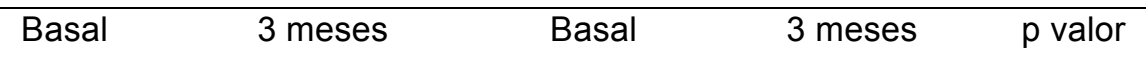

\begin{tabular}{|c|c|c|c|c|c|}
\hline Parceiro & \multicolumn{2}{|c|}{ Controle $(n=12)$} & \multicolumn{2}{|c|}{ Terapia $(n=13)$} & \\
\hline Pittsburgh & $99,0[6,5-12,0]$ & $8,5[7,0-11,5]$ & 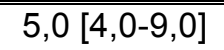 & "4,0[3,0-7,0] & 0,0618 \\
\hline Int. ronco, q. & $3,5[2,3-4,0]$ & $3,0[2,0-4,0]$ & $4,0[2,5-4,0]$ & $1,0[1,0-2,0]$ & 0,0006 \\
\hline Freq. ronco, q. & $4,0[3,0-4,0]$ & $3,5[3,0-4,0]$ & $4,0[3,0-4,0]$ & $2,0[1,5-3,0]$ & 0,0026 \\
\hline Paciente & \multicolumn{2}{|c|}{ Controle $(n=20)$} & \multicolumn{2}{|c|}{ Terapia $(n=19)$} & \\
\hline Pittsburgh & $7,0[4,0-10,0]$ & $6,0[3,0-9,5]$ & $5,0[3,0-9,0]$ & $4,0[2,0-6,0]$ & 0,098 \\
\hline Epworth & $9,0[7,0-13,5]$ & $8,0[3,5-12,5]$ & $7,0[3,0-11,0]$ & $7,0[4,0-10,0]$ & 0,529 \\
\hline Int. ronco, q. & $3,0[2,0-4,0]$ & $3,0[2,0-3,0]$ & $2,0[2,0-3,0]$ & $2,0[1,0-2,0]$ & 0,859 \\
\hline Freq. ronco, q. & $4,0[3,0-4,0]$ & $3,5[2,0-4,0]$ & $3,0[2,0-4,0]$ & $2,0[1,0-4,0]$ & 0,983 \\
\hline
\end{tabular}

A Tabela 7 apresenta os resultados no basal e após 3 meses de randomização das características antropométricas e clínicas dos pacientes no basal e após. As variáveis que mostraram significância estatística da interação grupo e período foram: circunferência cervical e protocolos de avaliação de motricidade orofacial: MGBR adaptado total e Avaliação Fonoaudiológica específica para ronco e AOS. 
Tabela 7 - Características antropométricas e clínicas dos pacientes incluídos no estudo no basal e após 3 meses de randomização

\begin{tabular}{|c|c|c|c|c|c|}
\hline & \multicolumn{2}{|c|}{ Controle } & \multicolumn{2}{|c|}{ Terapia } & \multirow[b]{2}{*}{$p$ valor } \\
\hline Variáveis & Basal & 3 meses & Basal & 3 meses & \\
\hline IMC, $\mathrm{kg} / \mathrm{m}^{2}$ & $28,1[25,2-30,8]$ & $28,2[25,0-31,1]$ & $27,5[26,6-30,9]$ & $27,3[26,2-30,9]$ & 0,330 \\
\hline $\mathrm{CC}, \mathrm{cm}$ & $37,8[35,9-40,3]$ & $37,2[36,3-40,1]$ & $38,0[36,4-39,5]$ & $37,5[36,0-39,0]$ & 0,038 \\
\hline $\mathrm{CA}, \mathrm{cm}$ & $93,3[84,8-103,3]$ & $91,5[86,5-105,8]$ & $93,0[89,8-96,0]$ & $93,0[90,0-98,0]$ & 0,826 \\
\hline MGBR adap. & $37,5[34,0-43,0]$ & $37,5[30,0-44,5]$ & $37,0[23,0-42,0]$ & $19,0[13,0-24,0]$ & $<0,000$ \\
\hline Av. FAR & $10,5[8,3-12,0]$ & $11,0[7,3-11,8]$ & $10,0[7,0-11,0]$ & $3,0[2,0-4,0]$ & $<0,000$ \\
\hline $\begin{array}{l}\text { CC: circunfe } \\
\text { MGBR - ade } \\
\text { AOS } \\
\text { Dados expre }\end{array}$ & $\begin{array}{l}\text { a cervical; } \mathrm{CA} \text { : } \\
\text { to para AOS e rc }\end{array}$ & $\begin{array}{l}\text { nferência abdon } \\
\text {; Av. FAR: avali } \\
\text { o interquartil] }\end{array}$ & $\begin{array}{l}\text { MGBR adap } \\
\text { fonoaudiológ }\end{array}$ & $\begin{array}{l}\text { ame miofunc } \\
\text { ara pacientes }\end{array}$ & orof \\
\hline
\end{tabular}

Na Figura 16 está representado o comportamento da mudança da circunferência cervical nos grupos Controle e Terapia. 


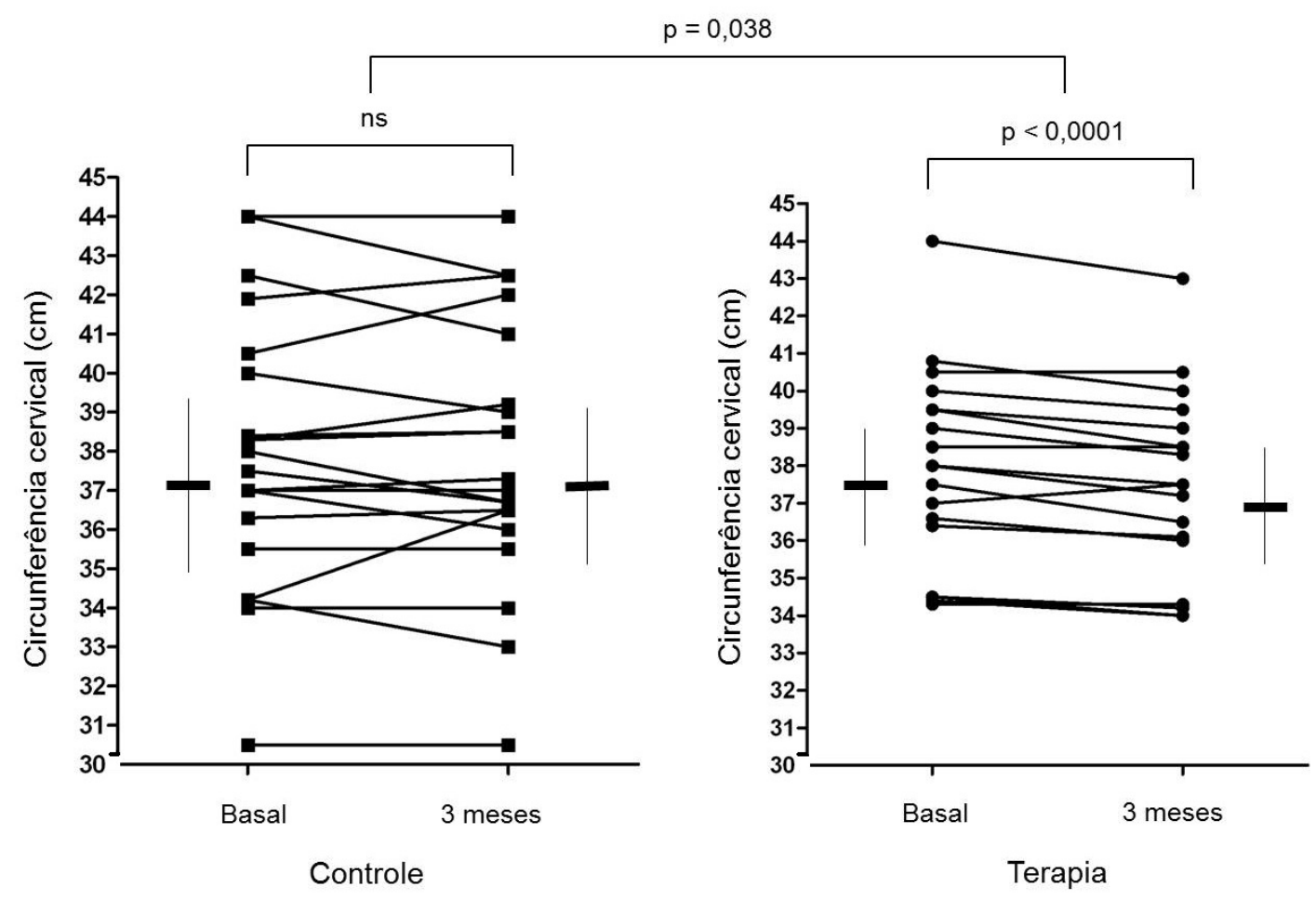

Figura 16 -Valores individuais da circunferência cervical no basal e após 3 meses no Grupo Controle e Terapia. Não ocorreram alterações estatisticamente significantes no Grupo Controle. Em contraste, no Grupo Terapia houve uma diminuição pequena $(0,5 \mathrm{~cm})$, porém estatisticamente significante

Na Figura 17 está representado o comportamento das mudanças dos escores do Exame Miofuncional Orofacial MGBR - adaptado para AOS e Ronco e na Figura 18, sua subdivisão, a Avaliação Fonoaudiológica para AOS e Ronco, no Grupo Controle e no Grupo Terapia. 


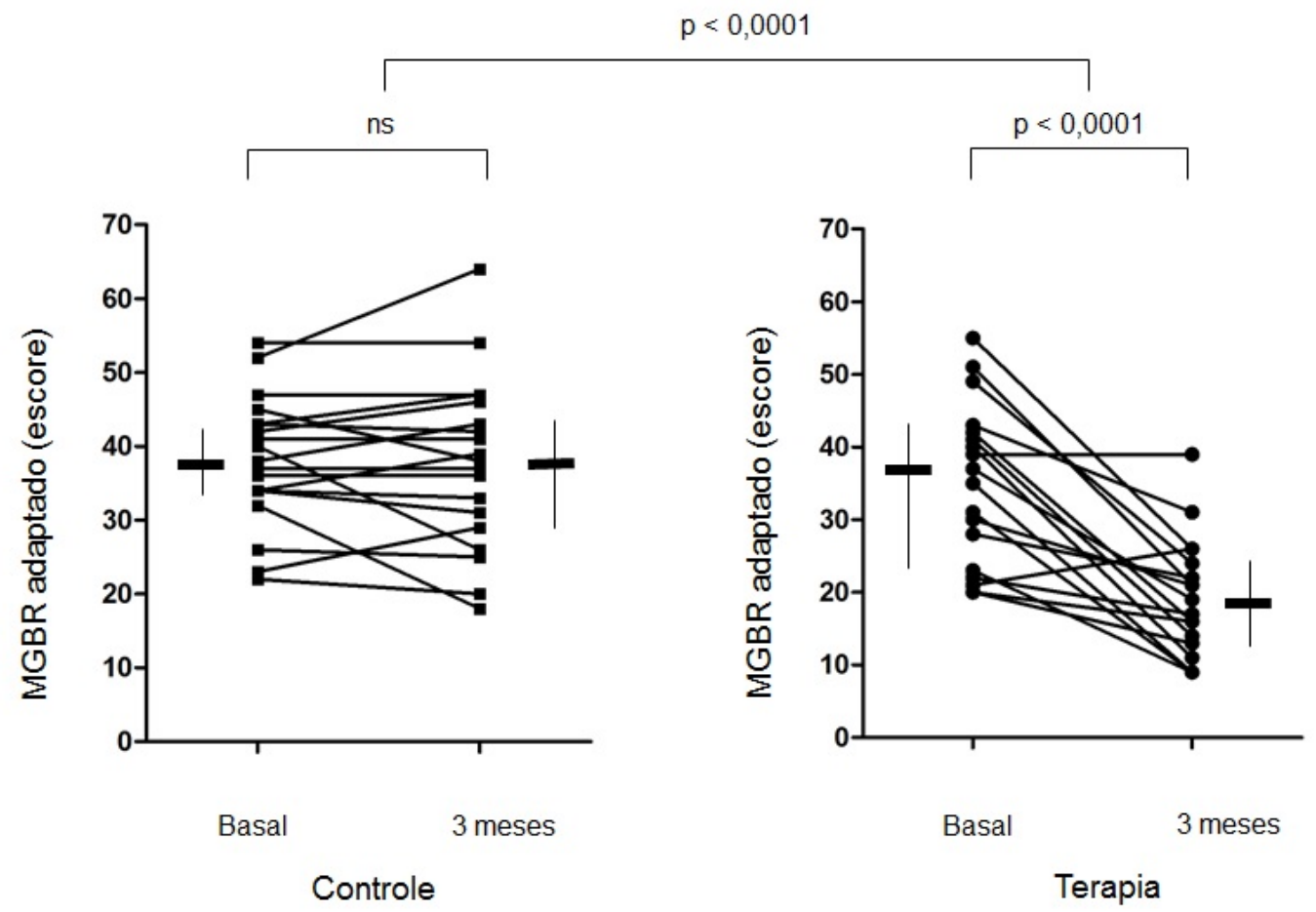

Figura 17 - Valores individuais da Avaliação Miofuncional Orofacial MGBR - adaptado para AOS e Ronco no basal e após 3 meses no Grupo Controle e Terapia. Não ocorreram alterações estatisticamente significantes no Grupo Controle. Em contraste, no Grupo Terapia houve uma diminuição estatisticamente significante das pontuações

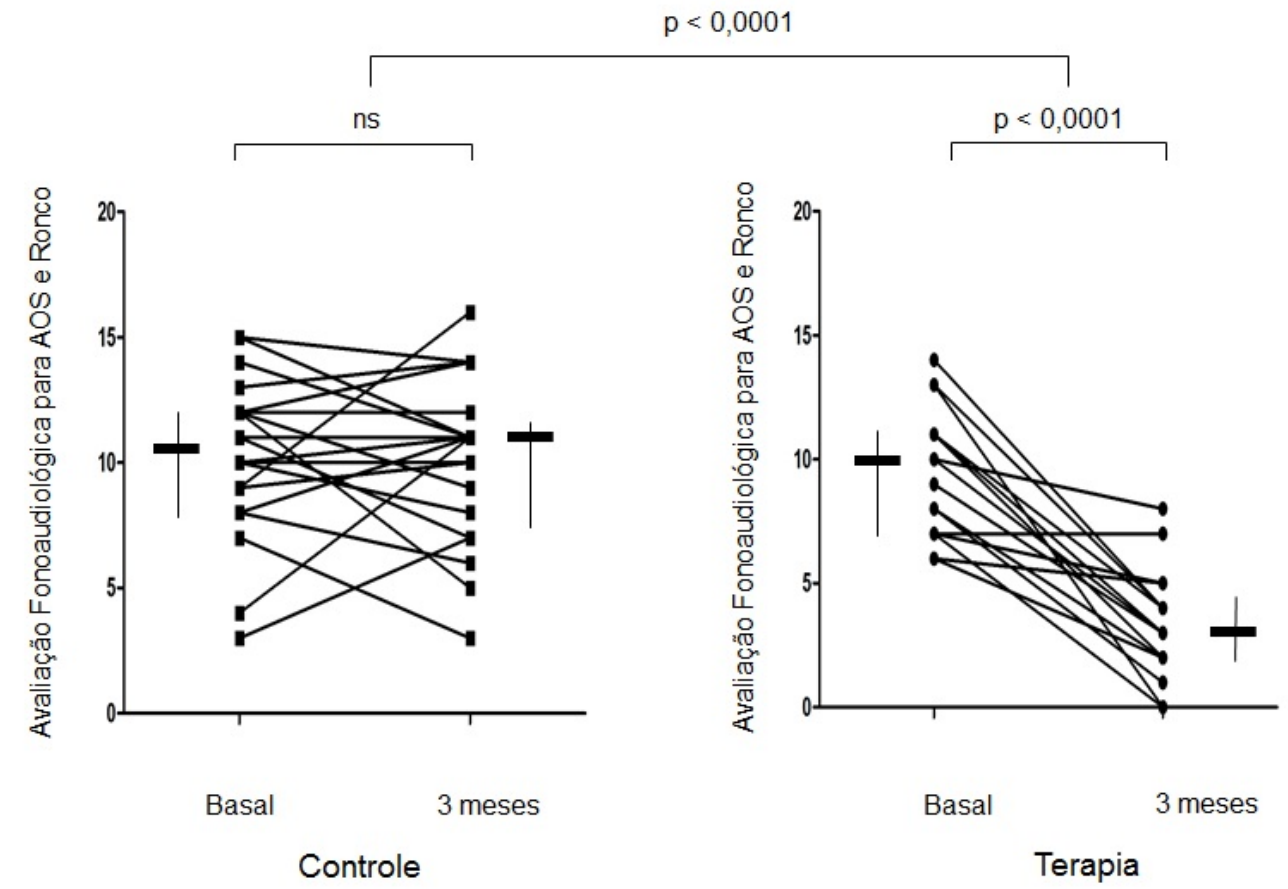

Figura 18 -Valores individuais das pontuações da Avaliação Fonoaudiológica para AOS e Ronco no basal e após 3 meses no Grupo Controle e Terapia. Não ocorreram alterações estatisticamente significantes no Grupo Controle. Em contraste, no Grupo Terapia houve uma diminuição estatisticamente significante das pontuações 
As Figuras 17 e 18 mostram que assim como o Exame Miofuncional Orofacial MGBR - adaptado para AOS e Ronco, a subdivisão Avaliação Fonoaudiológica para ronco e AOS também foi capaz de identificar as mudanças nos dois momentos no Grupo Terapia Miofuncional Orofacial.

A Figura 19 representa graficamente a ausência de modificação em ambos os escores de avaliações no Grupo Controle e as modificações em ambos os escores de avaliação no Grupo Terapia Miofuncional Orofacial, no basal e 3 meses após o tratamento.

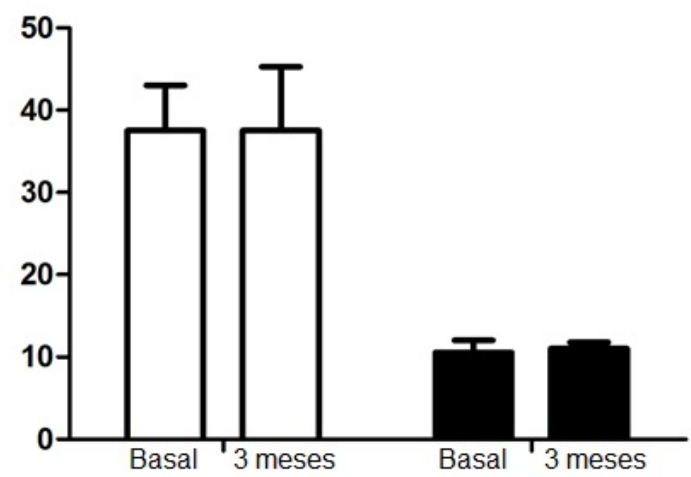

Grupo Controle

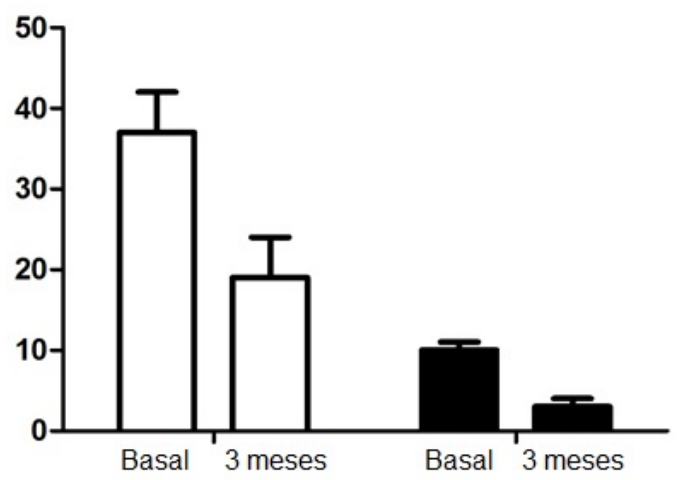

Grupo Terapia

Figura 19 - Achados semelhantes aos apresentados nas Figuras 17 e 18 na forma de barras. Comparação dos escores da Avaliação Miofuncional Orofacial MGBR - adaptado para AOS e Ronco e dos escores da Avaliação Fonoaudiológica para AOS e Ronco. Os resultados, no basal e após 3 meses, das duas avaliações: MGBR adaptado para AOS e Ronco e Avaliação fonoaudiológica para AOS e Ronco não se modificaram no Grupo Controle. Em contraste, a diferença entre o basal e após 3 meses foi estatisticamente significante no Grupo Terapia 
A Tabela 8 apresenta os resultados do exame de polissonografia e da mensuração objetiva do ronco. Quanto aos resultados da polissonografia, as variáveis índice de despertar, IAHNREM e índice de hipopneia apresentaram significância estatística quanto à interação grupo e período. Já em relação às medições do ronco, as variáveis Índice de Roncos e Índice Potência Total do Ronco apresentaram significância estatística quanto à interação grupo e período. 
Tabela 8 - Características polissonográficas e de ronco dos pacientes incluídos no estudo no basal e após 3 meses de randomização

Controle $(n=20)$

Terapia $(n=190)$

\begin{tabular}{|c|c|c|c|c|c|}
\hline Variáveis & Basal & 3 meses & Basal & 3 meses & $\mathrm{p}$ valor \\
\hline \multicolumn{6}{|c|}{ Polissonografia } \\
\hline TTS, hs & $6,2[5,7-6,6]$ & $6,4[5,4-7,1]$ & $6,0[5,5-6,7]$ & $6,8[5,7-7,2]$ & 0,406 \\
\hline TTSSup, hs & $3,2[1,4-4,8]$ & $2,80[1,6-5,9]$ & $3,6[2,1-5,0]$ & $2,7[1,2-3,7]$ & 0.147 \\
\hline Ef Sono, \% & $85,1[79,7-91,1]$ & $89,9[82,5-92,7]$ & $91,3[79,0-93,4]$ & $87,4[83,6-95,0]$ & 0,210 \\
\hline I desp & $13,6[12,1-18,4]$ & $17,75[13,5-19,8]$ & $19,00[12,2-23,7]$ & $15,30[12,7-20,0]$ & 0,039 \\
\hline $\mathrm{IAH}$ & $13,3[6,9-24,1]$ & $11,95[9,4-22,1]$ & $14,40[6,8-24,1]$ & $12,90[8,0-19,7]$ & 0,178 \\
\hline IAH NREM & $8,7[5,3-15,9]$ & $11,20[6,5-16,9]$ & $11,70[7,0-21,8]$ & $10,40[5,9-19,0]$ & 0,039 \\
\hline IAH REM & $25,8[9,4-48,2]$ & $26,60[10,9-41,7]$ & $14,40[6,2-33,1]$ & $15,10[5,0-26,6]$ & 0,585 \\
\hline IAH sup & $27,7[9,5-33,6]$ & $19,80[12,2-30,5]$ & $20,30[8,9-29,4]$ & $33,20[13,1-40,6]$ & 0,105 \\
\hline IAobst & $0,5[0,0-4,8]$ & $0,65[0,3-3,7]$ & $0,50[0,2-3,2]$ & $0,30[0,0-3,9]$ & 0,291 \\
\hline $\mathrm{IH}$ & $11,4[5,9-15,2]$ & $11,00[8,1-17,1]$ & $12,40[6,5-17,0]$ & $9,80[5,6-15,3]$ & 0,031 \\
\hline $\mathrm{SPO}_{2} \min$ & $85,5[82,0-90,5]$ & $85,50[82,5-88,0]$ & $88,00[82,0-90,0]$ & $86,00[82,0-89,0]$ & 0,761 \\
\hline I dessat & $10,0[5,5-19,4]$ & $10,85[7,7-16,6]$ & $10,00[2,9-17,3]$ & $9,50[6,1-12,9]$ & 0,596 \\
\hline \multicolumn{6}{|c|}{ Mensuração do ronco } \\
\hline IR & $107,5[13,6-257,6]$ & $=150,62[35,1-364,4]$ & 99,5[49,6-221,3] & "48,2 [25,5-219,2] & 0,017 \\
\hline IR sup & $186,6[11,6-426,1]$ & $179,75[88,9-379,4]$ & $152,0[19,9-278,2]$ & $124,4[15,7-312,9]$ & 0,560 \\
\hline IR nsup & $19,6[2,1-200,2]$ & $74,40[4,7-226,8]$ & $20,4[3,6-67,2]$ & $28,9[6,3-77,9]$ & 0,416 \\
\hline IPTR & $54,4[3,5-386,6]$ & $97,4(26,5-194,1)$ & $60,4[21,8-220,6]$ & $31,0[10,1-146,5]$ & 0,033 \\
\hline IPTR sup & $86,2[3,4-472,0]$ & $112,42[26,5-211,2]$ & $120,9[4,7-374,6]$ & $70,5[4,9-198,6]$ & 0,482 \\
\hline IPTR nsup & $5,7[0,6-73,3]$ & $17,94[2,0-137,2]$ & $7,7[1,1-47,2]$ & $11,4[1,9-29,8]$ & 0,229 \\
\hline$R \max , d B$ & $51,7[48,8-53,9]$ & $52,81[50,4-55,6]$ & $51,6[49,7-55,2]$ & $51,6[46,1-53,0]$ & 0,208 \\
\hline
\end{tabular}

TTS: Tempo total de sono; TTSSup: tempo total de sono na posição supina; hs: horas; Ef sono: eficiência do sono; I despertares: índice de despertares; IAH: índice de apneia e hipopneia; NREM: sono não REM, REM: sono REM; sup: posição supina; IAobst: índice de apneias obstrutivas; IH: índice de hipopnéias; $\mathrm{SPO}_{2}$ min: saturação mínima; I dessat: índice de dessaturação; IR: índice de roncos, IR sup: índice de roncos na posição supina; IRnsup: índice de roncos na posição não supina; IPTR: índice potência total do ronco; IPTR sup: índice potência total do ronco na posição supina; IPTR nsup: índice potência total do ronco na posição não supina; $R$ max: pico máximo de ronco Dados expressos em mediana [intervalo interquartil] 
A seguir, representamos o comportamento das mudanças das variáveis do ronco, Índice de Roncos (Figura 20) e Índice Potência Total do Ronco (Figura 21), no Grupo Controle e no Grupo Terapia.

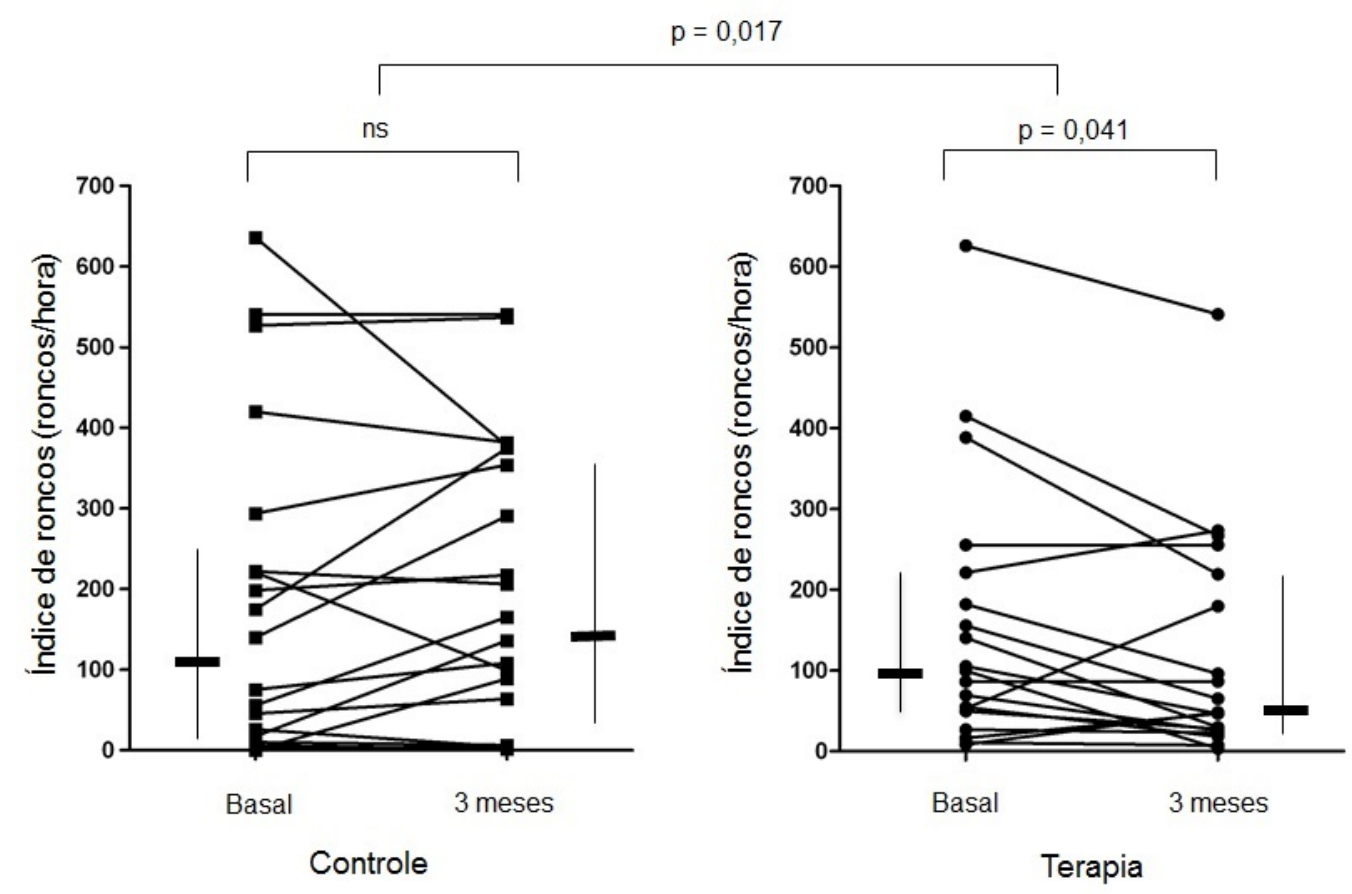

Figura 20 -Valores individuais dos Índices de Roncos no basal e após 3 meses no Grupo Controle e Terapia. Não ocorreram alterações estatisticamente significantes no Grupo Controle. Em contraste, no Grupo Terapia houve uma diminuição estatisticamente significante dos Índices de Roncos 


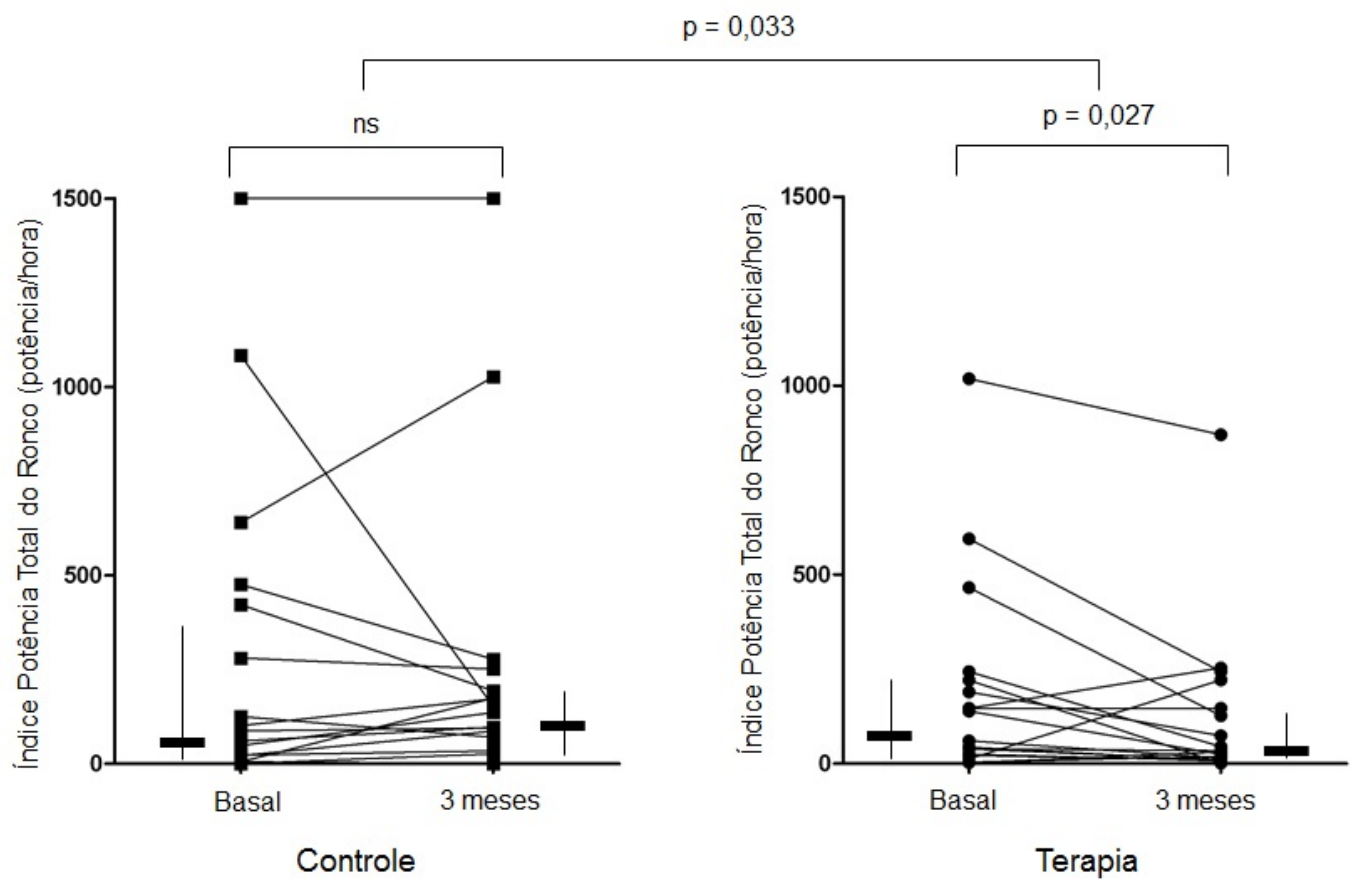

Figura 21 - Valores individuais dos Índices Potência Total do Ronco no basal e após 3 meses no Grupo Controle e Terapia. Não ocorreram alterações estatisticamente significantes no Grupo Controle. Em contraste, no Grupo Terapia houve uma diminuição estatisticamente significante dos Índices Potência Total do Ronco

Não foi encontrada diferença estatisticamente significante no que diz respeito ao IAH. No entanto, a redução do IAH no Grupo Terapia no basal e após 3 meses foi visível, conforme a Figura 22. 

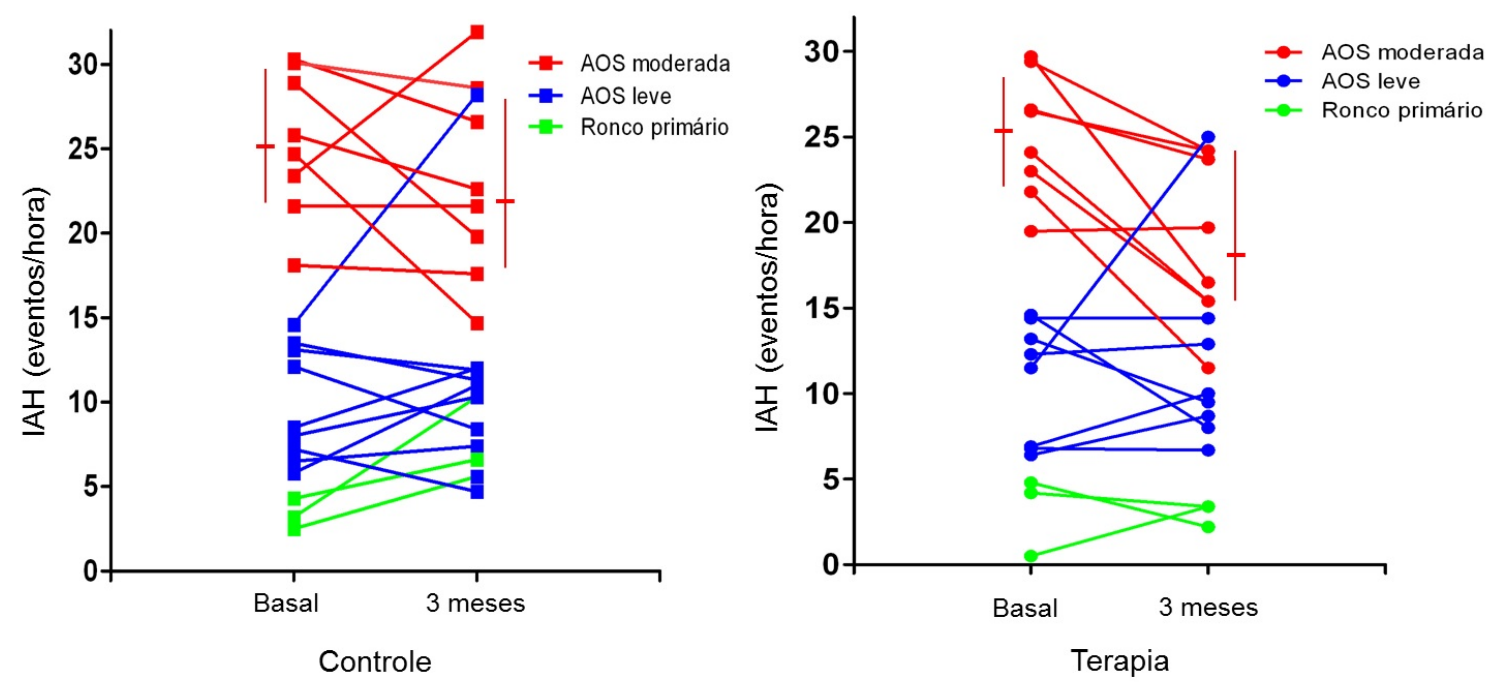

Figura 22 - Índice de apneia de hipopneia (IAH) nos Grupos Controle e Terapia no basal e após 3 meses. Não ocorreram diferenças significativas no IAH médio de ambos os Grupos. $O$ subgrupo de pacientes com apneia obstrutiva do sono moderada $(15 \leq \mathrm{IAH} \leq 30)$ tratados com Terapia Miofuncional Orofacial tiveram uma redução significativa do IAH (ver também Tabela 9).

Contudo, a fim de demonstrar o efeito da Terapia Miofuncional Orofacial no Grupo Controle e no Grupo Terapia e devido ao n reduzido de pacientes com AOS moderada ( $n=16)$, sendo 8 no Grupo Controle e 8 no Grupo Terapia, realizamos o teste de Wilcoxon nesta amostra de pacientes com AOS moderada e os resultados estão expressos na Tabela 9.

Tabela 9 - IAH dos pacientes com AOS moderada no basal e após 3 meses de randomização

\begin{tabular}{|c|c|c|c|c|c|c|}
\hline & \multicolumn{3}{|c|}{ Controle $(n=8)$} & \multicolumn{3}{|c|}{ Terapia $(n=8)$} \\
\hline Variável & Basal & 3 meses & $\mathrm{P}$ valor & Basal & 3 meses & $p$ valor \\
\hline $\mathrm{IAH}$ & $25,3[22,1-29,8]$ & $22,1[18,2-28,1]$ & 0,128 & $25,4[22,1-28,7]$ & $18,1[15,4-24,1]$ & 0,017 \\
\hline
\end{tabular}

Valores de $\mathrm{p}$ das variáveis não paramétricas obtido através do teste de Wilcoxon $\mathrm{IAH}$ : Índice de apneia e hipopneia

Dados expressos medianas [intervalo interquartil] 
Em relação aos objetivos secundários desta pesquisa, os gráficos a seguir (Figuras 23 e 24) mostram que existe uma correlação entre a gravidade da apneia (mensurada pelo $\mathrm{IAH}$ ) e a frequência e intensidade do ronco (mensurada pela variável Índice de Roncos e Índice Potência Total do Ronco, respectivamente) tanto no momento basal como após 3 meses de randomização.

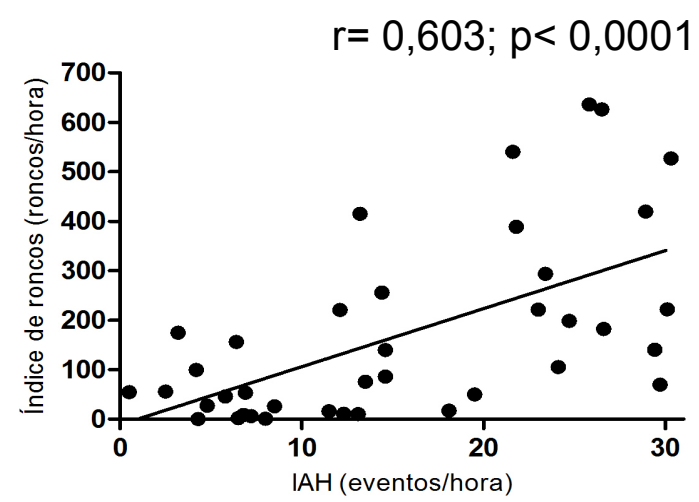

Basal

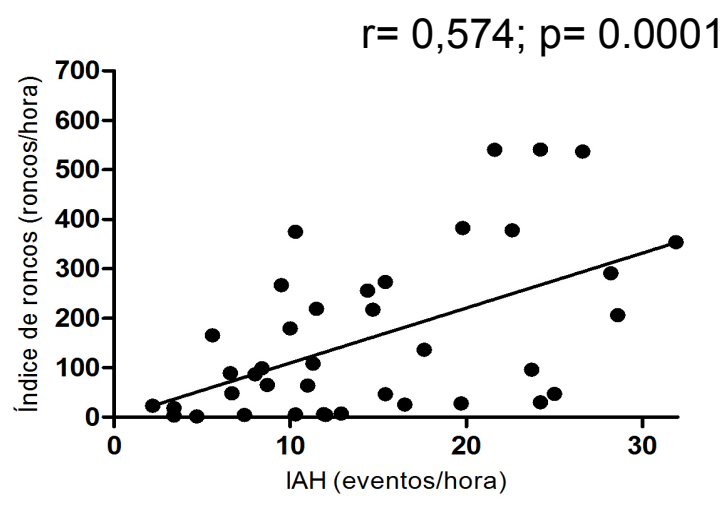

3 meses

Figura 23 - Correlações entre índice de apneia e hipopneia com o Índice de roncos. Foram incluídos todos os pacientes no basal e após 3 meses.

$$
r=0,505 ; p=0,001
$$

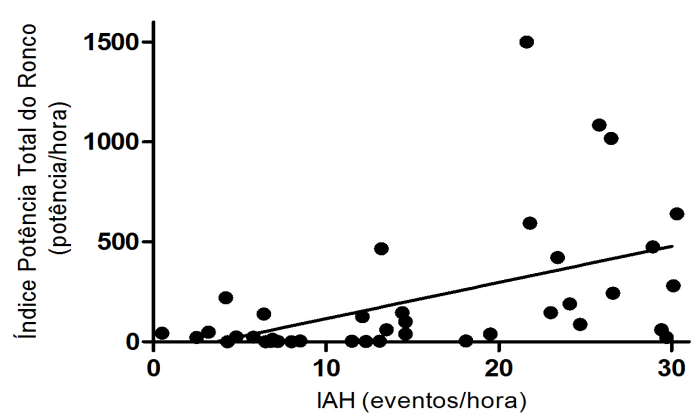

Basal$$
r=0.537 ; p=0.0005
$$

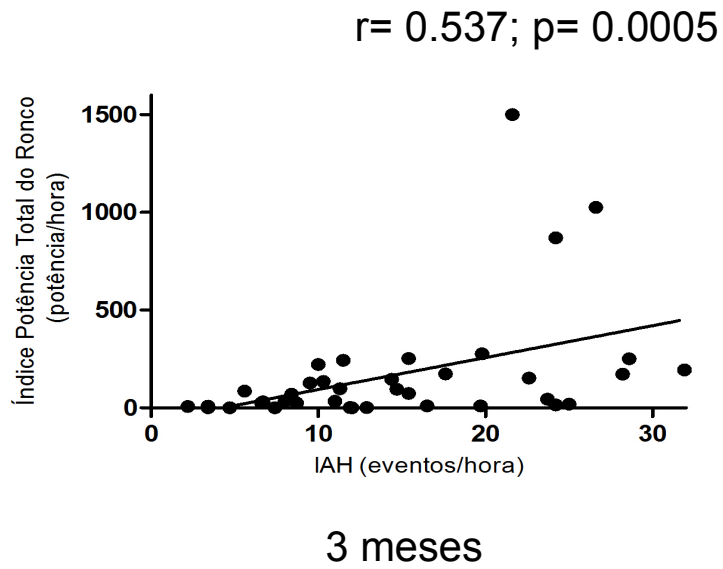

3 meses

Figura 24 - Correlações entre índice de apneia e hipopneia com o Índice PotênciaTotal do Ronco. Foram incluídos todos os pacientes no basal e após 3 meses. 
5. DISCUSSÃO 
Este estudo randomizado controlado foi o primeiro a investigar os efeitos da Terapia Miofuncional Orofacial sobre o ronco de pacientes com ronco primário, AOS leve e AOS moderada empregando uma metodologia de mensuração do ronco que não se limitasse à aplicação de questionários. Três meses de Terapia Miofuncional Orofacial reduziram significativamente a frequência e a intensidade do ronco. A frequência do ronco foi expressa pelo Índice de Roncos e a redução mediana observada no Grupo Terapia foi de $36 \%$. A intensidade do ronco foi expressa pelo Índice Potência Total do Ronco e a redução mediana no Grupo Terapia foi de $59 \%$. As medidas de circunferência cervical, Avaliação Miofuncional Orofacial MGBR - adaptado para AOS e questionários subjetivos de ronco realizados com o parceiro de quarto também tiveram redução no Grupo Terapia quando comparados com o Grupo Controle. Esse trabalho portanto abre a perspectiva de tratamento para formas leves de AOS associadas a ronco. A discussão que se segue foi dividida em tópicos, que não foram numerados e divididos em itens pois os assuntos estão interligados.

\section{Desenho experimental e adesão ao tratamento}

Todos os pacientes que foram randomizados para o Grupo Terapia Miofuncional Orofacial tiveram uma boa adesão quanto à realização dos exercícios. A marcação diária em tabela de simples visualização foi muito importante para controlar a frequência com que os pacientes realizavam o treino diariamente, além de poder motivá-los a cumprir a frequência estabelecida. 
Em relação ao Grupo Controle, também foi observada uma boa adesão. Estes pacientes fizeram uso do dilatador nasal, que era contado semanalmente, além de realizar exercícios para a respiração. Uma das opções quanto ao desenho experimental seria o uso do dilatador nasal nos Grupos Controle e Terapia. Optou-se por oferecer o dilatador nasal somente para o Grupo Controle, pois o objetivo foi proporcionar terapia placebo para estes pacientes. Caso a opção fosse oferecer o dilatador nasal para ambos os grupos, haveria o risco que ficasse óbvio para os pacientes do Grupo Controle que eles estariam sendo submetidos a um tratamento inferior. Justificou-se para os pacientes que um dos grupos focaria em exercícios para a "garganta" (Grupo Terapia), enquanto o outro focaria em procedimentos para o "nariz" (Grupo Controle) e ao final do estudo seria verificado qual tipo de intervenção havia sido eficiente na redução no ronco. Desta forma, acredita-se que foi oferecido um bom placebo para o Grupo Controle. Vale ressaltar que no presente estudo, os pacientes que usaram o dilatador nasal não tiveram diminuição do ronco medido objetivamente, assim como de todos os outros parâmetros, sugerindo que de fato o dilatador nasal é um bom placebo. Esse conceito foi previamente reportado pelo nosso grupo em um estudo com pacientes portadores de AOS e acromegalia ${ }^{58}$.

\section{Avaliações clínicas}

Em relação à Avaliação Miofuncional Orofacial MGBR - adaptado, a melhora do Grupo Terapia era esperada, já que estes pacientes realizaram 
treino da musculatura orofacial e das funções de mastigação e deglutição, aspectos avaliados neste exame. A melhora dos escores foi significante no Grupo Terapia, quando comparado ao Grupo Controle, que só realizou exercícios de respiração. Esta mesma diferença foi encontrada na pontuação de subitens a qual denominamos Avaliação Fonoaudiológica para AOS e Ronco. Este pode ser um caminho para a Fonoaudiologia, na área de Motricidade Orofacial no sentido de dirigir atenção especial para as alterações específicas encontradas em pacientes com AOS e ronco, visto que pacientes com ronco primário e AOS leve ainda não têm uma avaliação pré-estabelecida.

Uma das limitações se refere ao fato desta avaliação ter sido realizada pela própria pesquisadora. Apesar do escore final de todos os protocolos (no basal e após 3 meses) só ter sido somada ao final do estudo, não podemos excluir um viés de avaliação.

Os pacientes foram orientados a manter os hábitos alimentares e de atividade física durante o estudo. Portanto, não houve mudança significativa no IMC e na circunferência abdominal. Em contraste, a Terapia Miofuncional Orofacial reduziu significativamente a circunferência cervical do Grupo Terapia. A redução média deste Grupo foi de $0,5 \mathrm{~cm}$ em contraste com o estudo de Guimarães ${ }^{32}$, em que a redução foi de $1,0 \mathrm{~cm}$. 0 menor efeito do presente estudo pode ser explicado pelo fato dos pacientes serem menos graves do que no estudo de Guimarães ${ }^{32}$. Por exemplo, a circunferência cervical basal dos pacientes do Grupo Terapia era de $39,6 \pm 3,7 \mathrm{~cm}$, enquanto os pacientes do Grupo Terapia do presente estudo apresentaram $37,9 \pm 2,5 \mathrm{~cm}$. A redução da 
circunferência cervical parece ser um bom marcador da efetividade dos exercícios. No entanto, não foi encontrada boa correlação entre $\Delta$ Índice de roncos com $\Delta$ circunferência cervical no presente estudo.

\section{Questionários}

Quanto aos questionários aplicados com o parceiro de quarto, a intensidade e frequência do ronco tiveram redução significativa no Grupo Terapia, quando comparados ao Grupo Controle. Em contaste, o mesmo questionário aplicado com o próprio paciente não mostrou diferença significante, apontando para o fato de que a auto percepção do ronco é imprecisa.

Apesar de não haver significância estatística em relação à qualidade de sono do parceiro de quarto, existe uma tendência à melhora no Grupo Tratamento, se comparada ao Grupo Controle. Possivelmente esta melhora não pôde ser detectada pois nem todos os pacientes foram acompanhados por companheiros de quarto durante o tratamento para o qual foram randomizados sendo que essa análise foi feita com apenas 12 companheiros de quarto no Grupo Controle e 13 no Grupo Terapia.

\section{Medidas objetivas de ronco}

Grandes dificuldades metodológicas precisaram ser superadas a fim de que a frequência e a intensidade do ronco pudessem ser mensuradas de forma objetiva, já que não existem medidas padronizadas para tal. Este estudo 
descreve um novo método de aferição do ronco e é inédito pois quantifica o ronco em relação a intensidade e frequência após uma intervenção terapêutica. A quantificação do ronco que não se limite à aplicação de questionários é um desafio para os estudos que pretendem comparar a eficiência de um determinado tratamento. Em estudo realizado com 20 sujeitos que utilizaram o canto como método de tratamento ${ }^{59}$, o ronco foi gravado durante poucas horas e sua análise se restringiu a determinação do tempo de ronco em minutos presente em uma hora de sono. No entanto, neste estudo, as gravações foram realizadas na casa do paciente e a intensidade do ronco não foi mensurada.

O estabelecimento da metodologia do presente estudo não foi simples e pode explicar o porquê dos exames de polissonografia atualmente não mensurarem o ronco de forma objetiva. Essa metodologia sofreu diversas e importantes mudanças no que se refere à aquisição e análise dos registros de ronco. A cada modificação, foi necessária uma nova adaptação da pesquisadora à rotina de análises, além de nova submissão dos dados a cada programa computacional criado. Estes processos foram bastante trabalhosos e demorados. Todas estas modificações objetivaram o desenvolvimento de uma nova tecnologia capaz de mensurar o ronco de forma objetiva e confiável.

A adoção de um gravador profissional possibilitou a aquisição dos sons do ronco sem interferências que pudessem prejudicar a análise posterior. O posicionamento do gravador a um metro de distância, convencionado para todos os pacientes, pôde simular a distância entre o paciente e o companheiro de quarto, além de ser um método não invasivo ${ }^{60}$. No entanto, esta solução não 
eliminou ruídos que foram classificados como ronco pelo sistema automático de análise, o que gerou uma série de falsos-positivos, isto é, ruído identificado como ronco. Portanto, a metodologia de análise do ronco foi sendo adequada a fim de cumprir com o objetivo principal deste trabalho, que era avaliar os efeitos da Terapia Miofuncional Orofacial sobre o ronco. Diferentemente do estudo que correlacionou a intensidade do ronco mensurada em decibéis à gravidade da $\operatorname{AOS}^{16}$, foi adotada a utilização de um índice que definimos com sendo a somatória de todas as potência geradas por cada ronco individual dividido pelo tempo total de sono. Dessa forma esse índice quantifica numericamente a intensidade acústica média gerada pelo paciente durante toda a noite. Além disso, esta análise também possibilitou quantificar a frequência de roncos durante uma noite inteira. Desta forma, foi mensurado quantitativamente e objetivamente intensidade e frequência, padrões comumente utilizados para se avaliar o ronco por meio de questionários ${ }^{47}$.

Apesar de trabalhosa, a análise do ronco pela conferência auditiva de todos os ruídos possibilitou a identificação de todos os "falsos roncos", garantindo a fidedignidade dos dados. Esse sistema ainda não foi sensível o suficiente para realizar esta discriminação automaticamente, mas os dados gerados pela conferência auditiva podem auxiliar na criação de um algoritmo que realize esta identificação em trabalhos futuros.

O presente estudo mostra que a melhora do ronco medida de forma objetiva foi de $36 \%$ na frequência e $56 \%$ na intensidade, indicando portanto a efetividade da medida proposta. 


\section{Efeitos da Terapia Miofuncional Orofacial na gravidade da AOS}

No trabalho realizado por Guimarães ${ }^{32}$ a Terapia Miofuncional Orofacial foi aplicada em pacientes com AOS moderada e reduziu O IAH em $39 \%$. O presente estudo foi o primeiro a incluir pacientes com ronco primário e AOS leve e em contraste com o trabalho de Guimarães, não foi encontrada queda significativa do IAH nos pacientes do Grupo Terapia. A Tabela 8 demonstrou um comportamento diferente nos Índices de Despertares, IAHNREM e IH. No entanto, as diferenças intragrupo (isto é, no basal e após 3 meses) foram pequenas e não atingiram significância estatística. Isto pode ser explicado pelo fato de terem sido incluídos pacientes com um amplo espectro de gravidade do IAH. Contudo, ao analisar somente os pacientes com AOS moderada, observou-se uma redução mediana do IAH de aproximadamente 25\%. Portanto, o "efeito-chão" no IAH dos pacientes com AOS leve e ronco primário explica a diferença entre os estudos. Outra hipótese é a de que a redução dos exercícios do protocolo aplicado no presente estudo em relação ao de Guimarães poderia ter diminuído o efeito da terapia. No entanto, não acreditamos nessa hipótese pois os exercícios que foram retirados do protocolo original (escovação da língua, exercícios faciais, pressão do orbibular da boca, elevação alternada do músculo levantador do ângulo da boca e massagens) não têm impacto na musculatura da via aérea superior afetada em pacientes com AOS.

Em outro estudo randomizado e controlado, o uso do didgeridoo 
(instrumento de sopro que exige intenso treinamento da via aérea superior) durante 4 meses reduziu o IAH, ronco e a sonolência diurna ${ }^{41}$. A magnitude da melhora do IAH foi similar à descrita por Guimarães, assim como a gravidade da AOS.

Diaferia $^{61}$ em um estudo inédito que randomizou pacientes para 4 grupos, Placebo, Terapia Fonoaudiológica, CPAP e Grupo Combinado (terapia fonoaudiológica concomitante ao uso de CPAP), comparou o tratamento fonoaudiológico isolado e associado com o uso do CPAP em pacientes com a SAOS. Os resultados mostraram que a terapia fonoaudiológica isolada foi capaz de diminuir significativamente a sonolência excessiva, o ronco mensurado por questionários e o IAH, além de melhorar a qualidade de vida. Além disto, no Grupo Combinado, a adesão ao CPAP aumentou significativamente. Pode-se observar que neste estudo os pacientes apresentavam uma média mais elevada do IAH, sendo possível concluir que os paciente eram mais graves em relação à AOS.

A Tabela 10 a seguir sintetiza o perfil dos pacientes incluídos no grupo tratado e os resultados em relação ao IAH pré e pós tratamento nos estudos supracitados. 
Tabela 10 - Perfil dos pacientes que participaram de estudos que utilizaram o treinamento da via aérea superior como método de tratamento para pacientes com AOS

\begin{tabular}{|c|c|c|c|c|}
\hline & $\begin{array}{l}\text { Puhan et al. } \\
\text { (2005) }\end{array}$ & $\begin{array}{c}\text { Guimarães et al. } \\
(2009)\end{array}$ & $\begin{array}{c}\text { Diaferia et al. } \\
(2013)\end{array}$ & $\begin{array}{c}\text { Presente } \\
\text { estudo }\end{array}$ \\
\hline \multicolumn{5}{|l|}{$\mathrm{n}$ tratados $/ \mathrm{n}$} \\
\hline total & $14 / 25$ & $16 / 31$ & $27 / 100$ & $14 / 39$ \\
\hline \multicolumn{5}{|l|}{ Idade } \\
\hline (anos) & $49,9 \pm 6,7$ & $51,5 \pm 6,8$ & $45,3 \pm 13,0$ & $48,1 \pm 13,6$ \\
\hline \multicolumn{5}{|l|}{ IMC } \\
\hline$\left(\mathrm{kg} / \mathrm{m}^{2}\right)$ & $25,8 \pm 4,0$ & $29,6 \pm 3,8$ & $25,0 \pm 7,4$ & $28,1 \pm 2,7$ \\
\hline \multicolumn{5}{|l|}{ Gravidade } \\
\hline $\begin{array}{l}\text { AOS dos } \\
\text { incluídos }\end{array}$ & $\begin{array}{l}\text { somente AOS } \\
\text { moderada }\end{array}$ & $\begin{array}{c}\text { somente AOS } \\
\text { moderada }\end{array}$ & não reportou & $\begin{array}{c}\text { ronco primário } \\
\text { AOS leve } \\
\text { AOS moderada }\end{array}$ \\
\hline $\begin{array}{l}\text { IAH basal } \\
\text { (eventos/hora) }\end{array}$ & $22,3 \pm 5,0$ & $22,4 \pm 4,8$ & $28,0 \pm 22,7$ & $15,6 \pm 9,3$ \\
\hline \multicolumn{5}{|l|}{ IAH após } \\
\hline intervenção & $11,6 \pm 8,1$ & $13,7 \pm 8,5$ & $13,9 \pm 18,5$ & $13,4 \pm 7,4$ \\
\hline $\mathrm{p}$ & $=0,05$ & $<0,01$ & $<0,001$ & 0,127 \\
\hline
\end{tabular}

Estes resultados apontam para a necessidade de estudos com maior número de pacientes de acordo com o espectro de gravidade, a fim de elucidar se a Terapia Miofuncional Orofacial também pode ser efetiva em casos de AOS leve e os possíveis sintomas relacionados. No entanto, a maior perspectiva do presente estudo é demonstrar que o ronco pode ser ao menos parcialmente 
diminuído com a Terapia Miofuncional Orofacial.

\section{Correlações entre medidas de ronco e o IAH}

O sistema de aquisição e análise do ronco utilizado no presente estudo também foi capaz de correlacionar a intensidade e frequência do ronco (mensurados pelo Índice de Roncos e Índice Potência Total do Ronco, respectivamente) à gravidade da AOS (mensurada pelo IAH). Isso traz a possibilidade de adoção deste instrumento em pesquisas futuras como rastreamento de pacientes com AOS, uma tendência em estudos que analisam o som do ronco $29,62-64$.

\section{Limitações do estudo}

Apesar do caráter inovador no que se refere à mensuração do ronco e ao pioneirismo do grupo na publicação dos efeitos da Terapia Miofuncional Orofacial em pacientes com ronco e AOS, este estudo possui várias limitações. Uma das limitações se refere ao fato da metodologia de mensuração do ronco não ter sido validada em estudos anteriores. As diversas modificações realizadas no sentido de aprimorar a análise e o tempo gasto para isso inviabilizou a validação. O desenho experimental nos pareceu adequado, já que este é um trabalho cujo objetivo principal foi verificar os efeitos da Terapia Miofuncional Orofacial sobre o ronco. 
A adesão ao tratamento sempre será uma potencial limitação na prática. No entanto, conseguiu-se reduzir o número de exercícios, que atualmente dura em torno de 8 minutos e deve ser feito 3 vezes ao dia. Não foram obtidos dados dos efeitos a longo prazo, mas a princípio, os exercícios não podem ser abandonados. 
6. CONCLUSÕES 
- A Terapia Miofuncional Orofacial proposta no presente estudo é efetiva em reduzir a frequência e intensidade do ronco, mensurados objetivamente, em pacientes com ronco primário, AOS leve e moderada.

- A metodologia desenvolvida para mensuração do ronco no presente trabalho é efetiva para quantificar o ronco de forma objetiva.

- O ronco expresso por Índice de Roncos e Índice Potência Total do Ronco apresenta correlação significativa e moderada com a gravidade da AOS.

- A Terapia Miofuncional Orofacial resulta em melhora significativa na percepção do ronco pelo parceiro de quarto e melhora marginal da qualidade de sono do parceiro de quarto. 
7. ANEXOS 
ANEXO A - Termo de Consentimento Livre e Esclarecido

\section{hOSPITAL dAS CLÍNICAS DA FACULdAdE DE MEDICINA DA UNIVERSIDADE DE SÃO PAULO-HCFMUSP}

TERMO DE CONSENTIMENTO LIVRE E ESCLARECIDO

\section{DADOS DE IDENTIFICAÇÃO DO SUJEITO DA PESQUISA OU RESPONSÁVEL LEGAL}

1. NOME:

DOCUMENTO DE IDENTIDADE No : SEXO: $M \square F \square$

DATA NASCIMENTO: ........................

ENDEREÇO:

BAIRRO:

CEP:. CIDADE

$\mathrm{N}^{\circ}$ APTO:

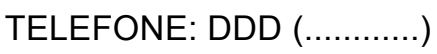

2.RESPONSÁVEL LEGAL

NATUREZA (grau de parentesco, tutor, curador etc.)

DOCUMENTO DE IDENTIDADE

DATA NASCIMENTO.: ....................

ENDEREÇO:

BAIRRO:

CEP: CIDADE: $\mathrm{N}^{0} \ldots \ldots \ldots \ldots \ldots . . . . . . . . . .2 T O$

SEXO: $M \square F \square$ TELEFONE: DDD (

..).

\section{DADOS SOBRE A PESQUISA}

1. TíTULO DO PROTOCOLO DE PESQUISA: EFEITOS DA TERAPIA MIOFUNCIONAL OROFACIAL EM PACIENTES COM RONCO PRIMÁRIO, APNEIA OBSTRUTIVA DO SONO LEVE E MODERADA SOBRE: 1. Pressão crítica de fechamento da faringe, pressão expiratória negativa e ressonância magnética; 2 . Ronco e qualidade de sono

PESQUISADOR PRINCIPAL: Geraldo Lorenzi-Filho

CARGO/FUNÇÃO: Diretor do Laboratório do Sono

UNIDADE DO HCFMUSP: Laboratório do Sono do InCor da Disciplina de Pneumologia PESQUISADOR EXECUTANTE: Fabiane Kayamori e Vanessa leto CARGO/FUNÇÃO: Fonoaudiólogas INSCRIÇÃO CONSELHO REGIONAL N CRFa 16503/ N CRFa 13183 UNIDADE DO HCFMUSP: Laboratório do Sono do InCor da Disciplina de Pneumologia 3. AVALIAÇÃO DO RISCO DA PESQUISA: 


\section{RISCO MÍNIMO $\quad$ RISCO MÉDIO \\ RISCO BAIXO $\square \quad$ RISCO MAIOR \\ 4.DURAÇÃO DA PESQUISA : 4 anos \\ HOSPITAL DAS CLÍNICAS DA FACULDADE DE MEDICINA DA UNIVERSIDADE DE SÃO PAULO-HCFMUSP}

As informações a seguir estão sendo fornecidas para sua participação voluntária neste estudo cujo objetivo é avaliar tratamentos não convencionais para o ronco e para a apneia obstrutiva do sono. Você será sorteado para participar de um dos dois grupos: o primeiro grupo será orientado a realizar exercícios para a musculatura da garganta e o segundo realizará lavagem nasal com soro fisiológico e utilizará uma fita adesiva nasal durante o sono. Os dois grupos realizarão exames que nos mostrará como está a garganta, o sono e o som do ronco. Caso concorde em participar do estudo, o(a) senhor(a) deve estar disponível por nos próximos três meses durante trinta minutos por semana para retornos semanais no Hospital para acompanhamento.

$\mathrm{O}$ (a) senhor(a) fará os seguintes exames: 1.Polissonografia: avaliará seu sono associado a um instrumento que medirá o som do ronco. Para a avaliação do sono é necessário que sejam colados na cabeça adesivos ligados a fios que não causarão desconforto na cabeça, um pequeno cano nasal e cintas no tórax e abdomen. Para a realização deste exame é necessário dormir no Laboratório do Sono do InCor em duas noites: sendo uma anterior e outra posterior ao tratamento. Este exame é realizado em ambiente confortável e não prejudicará o seu sono. 2. Pressão Crítica de fechamento da faringe - será realizado no mesmo local e com equipamento parecido, mas você utilizará uma máscara ao redor do nariz para respirar. No início do exame, após você adormecer, será realizado um exame para medir com qual facilidade sua garganta fecha. Este exame simula o que ocorre durante uma pausa na respiração durante o sono. Este exame é específico para este estudo, e portanto, experimental. Pode haver pequeno desconforto, pois será reduzida a pressão em sua garganta, o que pode fazer com que você desperte. Se você despertar, poderá respirar normalmente, sem qualquer desconforto. O risco para sua saúde é mínimo porque o teste é curto, realizado com acompanhamento contínuo do seu coração, de sua respiração e da oxigenação do sangue. 3 - Espirometria: será pedido 
para que o paciente assopre algumas vezes em um tubo. 4 - Pressão expiratória negativa: será colocada uma máscara na boca ligada a um aparelho e será pedido que respire normalmente. No final da saída do ar será enviada uma quantidade de ar pelo aparelho e sua respiração será acompanhada. 5 - Ressonância Magnética da garganta: o qual é feito deitado num aparelho de ressonância que dura aproximadamente 15 minutos. Este exame servirá para determinar as partes da garganta que podem estar relacionadas com 0 desenvolvimento das pausas na respiração durante o sono. Este exame não causará desconforto, sendo totalmente indolor.

Ao início e final do estudo o(a) senhor(a) deverá responder questionários sobre seu sono, problemas de saúde passados e/ou atuais, medicamentos que usa normalmente, sobre o risco de cochilar durante o dia, realizar medidas do pescoço, abdômen, altura e peso, avaliação fonoaudiológica (que avaliará as estruturas da boca e do pescoço, bem como a mastigação e o modo de engolir) e fotos do rosto e da parte interna da boca. Além disso, se existir alguém que durma no mesmo quarto, esta pessoa deverá responder um questionário sobre seu ronco e a qualidade de sono dela.

Trata-se de estudo experimental testando a hipótese de que os exercícios poderão diminuir o som do ronco e melhorar a apneia obstrutiva do sono. Os tratamentos propostos não trarão mal nenhum a saúde. Somente no final do estudo poderemos concluir a presença de algum benefício, os quais poderão incluir melhora nas pausas respiratórias, melhora do ronco, melhora da qualidade de sono do paciente e do parceiro de quarto.

Existem outras formas de tratamento para o seu problema e caso o senhor não se adapte ao tratamento proposto, o senhor será encaminhado no final do estudo para o ambulatório e nova avaliação do médico de sono.

Em qualquer etapa do estudo, você terá acesso aos profissionais responsáveis pela pesquisa para esclarecimento de eventuais dúvidas. O principal investigador é o $\mathrm{Dr}$ Geraldo Lorenzi-Filho que pode ser encontrado no endereço Av. Dr. Enéas de Carvalho Aguiar, $44-7^{\circ}$. Andar (Laboratório do Sono). Telefone(s) 3069-5486. Se você tiver alguma consideração ou dúvida sobre a ética da pesquisa, entre em contato com o Comitê de Ética em Pesquisa (CEP) - Rua Ovídio Pires de Campos, 225 - 5º andar - tel: 3069-6442 ramais 16, 17, 18 ou 20, FAX: 3069-6442 ramal 26 - E-mail: cappesq@hcnet.usp.br.

É garantida a liberdade da retirada de consentimento a qualquer momento e deixar de participar do estudo, sem qualquer prejuízo à continuidade de seu tratamento na Instituição. 
As informações obtidas serão analisadas em conjunto com outros pacientes, não sendo divulgado a identificação de nenhum paciente.

$\mathrm{O}$ (a) senhor(a) tem o direito de ser mantido atualizado sobre os resultados parciais das pesquisas, quando em estudos abertos, ou de resultados que sejam do conhecimento dos pesquisadores.

Não há despesas pessoais para o participante em qualquer fase do estudo, incluindo exames e consultas. Também não há compensação financeira relacionada à sua participação. Se existir qualquer despesa adicional, ela será absorvida pelo orçamento da pesquisa.

É compromisso do pesquisador de utilizar os dados e o material coletado somente para esta pesquisa.

Acredito ter sido suficientemente informado a respeito das informações que li ou que foram lidas para mim, descrevendo o estudo "EFEITOS DA TERAPIA MIOFUNCIONAL OROFACIAL EM PACIENTES COM RONCO PRIMÁRIO, APNEIA OBSTRUTIVA DO SONO LEVE E MODERADA SOBRE: 1. Pressão crítica de fechamento da faringe, pressão expiratória negativa e ressonância magnética; 2 . Ronco e qualidade de sono".

Eu discuti com o Dr. Geraldo Lorenzi-Filho sobre a minha decisão em participar nesse estudo. Ficaram claros para mim quais são os propósitos do estudo, os procedimentos a serem realizados, seus desconfortos e riscos, as garantias de confidencialidade e de esclarecimentos permanentes. Ficou claro também que minha participação é isenta de despesas e que tenho garantia do acesso a tratamento hospitalar quando necessário. Concordo voluntariamente em participar deste estudo e poderei retirar o meu consentimento a qualquer momento, antes ou durante o mesmo, sem penalidades ou prejuízo ou perda de qualquer benefício que eu possa ter adquirido, ou no meu atendimento neste Serviço.

Assinatura do paciente/representante legal Data $\quad / \quad /$ 
Assinatura da testemunha

Data $1 /$

para casos de pacientes menores de 18 anos, analfabetos, semi-analfabetos ou portadores de deficiência auditiva ou visual.

(Somente para o responsável do projeto)

Declaro que obtive de forma apropriada e voluntária o Consentimento Livre e Esclarecido deste paciente ou representante legal para a participação neste estudo. 
Anexo B - Tabela Grupo Controle

\section{PROTOCOLO DE FONOAUDIOLOGIA}

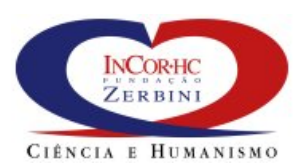

Orientações: Preencher a tabela abaixo de acordo com a realização dos exercícios. Se foram bem feitos (ok), se foram feitos mais ou menos (+ou-) ou se não foram feitos (não).

Em caso de dúvidas, favor entrar em contato com Fabiane (fabianekayamori@gmail.com) ou Vanessa (vanessaieto.fono@gmail.com).

FAVOR TRAZER NA PRÓXIMA CONSULTA

\begin{tabular}{|l|l|l|l|}
\hline dia & manhã & tarde & noite \\
\hline & & & \\
\hline & & & \\
\hline & & & \\
\hline & & & \\
\hline & & & \\
\hline & & & \\
\hline & & & \\
\hline
\end{tabular}

\begin{tabular}{|c|c|}
\hline $\begin{array}{l}\text { EXERCÍCIO } \\
\text { PROPOSTO }\end{array}$ & EXERCÍCIOS A SEREM REALIZADOS 3 VEZES AO DIA \\
\hline $\begin{array}{l}\text { RESPIRAÇÃO } \\
\text { DEITADO/SENTA } \\
\text { DO/EM PÉ }\end{array}$ & $\begin{array}{l}\text { COLOCAR AS MÃOS APOIADAS NA REGIÃO DA BARRIGA. PUXAR O AR PELO } \\
\text { NARIZ INFLANDO A BARRIGA E SOLTAR ESVAZIANDO A BARRIGA. } \\
\text { REPETIR } 10 \text { VEZES }\end{array}$ \\
\hline $\begin{array}{l}\text { RESPIRAÇÃO EM } \\
\text { TEMPOS }\end{array}$ & $\begin{array}{l}\text { COLOCAR AS MÃOS APOIADAS NA REGIÃO DA BARRIGA. PUXAR O AR PELO } \\
\text { NARIZ EM } \_ \text {SEGUNDOS, INFLANDO A BARRIGA E SOLTAR EM } \\
\text { SEGUNDOS, ESVAZIANDO A BARRIGA. } \\
\text { REPETIR } 10 \text { VEZES }\end{array}$ \\
\hline RESPIRAÇÃO E /S/ & $\begin{array}{l}\text { PUXAR O AR PELO NARIZ EM __ SEGUNDOS E SOLTAR FAZENDO O SOM DO } \\
\text { /SSSSSSS/. } \\
\text { REPETIR } 10 \text { VEZES }\end{array}$ \\
\hline $\begin{array}{l}\text { RESPIRAÇÃO } \\
\text { COSTO- } \\
\text { DIAFRAGMÁTICA }\end{array}$ & $\begin{array}{l}\text { EM PÉ, APOIAR A MÃO NA REGIÃO DAS COSTELAS. PUXAR O AR PELO NARIZ } \\
\text { INFLANDO A BARRIGA E ELEVANDO O BRAÇO. SOLTAR ESVAZIANDO A BARRIGA } \\
\text { E ABAIXANDO O BRAÇO. } \\
\text { REPETIR } 10 \text { VEZES }\end{array}$ \\
\hline $\begin{array}{l}\text { LAVAGEM COM } \\
\text { SORO } \\
\text { FISIOLÓGICO }\end{array}$ & ML DE ÁGUA E ___ ML DE SORO FISIOLÓGICO \\
\hline $\begin{array}{l}\text { DILATADOR } \\
\text { NASAL }\end{array}$ & $\begin{array}{l}\text { LIMPAR A PELE COM ÁGUA E SABÃO, SECAR E COLOCAR O DILATADOR } \\
\text { CONFORME ORIENTADO. }\end{array}$ \\
\hline
\end{tabular}

RETORNO EM :

Fga. Fabiane Kayamori

Fga. Vanessa Ieto CRFa 16503 CFFa 5723/12 
Anexo C - Tabela Grupo Tratamento

\section{PROTOCOLO DE FONOAUDIOLOGIA}

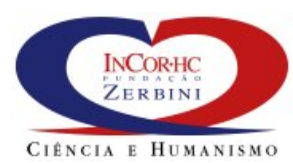

Orientações: Preencher a tabela abaixo de acordo com a realização dos exercícios. Se foram bem feitos (ok), se foram feitos mais ou menos (+ou-) ou se não foram feitos (não).

Em caso de dúvidas, favor entrar em contato com Fabiane (fabianekayamori@gmail.com) ou Vanessa (vanessaieto.fono@gmail.com).

\section{FAVOR TRAZER NA PRÓXIMA CONSULTA}

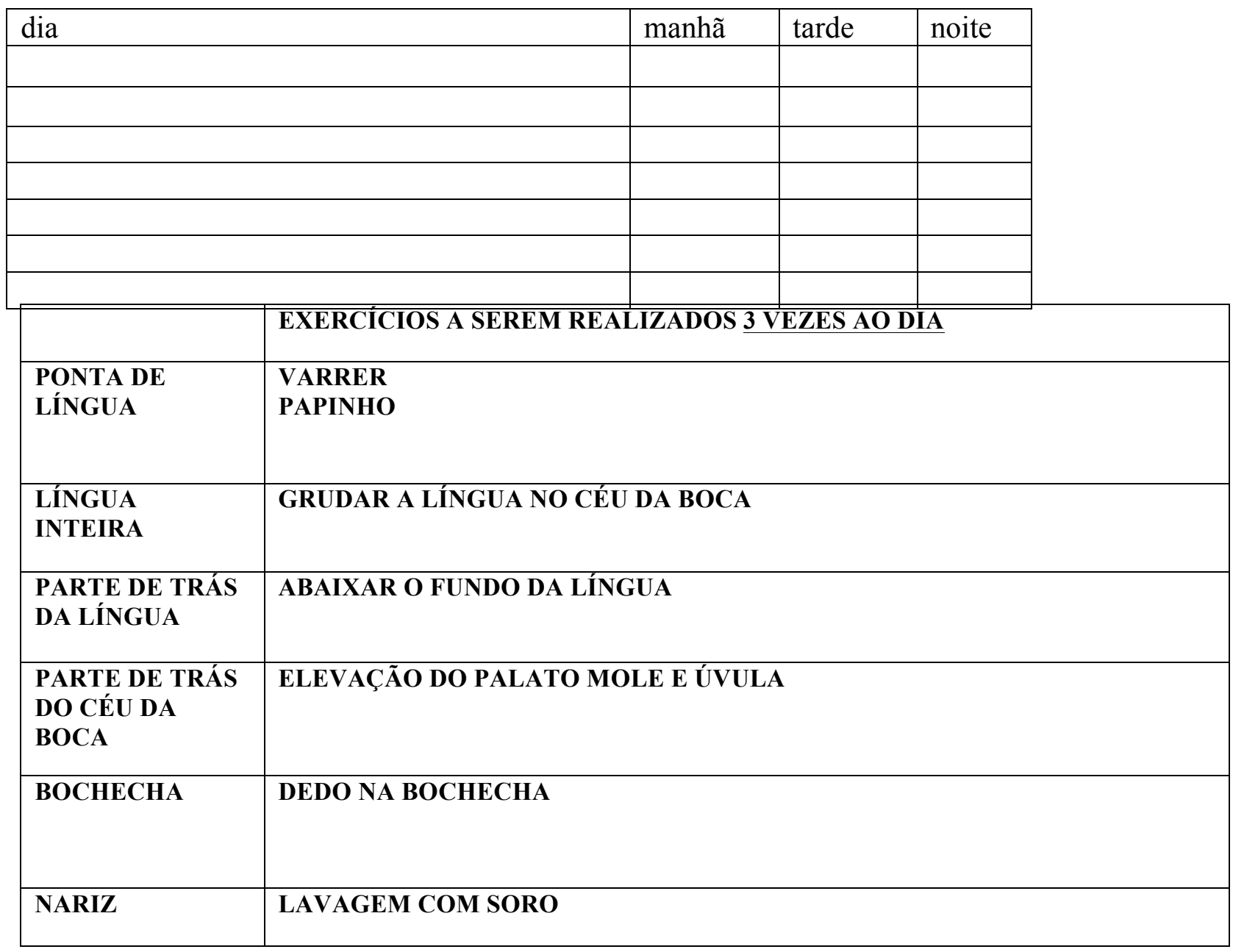

RETORNO EM :

às

Fga. Fabiane Kayamori

CRFa 16503 CFFa 5723/12

Fga. Vanessa Ieto

CRFa 13183 CFFa 5737/12 
Anexo D - Anamnese

ANAMNESE - Motricidade Orofacial no Ronco e na Apneia Obstrutiva do Sono

Data da Avaliação: 1

Nome do paciente:

Idade: anos $\mathrm{DN}$ : Estado civil: raça:

Endereço:

Bairro: Cidade: Estado:

CEP:

Telefones: casa ( $\_$) trabalho (_)

Celular (_ ) recado: (_ )

e-mail:

Profissão:

Peso: Altura: IMC (kg/ m2):

Circunferência cervical: Circunferência abdominal:

Melhores dias da semana e horário para terapia: Queixa:

\section{Sintomas:}

\begin{tabular}{|l|l|l|l|}
\hline & não & sim & frequência \\
\hline Sonolência diurna excessiva & & & \\
\hline Engasgos durante o sono & & & \\
\hline Despertares recorrentes & & & \\
\hline Sono não reparador & & & \\
\hline Fadiga diurna & & & \\
\hline Dificuldade de concentração & & & \\
\hline Ronco & & & \\
\hline
\end{tabular}

\section{Problemas de saúde/medicamentos:}


Problemas respiratórios:

\begin{tabular}{|c|c|c|c|c|c|}
\hline & \multirow{2}{*}{ Frequência anual } & \multirow[t]{2}{*}{ Tratamento } & \multirow[t]{2}{*}{ Medicamentos } \\
\hline Resfriados frequentes & não & $\operatorname{sim}$ & & & \\
\hline $\begin{array}{ll}\text { Problemas } & \text { de } \\
\text { garganta } & \end{array}$ & não & $\operatorname{sim}$ & & & \\
\hline Amidalite & não & $\operatorname{sim}$ & & & \\
\hline Halitose & não & $\operatorname{sim}$ & & & \\
\hline Asma & não & $\operatorname{sim}$ & & & \\
\hline Bronquite & não & $\operatorname{sim}$ & & & \\
\hline Pneumonia & não & $\operatorname{sim}$ & & & \\
\hline Rinite & não & $\operatorname{sim}$ & & & \\
\hline Sinusite & não & $\operatorname{sim}$ & & & \\
\hline Obstrução nasal & não & $\operatorname{sim}$ & & & \\
\hline Prurido nasal & não & $\operatorname{sim}$ & & & \\
\hline Coriza & não & $\operatorname{sim}$ & & & \\
\hline Espirros em salva & não & $\operatorname{sim}$ & & & \\
\hline
\end{tabular}

\section{Outros:}

\section{Sono}

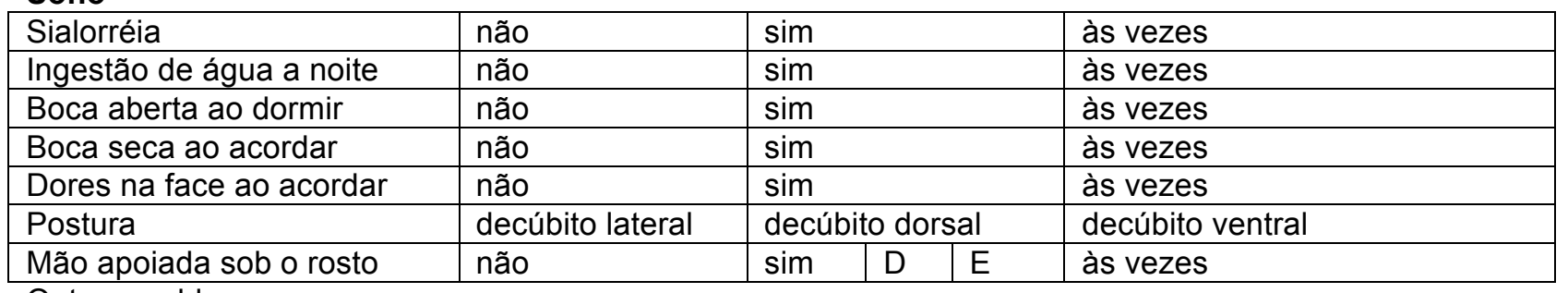

Outros problemas:

Tratamentos

\begin{tabular}{|l|l|l|l|l|l|}
\hline & não & realizado & atual & motivo & profissional \\
\hline Fonoaudiológico & & & & & \\
\hline Médico & & & & & \\
\hline Fisioterápico & & & & & \\
\hline Odontológico & & & & & \\
\hline Procedimento & exodontia & prótese & implante & aparatologia fixa & aparatologia removível \\
\hline Cirúrgicos & não & sim & qual & & quando \\
\hline
\end{tabular}

Outros tratamentos:

\section{Alimentação atual}

\begin{tabular}{|l|l|l|l|}
\hline & sim & não & às vezes \\
\hline Frutas & & & \\
\hline Verduras & & & \\
\hline Legumes & & & \\
\hline Cereais (arroz, macarrão, trigo) & & & \\
\hline Grãos (feijão, lentilha, ervilha) & & & \\
\hline Carnes & & & \\
\hline Leite e derivados & & & \\
\hline Açucares & & & \\
\hline
\end{tabular}

\section{De maneira geral ingere predominantemente alimentos}

\begin{tabular}{|l|l|l|}
\hline líquidos & pastosos & sólidos \\
\hline
\end{tabular}


Mastigação

\begin{tabular}{|c|c|c|c|c|c|}
\hline Ingestão de líquidos durante as refeições & $\operatorname{sim}$ & \multicolumn{3}{|c|}{ às vezes } & \\
\hline Dor ou desconforto ao mastigar & não & sim & $\mathrm{D}$ & $E$ & às vezes \\
\hline Ruído articular & não & $\operatorname{sim}$ & $\mathrm{D}$ & $E$ & às vezes \\
\hline Dificuldade mastigatória & não & \multicolumn{4}{|c|}{ sim - qual: } \\
\hline Escape de alimentos durante a mastigação & não & \multicolumn{4}{|l|}{$\operatorname{sim}$} \\
\hline
\end{tabular}

Outros problemas:

Deglutição

\begin{tabular}{|l|l|l|l|}
\hline Com dificuldade & não & $\operatorname{sim}$ & às vezes \\
\hline Com ruído & não & $\operatorname{sim}$ & às vezes \\
\hline Engasgos & não & $\operatorname{sim}$ & às vezes \\
\hline Odinofagia (dor ao deglutir) & não & $\operatorname{sim}$ & às vezes \\
\hline Refluxo nasal & não & $\operatorname{sim}$ & às vezes \\
\hline Escape anterior & não & $\operatorname{sim}$ & às vezes \\
\hline Pigarro & não & $\operatorname{sim}$ & às vezes \\
\hline Tosse & não & $\operatorname{sim}$ & às vezes \\
\hline Resíduos após a deglutição & não & $\operatorname{sim}$ & às vezes \\
\hline
\end{tabular}

Outros problemas:

Hábitos Orais:

\begin{tabular}{|l|l|l|l|}
\hline Umidificar os lábios & não & $\operatorname{sim}$ & época \\
\hline Tabagismo?o quê? & não & $\operatorname{sim}$ & Quantidade/dia \\
\hline Etilismo & não & $\operatorname{sim}$ & Quantidade/ dia \\
\hline
\end{tabular}

Outros hábitos:

Hábitos de Mordida

\begin{tabular}{|l|l|l|l|l|}
\hline Bruxismo (ranger dentes) & não & \multicolumn{2}{l|}{$\operatorname{sim}$} & \multicolumn{2}{l|}{} \\
\hline Apertamento dentário & não & $\operatorname{sim}$ & quando \\
\hline Onicofagia (roer unhas) & não & $\operatorname{sim}$ & quando & \\
\hline Morder mucosa oral & não & $\operatorname{sim}$ & quando & \\
\hline Morder objetos & não & $\operatorname{sim}$ & qual & quando \\
\hline
\end{tabular}

Outros hábitos:

Hábitos de Postura

\begin{tabular}{|l|l|l|l|l|}
\hline Interpor lábio inferior & não & $\operatorname{sim}$ & \multicolumn{2}{|l|}{} \\
\hline Protrair a mandíbula & não & $\operatorname{sim}$ & & E \\
\hline Apoiar de mão na mandíbula & não & $\operatorname{sim}$ & D & E \\
\hline Apoiar de mão na cabeça & não & $\operatorname{sim}$ & D & \\
Outros hábitos:
\end{tabular}

Outros hábitos: 
Anexo E - Exame Miofuncional Orofacial - MBGR - ADAPTADO PARA AOS e RONCO

\section{Exame Miofuncional Orofacial - MBGR - ADAPTADO PARA AOS e RONCO}

Nome:

Data do exame: Idade: anos e meses DN:

1. Medidas antropométricas: Peso: kg Altura: m IMC $\left(\mathrm{kg} / \mathrm{m}^{2}\right)$ :

Circunferência cervical: cm Circunferência abdominal: $\mathbf{c m}$

\section{MEDIDAS DA FACE, MOVIMENTO MANDIBULAR E OCLUSÃO}

Face (manter os lábios em contato, tomar cada medida 3 vezes com paquímetro e calcular a média)

\begin{tabular}{|l|c|c|c|c|}
\hline & $\begin{array}{c}\mathbf{1}^{\mathbf{a}} \text { medida } \\
(\mathbf{m m})\end{array}$ & $\begin{array}{c}\mathbf{2}^{\mathbf{a}} \text { medida } \\
(\mathbf{m m})\end{array}$ & $\begin{array}{c}\mathbf{3}^{\mathbf{a}} \text { medida } \\
(\mathbf{m m})\end{array}$ & $\begin{array}{c}\text { Média } \\
(\mathbf{m m})\end{array}$ \\
\hline terço superior (raiz do cabelo até meio das sobrancelhas) & & & & \\
\hline terço médio da face (meio das sobrancelhas a sub-nasal) & & & & \\
\hline terço inferior da face (sub-nasal a gnatio) & & & & \\
\hline
\end{tabular}

Movimento Mandibular e Oclusão(usar paquimetro e lápis cópia, tomar cada medida 3 vezes e calcular a média)

\begin{tabular}{|c|c|c|c|c|}
\hline & $\begin{array}{l}1^{\text {a }} \text { medida } \\
(\mathrm{mm})\end{array}$ & $\begin{array}{l}2^{\mathrm{a}} \text { medida } \\
(\mathrm{mm})\end{array}$ & $\begin{array}{l}3^{\mathrm{a}} \text { medida } \\
(\mathrm{mm})\end{array}$ & $\begin{array}{l}\text { Média } \\
(\mathrm{mm})\end{array}$ \\
\hline \multicolumn{5}{|l|}{ Sobremordida (TV) } \\
\hline \multicolumn{5}{|l|}{ Sobresaliência } \\
\hline \multicolumn{5}{|c|}{$\begin{array}{l}\text { distância interincisal máxima ativa - DIMA (do incisivo central ou lateral } \\
\text { superior ao inferior com a máxima abertura da boca) }\end{array}$} \\
\hline \multicolumn{5}{|c|}{ Abertura da boca (DIMA +TV) } \\
\hline \multicolumn{5}{|c|}{ DIMA com o ápice da língua tocando a papila incisiva (DIMALP) } \\
\hline calcular: $\frac{(\text { DIMALP) } \times 100}{\text { DIMA }}$ & & & & \\
\hline
\end{tabular}

3. POSTURA CORPORAL (Observar o paciente em pé e sem calçado)

Cabeça[ ]Somar todas as pontuações (melhor resultado $=0$ e pior $=4$ )
[flexão e extensão $=$ sim]
[rotação $=$ não]
[inclinação $=$ talvez]

\begin{tabular}{llllll}
\hline Frontal: & $(0)$ normal & (1) rotação $D$ & (1) rotação $E$ & (1) inclinação $D$ & (1) inclinação $E$ \\
\hline Lateral: & (0) normal & (1) anteriorizada & (1) flexão & (1) extensão &
\end{tabular}

Ombros [ ]Somar todas as pontuações (melhor resultado $=0$ e pior $=3$ )

\begin{tabular}{|c|c|c|c|}
\hline Frontal: & (0) normal & (1) elevado D & (1) elevado E \\
\hline Lateral: & (0) normal & (1) rotação al & orizado \\
\hline
\end{tabular}

Observação: 


\section{EXAME EXTRA-ORAL}

Temporal [ ] (melhor resultado $=0$ e pior $=1$ ). Deve-se realizar via palpação

$\begin{array}{llll}\text { Recrutamento na contração isométrica: } & \text { (0) simultâneo } & \text { (1) primeiro lado } D & \text { (1) primeiro lado } E\end{array}$

Masseter [ ] (melhor resultado = 0 e pior $=1$ ). Deve-se realizar via palpação

$\begin{array}{llll}\text { Recrutamento na contração isométrica: } & (0) \text { simultâneo } & \text { (1) primeiro lado } D & \text { (1) primeiro lado } E\end{array}$

Mandíbula [ ] Somar todas as pontuações (melhor resultado $=0$ e pior $=2$ )

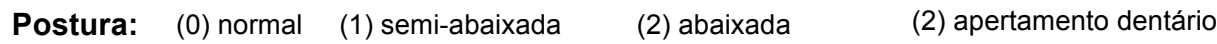

Lábios [ ] Somar todas as pontuações (melhor resultado $=0$ e pior $=17$ )

\begin{tabular}{|c|c|c|c|}
\hline Posição habitual: & $\begin{array}{l}\text { (0) fechados } \\
\text { (2) entreabertos }\end{array}$ & $\begin{array}{l}\text { (1) fechados com tensão } \\
\text { (3) fechados em contato dentário }\end{array}$ & $\begin{array}{l}\text { (2) ora abertos ora fechados } \\
\text { (4) abertos }\end{array}$ \\
\hline Saliva:(0)deglutida & (1)acumulada na comissura $D$ & (1)acumulada na comissura $E$ & (1)acumulada no lábio inferior (2)baba \\
\hline Mucosa: (0)normal & (1)com marcas dentárias & (1)ressecada & (1) ferida \\
\hline $\begin{array}{c}\text { Forma- Superior: } \\
\text { - Inferior: }\end{array}$ & $\begin{array}{l}\text { (0) normal } \\
\text { (0) normal }\end{array}$ & $\begin{array}{l}\text { (1) em asa de gaivota }\left(1^{\circ} \text { e } 2^{\circ} \text { arco do cupido) }\right. \\
\text { (1) com eversão discreta }\end{array}$ & (2) com eversão acentuada \\
\hline \multicolumn{3}{|c|}{ Comprimento do superior: $(0)$ cobre $2 / 3$ dos incisivos } & (2) cobre menos que $2 / 3$ \\
\hline
\end{tabular}

\section{EXAME INTRA-ORAL}

Lábios [ ] Somar todas as pontuações (melhor resultado $=0$ e pior $=3$ )

\begin{tabular}{|c|c|c|}
\hline Mucosa: & (0)normal & (1) ferida \\
\hline Frênulo superior: & $\begin{array}{ll}\text { fixação: } & (0) \text { normal } \\
\text { espessura: } & (0) \text { normal }\end{array}$ & $\begin{array}{l}\text { (1) baixa } \\
\text { (1) alterada (descrever): }\end{array}$ \\
\hline
\end{tabular}

Bochechas [ ]Somar todas as pontuações (melhor resultado $=0$ e pior $=10$ )

\begin{tabular}{|c|c|c|c|}
\hline sa: (C & $\begin{array}{l}\text { (1) marcas dentárias } D \\
\text { (1) marcas dentárias } E\end{array}$ & $\begin{array}{l}\text { (1) linha Alba D } \\
\text { (1) linha Alba E }\end{array}$ & $\begin{array}{l}\text { (2) ferida } D \\
\text { (2) ferida } E\end{array}$ \\
\hline
\end{tabular}

Língua[ ] ]Somar todas as pontuações (melhor resultado $=0$ e pior $=20$ )

\begin{tabular}{|c|c|c|c|c|}
\hline \multicolumn{3}{|c|}{ Sulco longitudinal: } & (0) adequado & (1) profundo \\
\hline \multicolumn{2}{|c|}{ Posição habitual: } & (0) acoplada & assoalho & (1) interdental: \\
\hline \multicolumn{2}{|c|}{ Simetria: } & (0) sim & o (descrever): & \\
\hline \multicolumn{2}{|l|}{ Largura: } & (0) adequada & & (1) aumentada \\
\hline \multicolumn{2}{|c|}{ Altura do dorso: } & (0) adequada & (1) aumentada & (2) muito aumentada \\
\hline \multicolumn{3}{|c|}{$\begin{array}{lll}\text { Tremor: } & (0) \text { ausente } & \text { (1) na posição habitual } \\
\end{array}$} & (1) ao protrair & (1) nos movimentos (quatro pontos cardeais) \\
\hline \multicolumn{4}{|c|}{ 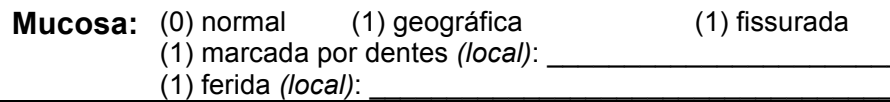 } & (1) marcada por aparelho(local): \\
\hline Frênulo: & $\begin{array}{l}\text { extensão: } \\
\text { fixação na }\end{array}$ & $\begin{array}{l}\text { (0) normal } \\
(0) \text { parte }\end{array}$ & (1) anterio & $\begin{array}{l}\text { (1) curto } \\
\text { média }\end{array}$ \\
\hline
\end{tabular}




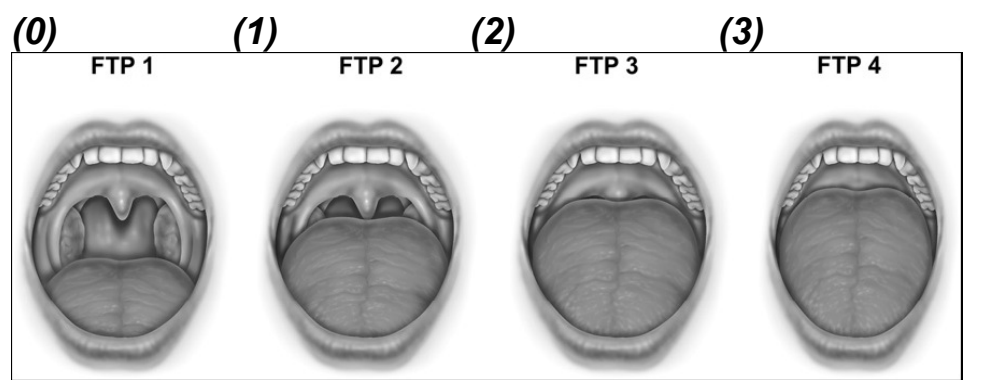

Palato[ ] Somar todas as pontuações (melhor resultado $=0$ e pior $=10$ )

\begin{tabular}{|c|c|c|c|c|}
\hline Duro: & $\begin{array}{l}\text { Profundidade: } \\
\text { Largura: }\end{array}$ & $\begin{array}{l}(0) \text { normal } \\
(0) \text { normal } \\
\end{array}$ & $\begin{array}{l}\text { (1) reduzida (baixo) } \\
\text { (1) aumentada (larga) }\end{array}$ & $\begin{array}{l}\text { (2) aumentada (alto) } \\
\text { (2) reduzida (estreitada) }\end{array}$ \\
\hline Mole: & $\begin{array}{l}\text { Simetria: } \\
\text { Extensão: }\end{array}$ & $\begin{array}{l}\text { (0) presente } \\
(0) \text { adequada }\end{array}$ & $\begin{array}{l}\text { (1) ausente - D + alto } \\
\text { (1) longo }\end{array}$ & $\begin{array}{l}\text { (1) ausente }-E+\text { alto } \\
\text { (2) muito longo }\end{array}$ \\
\hline Úvula: & & (0) normal & (1) longa (2) muito longa & (1) desviada para $D$ \\
\hline
\end{tabular}

Tonsilas palatinas(amídalas)[ ]Somar todas as pontuações $($ melhor resultado $=0$ e pior $=4$ )

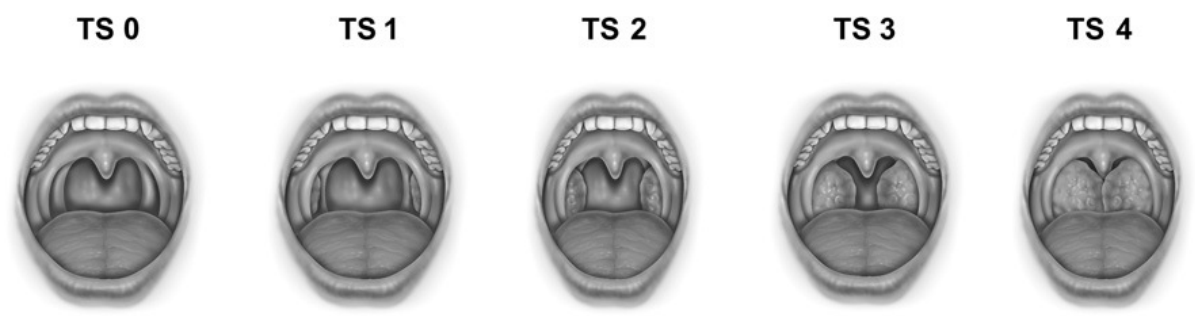

Dentes e Oclusão[ ]Somar todas as pontuações (melhor resultado $=0$ e pior $=13$ )

(1)

8.7.6.5.4.3.2.1

(4)

8.7.6.5.4.3.2.1

(2)

1.2.3.4.5.6.7.8

(3)

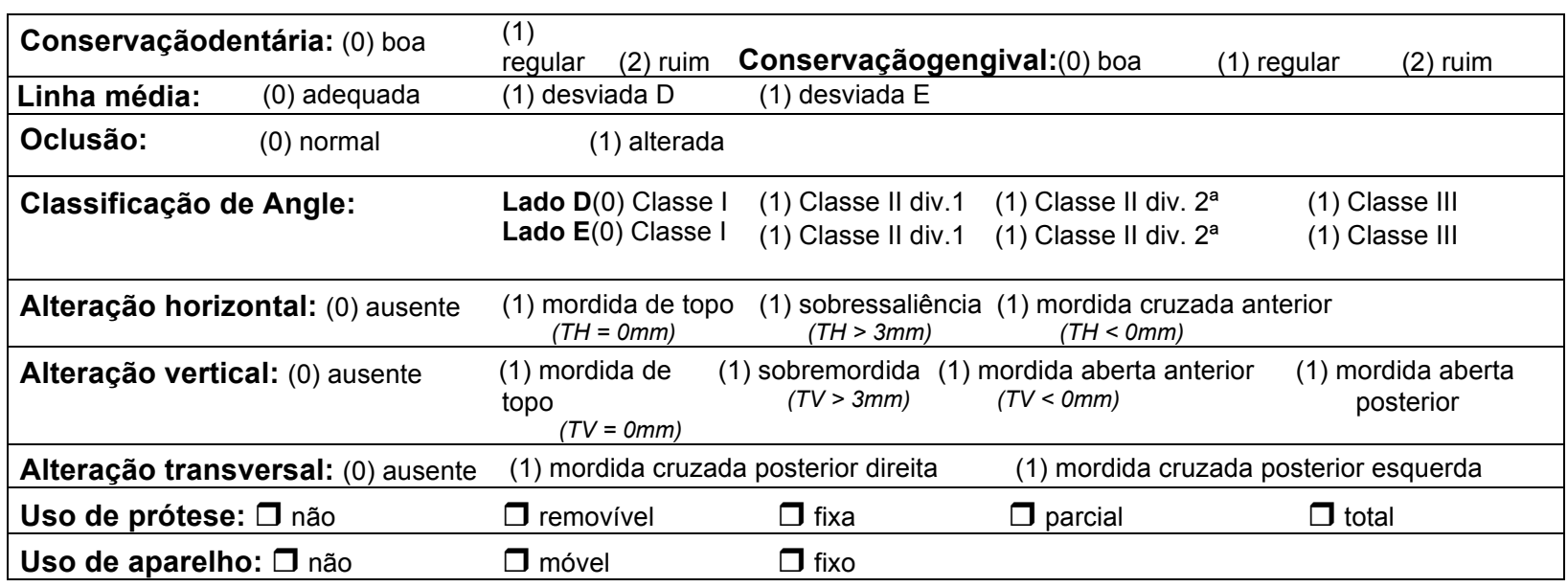

Descrever o aparelho e/ou prótese:

Outras alterações: 
6. MOBILIDADE(Quando o movimento solicitado for alterado, se necessário, descrever)

Lábios [ ] Somar todas as pontuações (melhor resultado $=0$ e pior $=21$ )

\begin{tabular}{|lcccc|}
\hline & normal & aproximado tenta realizar & não realiza \\
\hline 1. Protrair fechados = "bico fechado" & $(0)$ & $(1)$ & $(2)$ & $(3)$ \\
\hline 2. Protrair abertos = "bico aberto" & $(0)$ & $(1)$ & $(2)$ & $(3)$ \\
\hline 3. "Sorriso fechado" & $(0)$ & $(1)$ & $(2)$ & $(3)$ \\
\hline $\begin{array}{l}\text { 4. "sorriso aberto elevando as } \\
\text { bochechas" }\end{array}$ & $(0)$ & $(1)$ & $(2)$ & $(3)$ \\
\hline 5. "Lábios estirados para dentro" & $(0)$ & $(1)$ & $(2)$ & $(3)$ \\
\hline 6. "Mostrar dentes inferiores" & $(0)$ & $(1)$ & $(2)$ & $(3)$ \\
\hline 7. "cara de cheiro ruim" & $(0)$ & $(1)$ & $(2)$ & $(3)$ \\
\hline
\end{tabular}

Língua [ ] Somar todas as pontuações (melhor resultado $=0$ e pior $=39$ )

Nos movimentos alternados, executar 3 vezes e com ritmo.

\begin{tabular}{|lcccc|}
\hline & normal & aproximado & tenta realizar & não realiza \\
\hline Protrair & $(0)$ & $(1)$ & $(2)$ & $(3)$ \\
\hline Elevar na papila incisiva & $(0)$ & $(1)$ & $(2)$ & $(3)$ \\
\hline Elevar no lábio superior & $(0)$ & $(1)$ & $(2)$ & $(3)$ \\
\hline Tocar a comissura labial D & $(0)$ & $(1)$ & $(2)$ & $(3)$ \\
\hline Tocar a comissura labial E & $(0)$ & $(1)$ & $(2)$ & $(3)$ \\
\hline Tocar internamente a bochecha D & $(0)$ & $(1)$ & $(2)$ & $(3)$ \\
\hline Tocar internamente a bochecha E & $(0)$ & $(1)$ & $(2)$ & $(3)$ \\
\hline Estalar o ápice & $(0)$ & $(1)$ & $(2)$ & $(3)$ \\
\hline Estalar o corpo & $(0)$ & $(1)$ & $(2)$ & $(3)$ \\
\hline Sugar a língua no palato & $(0)$ & $(1)$ & $(2)$ & $(3)$ \\
\hline Vibrar & $(0)$ & $(1)$ & $(2)$ & $(3)$ \\
\hline Abaixar o dorso espontaneamente & $(0)$ - normal & (1) - lentificado & $\begin{array}{l}(2)-\text { muito } \\
\text { lentificado }\end{array}$ & $(3)$ - ausente \\
\hline Abaixar o dorso através da estimulação do reflexo & $(0)$ - normal & (1) - lentificado & $\begin{array}{l}(2)-\text { muito } \\
\text { lentificado }\end{array}$ & $(3)$ - ausente \\
\hline
\end{tabular}

Bochechas [ ] Somar todas as pontuações (melhor resultado $=0$ e pior $=9$ )

\begin{tabular}{|lcccc|}
\hline & normal & aproximado & tenta realizar & não realiza \\
\hline Inflar & $(0)$ & $(1)$ & $(2)$ & $(3)$ \\
\hline Inflar o lado direito & $(0)$ & $(1)$ & $(2)$ & $(3)$ \\
\hline Inflar o lado esquerdo & $(0)$ & $(1)$ & $(2)$ & $(3)$ \\
\hline
\end{tabular}

Véu palatino [ ] Somar todas as pontuações (melhor resultado $=0$ e pior $=4$ )

\begin{tabular}{|c|c|c|c|c|}
\hline & normal & movimento reduzido & movimento ausente & Observação \\
\hline Falar [a] repetidamente & $\begin{array}{ll}(0) D & (0) E\end{array}$ & (1) $\mathrm{D}(1) \mathrm{E}$ & $\begin{array}{ll}(2) D & \text { (2) } E\end{array}$ & \\
\hline
\end{tabular}

Úvula - contração [ ] Somar todas as pontuações (melhor resultado = 0 e pior $=4$ )

\begin{tabular}{|lcccc|}
\hline & normal & movimento reduzido & movimento ausente & Observação \\
\hline Falar [a] repetidamente & $(0)$ & $(1)$ & $(2)$ & \\
\hline Bocejo & $(0)$ & $(1)$ & $(2)$ & \\
\hline
\end{tabular}

Mandíbula [ ] Somar todas as pontuações (melhor resultado $=0$ e pior $=10$ )

\begin{tabular}{|lcccccc|}
\hline & normal & reduzido & aumentado & não realiza & \multicolumn{1}{c|}{ com desvio } \\
\hline Abertura da boca & $(0)$ & $(1)<40 \mathrm{~mm}$ & $(1)>55 \mathrm{~mm}$ & $(2)$ & $(1) \mathrm{D}$ & $(1) \mathrm{E}$ \\
\hline Fechamento da boca & $(0)$ & - & - & - & $(1) \mathrm{D}$ & $(1) \mathrm{E}$ \\
\hline Lateralidade à direita & $(0)$ & $(1)<6 \mathrm{~mm}$ & $(1)>12 \mathrm{~mm}$ & $(2)$ & - & - \\
\hline Lateralidade à esquerda & $(0)$ & $(1)<6 \mathrm{~mm}$ & $(1)>12 \mathrm{~mm}$ & $(2)$ & - & - \\
\hline Presença de desvio (em algum movimento) & $(0)$ não & $(1) \mathrm{sim}$ & & & \\
\hline Presença de dor(em algum movimento) & $(0)$ não & $(1) \mathrm{sim}$ & & \\
\hline
\end{tabular}


7. TÔNUS [ ] ] Somar todas as pontuações (melhor resultado $=0$ e pior $=7$ )

\begin{tabular}{|lccc|}
\hline & Normal & Diminuído & Aumentado \\
\hline Lábio superior & $(0)$ & $(1)$ & $(1)$ \\
\hline Lábio inferior & $(0)$ & $(1)$ & $(1)$ \\
\hline Mento & $(0)$ & $(1)$ & $(1)$ \\
\hline Sulco mento labial & $(0)$ & $(1)$ & $(1)$ \\
\hline $\begin{array}{l}\text { Assoalho da boca } \\
\text { (supra-hióideos) }\end{array}$ & $(0)$ & $(1)$ & $(1)$ \\
\hline Bochecha direita & $(0)$ & $(1)$ & $(1)$ \\
\hline Bochecha esquerda & $(0)$ & $(1)$ & \\
\hline
\end{tabular}

Realizar palpação e observação visual, exceto do assoalho que deve ser apenas observado.

8. Língua - ativação [ ] Jomar todas as pontuações (melhor resultado $=0$ e pior $=2$ )

\begin{tabular}{|lccc|}
\hline & Normal & Reduzida & Aumentada \\
\hline $\begin{array}{l}\text { Musculatura } \\
\text { propulsora }\end{array}$ & $(0)$ & & $(1)$ \\
\hline Musculatura retratora & $(0)$ & $(1)$ & \\
\hline
\end{tabular}

9. DOR À PALPAÇÃO [ ] Somar todas as pontuações (melhor resultado $=0$ e pior $=10$ )

\begin{tabular}{|lcclll|}
\hline & \multicolumn{2}{c}{ ausente } & \multicolumn{2}{c|}{ presente } \\
\hline Temporal anterior & $(0) D$ & $(0) E$ & (1) $D$ & $(1) E$ \\
\hline Masseter superficial & $(0) D$ & $(0) E$ & (1) $D$ & $(1) E$ \\
\hline Trapézio & $(0) D$ & $(0) E$ & $(1) D$ & $(1) E$ \\
\hline Esternocleidomastóideo & $(0) D$ & $(0) E$ & (1) $D$ & $(1) E$ \\
\hline ATM & $(0) D$ & $(0) E$ & (1) $D$ & $(1) E$ \\
\hline
\end{tabular}

\section{FUNÇÕES ORAIS}

Respiração [ ] Somar todas as pontuações (melhor resultado = 0 e pior $=9$ )

\begin{tabular}{|c|c|c|c|}
\hline Tipo: $\quad(0)$ médio/inferior & (1) médio/superior & (1) outro (descrever): & \\
\hline Modo: (0) nasal & (1) oronasal & (2) oral & \\
\hline \multirow[t]{2}{*}{ Fluxo nasal (usar o espelho) } & ao chegar: $(0)$ simétrico & (1) reduzido à direita & (1) reduzido à esquerda \\
\hline & após limpeza: $(0)$ simétrico & (1) reduzido à direita & (1) reduzido à esquerda \\
\hline \multicolumn{2}{|c|}{ Possibilidade de uso nasal: (0) 2 minutos ou mais } & (1) entre 1 e 2 minutos & (2) menos que 1 minuto \\
\hline
\end{tabular}

Observações:

Mastigação: $\square$ adequada $\square$ alterada: de origem[ ] funcional [ ] anatômica [ ] articular [ ] outro (mastigatória utilizar sempre o mesmo alimento)

Mastigação Habitual [ ] Somar todas as pontuações (melhor resultado $=0$ e pior $=15$ )

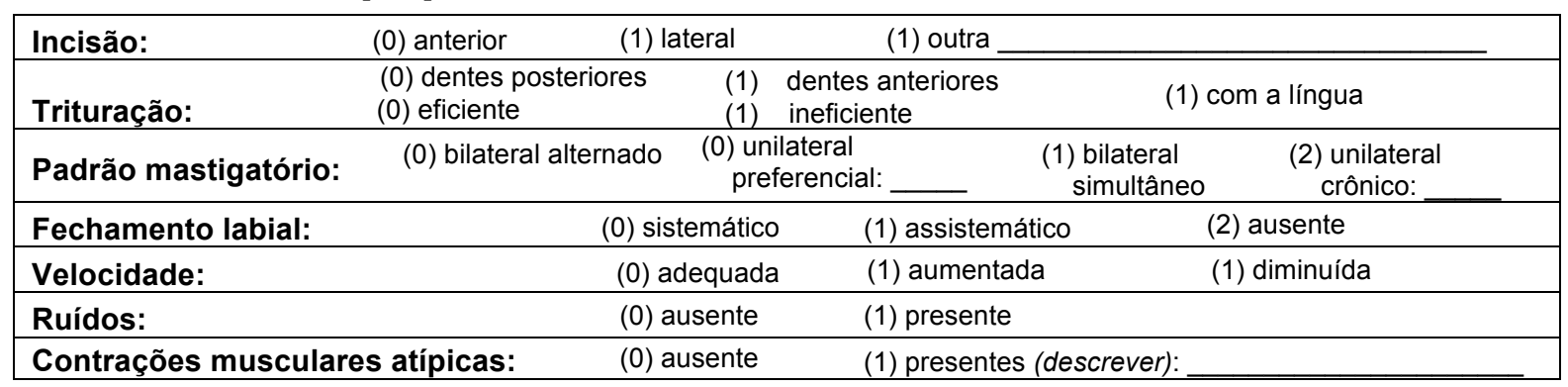


Outros:

Perguntar ao paciente

\begin{tabular}{|lllll|}
\hline Lado preferencial de mastigação: & (0) direito e esquerdo & (1) direito & (1) esquerdo & (0) não sabe \\
\hline Dor ao mastigar: & (0) ausente & (1) direito & (1) esquerdo & \\
\hline Ruído na ATM: & (0) ausente & (1) direita & (1) esquerda & \\
\hline
\end{tabular}

Observações:

Deglutição: $\square$ adequada $\square$ alterada: de origem[ ] funcional [ ] anatômica [ ] articular [ ] outro

$1^{\text {a }}$ Prova (habitual de sólidos) [ ] Somar todas as pontuações (melhor resultado $=0$ e pior $=18$ )

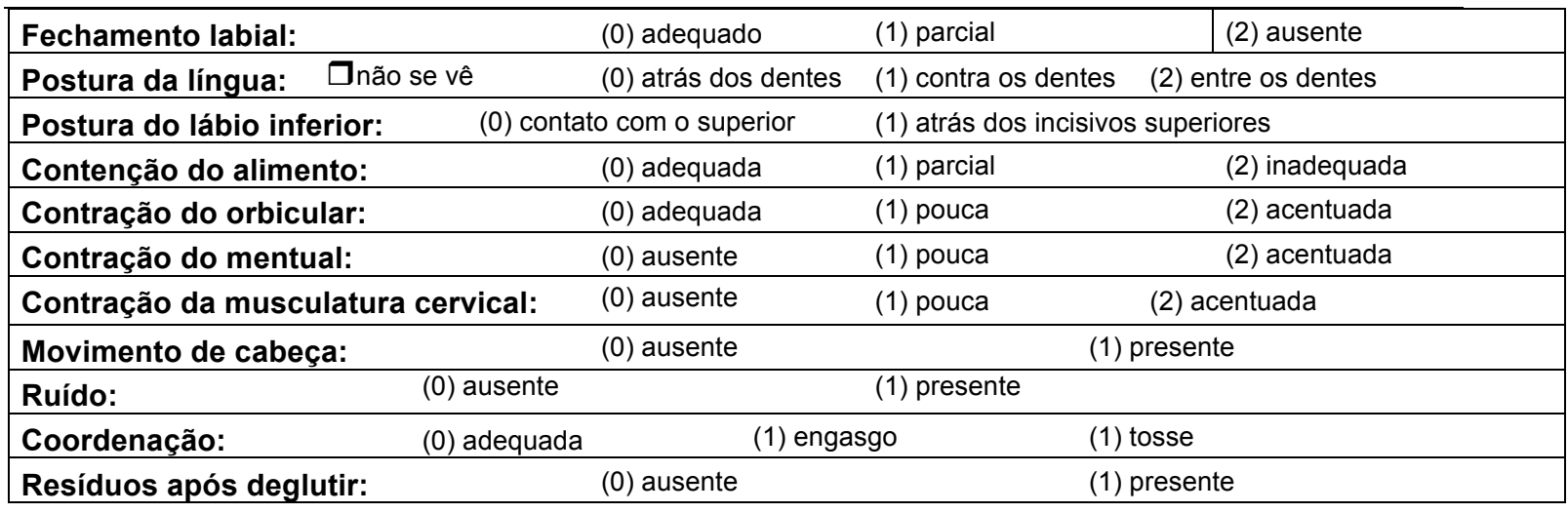

Observações:

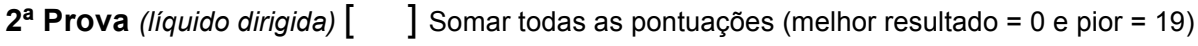

Colocar água na boca e deglutir somente após ordem do avaliador

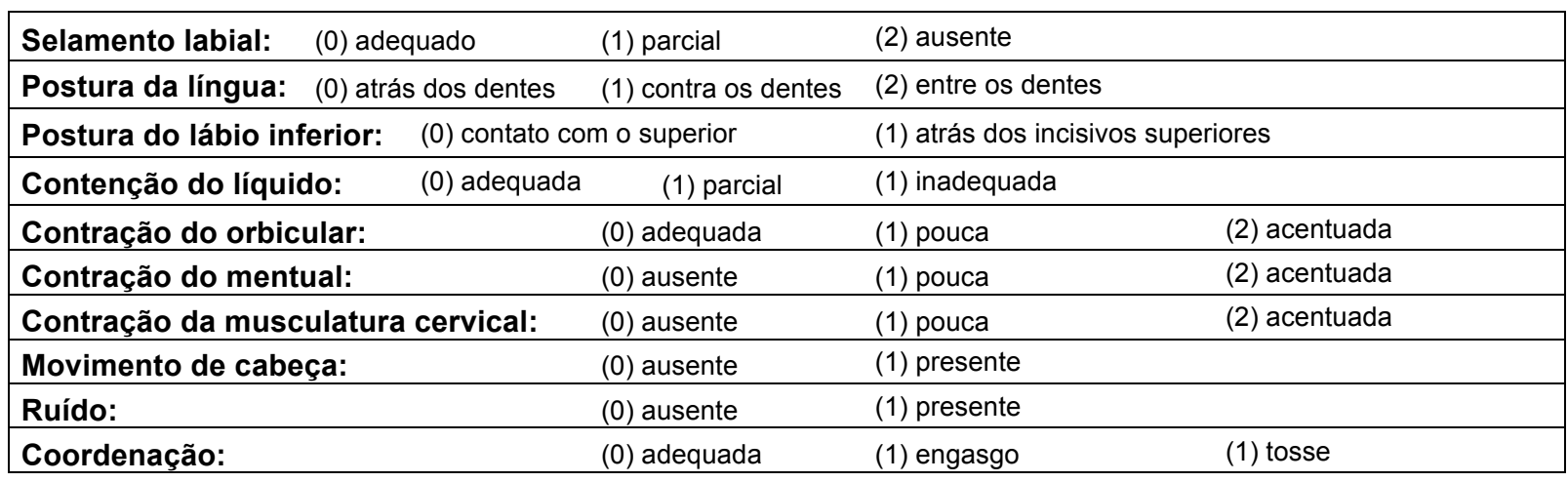

Observações:

Perguntar ao paciente

$\begin{array}{lll}\text { Dificuldade para deglutir: } & (0) \text { não } & \text { (1) sim (descrever): }\end{array}$

Posição da língua: (0) atrás dos dentes superiores $\quad(1)$ atrás dos dentes inferiores $\quad(2)$ entre os dentes $\quad(0)$ não sabe

Observações:

Fala: $\square$ adequada

Voz: $\square$ adequada

Observações: $\square$ alterada. Descrever:

$\square$ alterada. Descrever:

Fga. Responsável: 
Anexo F - Avaliação subjetiva do ronco

\section{QUESTIONÁRIO PARA RONCO (PARTE DO QUESTIONÁRIO DE BERLIN)}

1-Você ronca?

\begin{tabular}{|l|l|l|l|l|l|l|l|}
\hline Sim & Não & Não sabe & Esposa (o) & Sim & Não & \\
\hline
\end{tabular}

Intensidade do ronco:

\begin{tabular}{|l|l|}
\hline 1-Tão alto quanto a respiração & \\
\hline 2-Tão alto quanto falar & \\
\hline 3-Mais alto que falar & \\
\hline 4-Muito alto, houve-se do outro quarto & \\
\hline
\end{tabular}

Freqüência do ronco:

0 - nunca ou quase nunca

$1-1$ a 2 vezes por mês

2 - 1 a 2 vezes por semena

3 - 3 a 4 vezes por semana

4 - quase todo dia

O seu ronco incomoda outras pessoas?

\begin{tabular}{|l|l|}
\hline Sim & Não \\
\hline
\end{tabular}




\section{Anexo G - Questionário de Pittsburg}

\section{QUESTIONÁRIO DE QUALIDADE DE SONO DE PITTSBURGH}

Responda as questões a seguir de acordo com as características do seu sono apenas no último mês:

1. Durante o mês passado, a que horas você foi se deitar à noite, na maioria das vezes?

2. Durante o mês passado, quanto tempo (em minutos) você demorou para pegar no sono, na maioria das vezes?

3. Durante o mês passado, a que horas você acordou de manhã, na maioria das vezes?

4. Durante o mês passado, quantas horas de sono por noite você dormiu? (pode ser diferente do número de horas que você ficou na cama)

5. Para cada uma das questões seguintes, escolha uma única resposta, que você ache mais correta. Por favor, responda a todas as questões. Durante o mês passado, quantas vezes você teve problemas para dormir por causa de:

a. Demorar mais de 30 minutos para pegar no sono:

( ) nenhuma vez; ( ) menos de uma vez por semana; ( ) uma ou duas vezes por semana; ( ) três vezes por semana ou mais

b. Acordar no meio da noite ou de manhã muito cedo:

( ) nenhuma vez; ( ) menos de uma vez por semana; ( ) uma ou duas vezes por semana; $($ ) três vezes por semana ou mais

c. Levantar-se para ir ao banheiro:

( ) nenhuma vez; ( ) menos de uma vez por semana; ( ) uma ou duas vezes por semana; ( ) três vezes por semana ou mais

d. Ter dificuldade para respirar:

( ) nenhuma vez; ( ) menos de uma vez por semana; ( ) uma ou duas vezes por semana; ( ) três vezes por semana ou mais

e. Tossir ou roncar muito alto:

( ) nenhuma vez; ( ) menos de uma vez por semana; ( ) uma ou duas vezes por semana; ( ) três vezes por semana ou mais

f. Sentir muito frio

( ) nenhuma vez; ( ) menos de uma vez por semana; ( ) uma ou duas vezes por semana; ( ) três vezes por semana ou mais

g. Sentir muito calor

( ) nenhuma vez; ( ) menos de uma vez por semana; ( ) uma ou duas vezes por semana; ( ) três vezes por semana ou mais

h. Ter sonhos ruins ou pesadelos

( ) nenhuma vez; ( ) menos de uma vez por semana; ( ) uma ou duas vezes por semana; ( ) três vezes por semana ou mais

i. Sentir dores

( ) nenhuma vez; ( ) menos de uma vez por semana; ( ) uma ou duas vezes por semana; ( ) três vezes por semana ou mais

j. Outras razões (por favor descreva) Quantas vezes você teve problemas pra dormir por esta razão, durante o mês passado?

( ) nenhuma vez; ( ) menos de uma vez por semana; ( ) uma ou duas vezes por semana; ( ) três vezes por semana ou mais

6. Durante o mês passado, como você classificaria a qualidade do seu sono?

( ) Muito boa ( ) boa ( ) ruim ( ) muito ruim

7. Durante o mês passado, você tomou algum remédio para dormir, receitado pelo médico, ou indicado por outra pessoa (farmacêutico, amigo, familiar) ou mesmo por sua conta?

( ) nenhuma vez; ( ) menos de uma vez por semana; ( ) uma ou duas vezes por semana; ( ) três vezes por semana ou mais

8. Durante o mês passado, se você teve problemas para ficar acordado enquanto estava dirigindo, fazendo suas refeições ou participando de qualquer outra atividade social, quantas vezes isto aconteceu?

( ) nenhuma vez; ( ) menos de uma vez por semana; ( ) uma ou duas vezes por semana; ( ) três vezes por semana ou mais

9. Durante o mês passado, você sentiu indisposição ou falta de entusiasmo para realizar suas atividades diárias?

( ) nenhuma indisposição nem falta de entusiasmo; ( ) indisposição e falta de entusiasmos pequenas; ( ) indisposição e falta de entusiasmos moderadas; ( ) muita indisposição e falta de entusiasmo

10. Para você, o sono é ( ) um prazer （ ) uma necessidade Outro-qual?

11. Você cochila? ( ) sim （ ） não Caso sim - você cochila intencionalmente, ou seja, por que quer cochilar? ( ) sim ( ) não

12. Para você, cochilar é: ( ) um prazer （ ) uma necessidade Outro-qual? 
Anexo H - Questionário de Epworth

\section{ESCALA DE SONOLÊNCIA DE EPWORTH (Quantifica grau de sonolência)}

0 - nenhuma chance de cochilar; 1 - pequena chance de cochilar ; 2 moderada chance de cochilar; 3 - alta chance de cochilar

\begin{tabular}{|l|l|l|l|l|}
\hline SITUAÇÃO & & & & \\
\hline Sentado e lendo & 0 & 1 & 2 & 3 \\
\hline Assistindo TV & 0 & 1 & 2 & 3 \\
\hline Sentado em lugar público (cinema, igreja, sala de espera) & 0 & 1 & 2 & 3 \\
\hline $\begin{array}{l}\text { Como passageiro de trem, carro ou ônibus, andando uma } \\
\text { hora sem parar }\end{array}$ & 0 & 1 & 2 & 3 \\
\hline Deitando-se para descansar à tarde, quando as circunstâncias & 0 & 1 & 2 & 3 \\
permitem & & & & \\
\hline Sentado e conversando com alguém & 0 & 1 & 2 & 3 \\
\hline Sentado calmamente após o almoço (sem álcool) & 0 & 1 & 2 & 3 \\
\hline Dirigindo um carro, enquanto pára por alguns minutos ao & 0 & 1 & 2 & 3 \\
pegar um trânsito intenso & & & & \\
\hline
\end{tabular}

Resultado : até $10=$ normal; $>10=$ sonolência excessiva diurna. 
8. REFERÊNCIAS 
1. Liistro G, Stanescu DC, Veriter C, Rodenstein DO, Auberttulkens G. Pattern of snoring in obstructive sleep-apnea patients and in heavy snorers. Sleep. 1991;14(6):517-25.

2. Ng AK, Koh TS. Using psychoacoustics of snoring sounds to screen for obstructive sleep apnea. Conference proceedings : Annual International Conference of the IEEE Engineering in Medicine and Biology Society IEEE Engineering in Medicine and Biology Society Conference. 2008;2008:1647-50.

3. Lee SA, Amis TC, Byth K, Larcos G, Kairaitis K, Robinson TD, Wheatley JR. Heavy snoring as a cause of carotid artery atherosclerosis. Sleep. 2008;31(9):1207-13.

4. Young T, Palta M, Dempsey J, Skatrud J, Weber S, Badr S. The occurrence of sleep-disordered breathing among middle-aged adults. New England Journal of Medicine. 1993;328(17):1230-5.

5. Ohayon MM, Guilleminault C, Priest RG, Caulet M. Snoring and breathing pauses during sleep: Telephone interview survey of a united kingdom population sample. British Medical Journal. 1997;314(7084):860-3.

6. Santos-Silva R, Bittencourt LR, Pires ML, de Mello MT, Taddei JA, BeneditoSilva AA, Pompeia C, Tufik S. Increasing trends of sleep complaints in the city of sao paulo, brazil. Sleep Med. 2010;11(6):520-4.

7. Nagayoshi M, Yamagishi K, Tanigawa T, Sakurai S, Kitamura A, Kiyama M, Imano $\mathrm{H}$, Ohira $\mathrm{T}$, Sato $\mathrm{S}$, Sankai $\mathrm{T}$, Iso $\mathrm{H}$, Investigators $\mathrm{C}$. Risk factors for snoring among japanese men and women: A community-based cross-sectional study. Sleep and Breathing. 2011;15(1):63-9.

8. Hoffstein V, Mateika S, Anderson D. Snoring - is it in the ear of the beholder. Sleep. 1994;17(6):522-6.

9. Parish JM, Lyng PJ. Quality of life in bed partners of patients with obstructive sleep apnea or hypopnea after treatment with continuous positive airway pressure. Chest. 2003;124(3):942-7. 
10. Nakano H, Furukawa T, Nishima S. Relationship between snoring sound intensity and sleepiness in patients with obstructive sleep apnea. Journal of clinical sleep medicine : JCSM : official publication of the American Academy of Sleep Medicine. 2008;4(6):551-6.

11. Ibrahim AS, Almohammed AA, Allangawi MH, HA AS, Mobayed HS, Pannerselvam B, Philipose MV. Predictors of obstructive sleep apnea in snorers. Annals of Saudi medicine. 2007;27(6):421-6.

12. Patil SP, Schneider H, Schwartz AR, Smith PL. Adult obstructive sleep apnea: Pathophysiology and diagnosis. Chest. 2007;132(1):325-37.

13. Dempsey JA, Veasey SC, Morgan BJ, O'Donnell CP. Pathophysiology of sleep apnea. Physiological reviews. 2010;90(1):47-112.

14. Epstein LJ, Kristo D, Strollo PJ, Jr., Friedman N, Malhotra A, Patil SP, Ramar K, Rogers R, Schwab RJ, Weaver EM, Weinstein MD, Amer Acad Sleep M. Clinical guideline for the evaluation, management and long-term care of obstructive sleep apnea in adults. Journal of Clinical Sleep Medicine. 2009;5(3):263-76.

15. Fajdiga I. Snoring imaging - could bernoulli explain it all? Chest. 2005;128(2):896-901.

16. Maimon N, Hanly PJ. Does snoring intensity correlate with the severity of obstructive sleep apnea? Journal of Clinical Sleep Medicine. 2010;6(5):475-8.

17. Tufik S, Santos-Silva R, Taddei JA, Azeredo Bittencourt LR. Obstructive sleep apnea syndrome in the sao paulo epidemiologic sleep study. Sleep Medicine. 2010;11(5):441-6.

18. Beninati W, Harris CD, Herold DL, Shepard JW. The effect of snoring and obstructive sleep apnea on the sleep quality of bed partners. Mayo Clinic Proceedings. 1999;74(10):955-8.

19. Hanak V, Jacobson DJ, McGree ME, St. Sauver J, Lieber MM, Olson EJ, Somers VK, Gades NM, Jacobsen SJ. Snoring as a risk factor for sexual dysfunction in community men. Journal of Sexual Medicine. 2008;5(4):898-908. 
20. Friberg D, Ansved T, Borg K, Carlsson-Nordlander B, Larsson H, Svanborg E. Histological indications of a progressive snorers disease in an upper airway muscle. American Journal of Respiratory and Critical Care Medicine. 1998;157(2):586-93.

21. Poothrikovil RP, Al Abri MA. Snoring-induced nerve lesions in the upper airway. Sultan Qaboos University medical journal. 2012;12(2):161-8.

22. Lee NR. Evaluation of the obstructive sleep apnea patient and management of snoring. Oral and maxillofacial surgery clinics of North America. 2009;21(4):377-87.

23. Marshall NS, Bartlett DJ, Matharu KS, Williams A, Grunstein RR. Prevalence of treatment choices for snoring and sleep apnea in an australian population. Journal of clinical sleep medicine : JCSM : official publication of the American Academy of Sleep Medicine. 2007;3(7):695-9.

24. Fiz JA, Morera Prat J, Jane R. [treatment of patients with simple snoring]. Archivos de bronconeumologia. 2009;45(10):508-15.

25. Caffier PP, Berl JC, Muggli A, Reinhardt A, Jakob A, Moeser M, Fietze I, Scherer H, Hoelzl M. Snoring noise pollution - the need for objective quantification of annoyance, regulatory guidelines and mandatory therapy for snoring. Physiological Measurement. 2007;28(1):25-40.

26. Hoffstein V, Mateika S, Nash S. Comparing perceptions and measurements of snoring. Sleep. 1996;19(10):783-9.

27. Dalmasso F, Prota R. Snoring: Analysis, measurement, clinical implications and applications. European Respiratory Journal. 1996;9(1):146-59.

28. Berry RB, Budhiraja R, Gottlieb DJ, Gozal D, Iber C, Kapur VK, Marcus CL, Mehra R, Parthasarathy S, Quan SF, Redline S, Strohl KP, Davidson Ward SL, Tangredi MM, American Academy of Sleep M. Rules for scoring respiratory events in sleep: Update of the 2007 aasm manual for the scoring of sleep and associated events. Deliberations of the sleep apnea definitions task force of the american academy of sleep medicine. Journal of clinical sleep medicine : JCSM 
: official publication of the American Academy of Sleep Medicine. 2012;8(5):597619.

29. Alencar AM, Vaz da Silva DG, Oliveira CB, Vieira AP, Moriya HT, LorenziFilho G. Dynamics of snoring sounds and its connection with obstructive sleep apnea. Physica a-Statistical Mechanics and Its Applications. 2013;392(1):271-7. 30. Ben-Israel N, Tarasiuk A, Zigel Y. Obstructive apnea hypopnea index estimation by analysis of nocturnal snoring signals in adults. Sleep. 2012;35(9):1299-305.

31. Lin HC, Friedman M, Chang HW, Gurpinar B. The efficacy of multilevel surgery of the upper airway in adults with obstructive sleep apnea/hypopnea syndrome. The Laryngoscope. 2008;118(5):902-8.

32. Guimarães KC, Drager LF, Genta PR, Marcondes BF, Lorenzi-Filho G. Effects of oropharyngeal exercises on patients with moderate obstructive sleep apnea syndrome. Am J Respir Crit Care Med. 2009;179(10):962-6.

33. Guimarães KC. Efeitos dos exercícios orofaríngeos em pacientes com apneia obstrutiva do sono moderada: Estudo controlado e randomizado [tese]. São Paulo: Faculdade de Medicina, Universidade de São Paulo; 2008.

34. Clark HM, O'Brien K, Calleja A, Corrie SN. Effects of directional exercise on lingual strength. Journal of speech, language, and hearing research : JSLHR. 2009;52(4):1034-47.

35. Jardini R. Avaliaçao eletromiográfica do músculo bucinador flácido usando o exercitador facial / electromyographic analysis of the weak buccinator muscle using the facial exerciser. Pró-fono. 2002;14(3):331-42.

36. Jardini R. Uso do exercitador facial: Um estudo preliminar para fortalecer os músculos faciais / usage of the facial exerciser: Preliminar study to strengthen facial muscles. Pró-fono. 2001;13(1):83-9.

37. Yoshida M, Groher ME, Crary MA, Mann GC, Akagawa Y. Comparison of surface electromyographic (semg) activity of submental muscles between the head lift and tongue press exercises as a therapeutic exercise for pharyngeal dysphagia. Gerodontology. 2007;24(2):111-6. 
38. Palmer PM, Jaffe DM, McCulloch TM, Finnegan EM, Van Daele DJ, Luschei ES. Quantitative contributions of the muscles of the tongue, floor-of-mouth, jaw, and velum to tongue-to-palate pressure generation. Journal of Speech Language and Hearing Research. 2008;51(4):828-35.

39. Koren A, Groselj LD, Fajdiga I. Ct comparison of primary snoring and obstructive sleep apnea syndrome: Role of pharyngeal narrowing ratio and soft palate-tongue contact in awake patient. European Archives of Oto-RhinoLaryngology. 2009;266(5):727-34.

40. Willcox DS. Cleft-palate rehabilitation - interim strategies in indonesia. Cleft Palate-Craniofacial Journal. 1994;31(4):316-20.

41. Puhan MA, Suarez A, Lo Cascio C, Zahn A, Heitz M, Braendli O. Didgeridoo playing as alternative treatment for obstructive sleep apnoea syndrome: Randomised controlled trial. Bmj. 2006;332(7536):266-70.

42. Sfeele CM. On the plausibility of upper airway remodeling as an outcome of orofacial exercise. American Journal of Respiratory and Critical Care Medicine. 2009;179(10):858-9.

43. Tachimura $\mathrm{T}$, Nohara K, Hara H, Wada T. Effect of placement of a speech appliance on levator veli palatini muscle activity during blowing. Cleft PalateCraniofacial Journal. 1999;36(3):224-32.

44. Genaro KB-FGRMMI. Avaliação miofuncional orofacial - protocolo mgbr. Rev Cefac. 2009;11(2):18.

45. Marchesan IQ, Berretin-Felix G, Genaro KF. Mbgr protocol of orofacial myofunctional evaluation with scores. The International journal of orofacial myology : official publication of the International Association of Orofacial Myology. 2012;38:38-77.

46. Friedman $M$, Schalch $P$. Surgery of the palate and oropharynx. Otolaryngologic clinics of North America. 2007;40(4):829-43.

47. Netzer NC, Stoohs RA, Netzer CM, Clark K, Strohl KP. Using the berlin questionnaire to identify patients at risk for the sleep apnea syndrome. Annals of internal medicine. 1999;131(7):485-91. 
48. Buysse DJ, Reynolds CF, 3rd, Monk TH, Berman SR, Kupfer DJ. The pittsburgh sleep quality index: A new instrument for psychiatric practice and research. Psychiatry research. 1989;28(2):193-213.

49. Johns MW. A new method for measuring daytime sleepiness: The epworth sleepiness scale. Sleep. 1991;14(6):540-5.

50. Oliveira CB Vaz da Silva DG, Moriya HT, Skomro R, Alencar AM, LorenziFilho G. Snoring: The silent signal in sleep medicine. Sleep Sci 2011;4(1):21-7. 51. Oliveira CB, Vaz da Silva DG, Moryia HT, Genta PR, Paschoal FHA, Alencar AM, Lorenzi-Filho G. Objective analysis of snoring during polysomnography: Proposal of a simple device. . American Thoracic Society International Conference, 2010; New Orleans, LA, USA: American J. of Resp. and Crit. Care Med; 2010. v.181.

52. Azarbarzin A, Moussavi Z. Intra-subject variability of snoring sounds in relation to body position, sleep stage, and blood oxygen level. Medical \& biological engineering \& computing. 2013;51(4):429-39.

53. Nakano H, Ikeda T, Hayashi M, Ohshima E, Onizuka A. Effects of body position on snoring in apneic and nonapneic snorers. Sleep. 2003;26(2):169-72.

54. Puri Be. Nonparametric methods in factorial designs. Statistical Papers. 2001;42:1-52.

55. Schulz KF, Altman DG, Moher D, Group C. Consort 2010 statement: Updated guidelines for reporting parallel group randomized trials. Annals of internal medicine. 2010;152(11):726-32.

56. RW M. Handling missing data in clinical trials: An overview. Drug Information Journal. 2000;34:525-33.

57. Team RC. R: A language and environment for statistical computing. Vienna, austria. Http://www.R-project.Org/ 2013.

58. Amaro AC, Duarte FH, Jallad RS, Bronstein MD, Redline S, Lorenzi-Filho G. The use of nasal dilator strips as a placebo for trials evaluating continuous positive airway pressure. Clinics. 2012;67(5):469-74. 
59. Ojay A, Ernst E. Can singing exercises reduce snoring? A pilot study. Complementary therapies in medicine. 2000;8(3):151-6.

60. Koutsourelakis I, Perraki E, Zakynthinos G, Minaritzoglou A, Vagiakis E, Zakynthinos S. Clinical and polysomnographic determinants of snoring. Journal of sleep research. 2012;21(6):693-9.

61. Diaferia G, Badke L, Santos-Silva R, Bommarito S, Tufik S, Bittencourt L. Effect of speech therapy as adjunct treatment to continuous positive airway pressure on the quality of life of patients with obstructive sleep apnea. Sleep Med. 2013;14(7):628-35.

62. Jane R, Fiz JA, Sola-Soler J, Mesquita J, Morera J. Snoring analysis for the screening of sleep apnea hypopnea syndrome with a single-channel device developed using polysomnographic and snoring databases. Conference proceedings : Annual International Conference of the IEEE Engineering in Medicine and Biology Society IEEE Engineering in Medicine and Biology Society Conference. 2011;2011:8331-3.

63. Sola-Soler J, Fiz JA, Morera J, Jane R. Multiclass classification of subjects with sleep apnoea-hypopnoea syndrome through snoring analysis. Medical engineering \& physics. 2012;34(9):1213-20.

64. Sola-Soler J, Jane R, Fiz JA, Morera J. Automatic classification of subjects with and without sleep apnea through snoring analysis. Conference proceedings: Annual International Conference of the IEEE Engineering in Medicine and Biology Society IEEE Engineering in Medicine and Biology Society Conference. 2007;2007:6094-7. 